\title{
Projeto e Implementação de um Sistema de Auxílio a Preparação de Material Didático para uso na World-Wide Wed
}

\author{
Maria Alice Soares de Castro
}

\author{
Orientador \\ Prof. Dr. Edson dos Santos Moreira
}

Dissertação apresentada ao Instituto de Ciências Matemáticas de São Carlos, Universidade de São Paulo, como parte dos requisitos para obtenção do título de Mestre na área de Ciências da Computação e Matemática Computacional. 


\section{DEDICATÓRIA}

Àquele sem o qual

nada sou,

nada possuo,

nada faço,

nada sei,

nada quero,

nada alcanço:

Deus. 


\title{
AGRADECIMENTOS
}

\author{
I familia, pelo apoio.
}

- to professor Edson, pela confianca e incentivo.

tos professores, colegas e funcionários do ICMSC, pela amizade. 


\section{ÍNDICE}

Índice

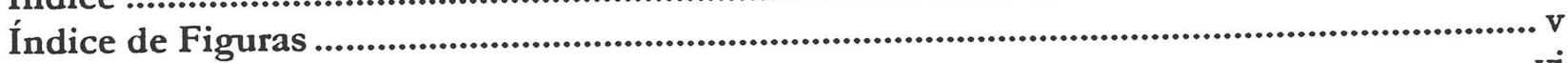

Resumo

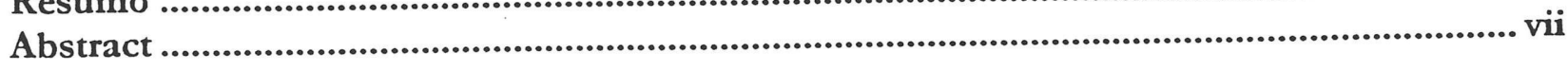

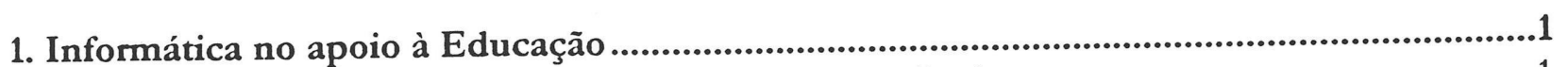

1.1 Recursos eletrônicos no suporte ao ensino e aprendizado ..............................................................

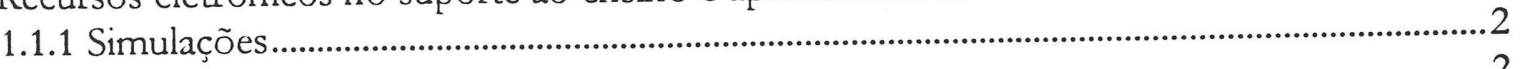

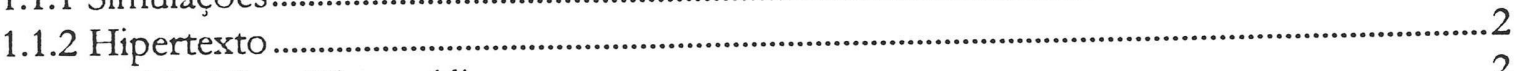

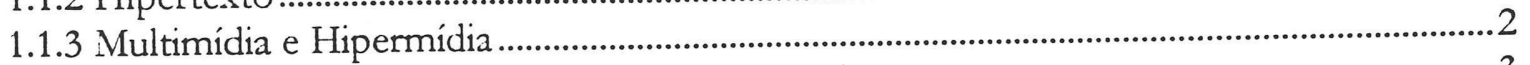

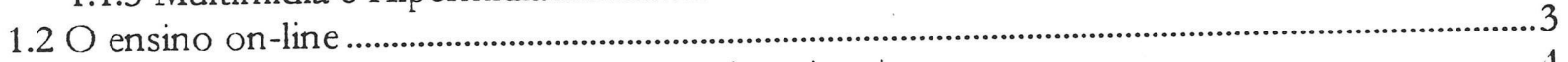

1.2.1 Modelos de ambientes e sistemas educacionais .........................................................................

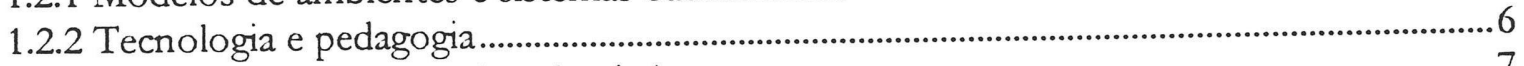

$1.3 \mathrm{~A}$ produção de material didático eletrônico …….......................................................................

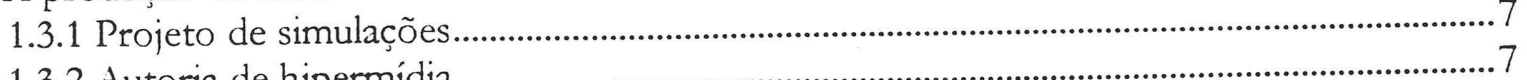

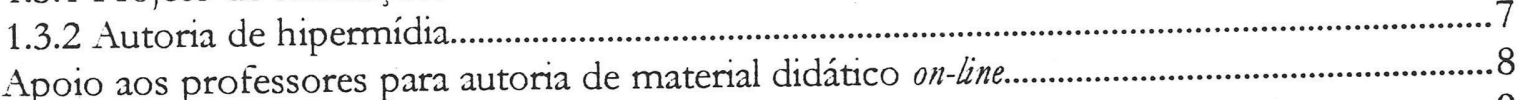

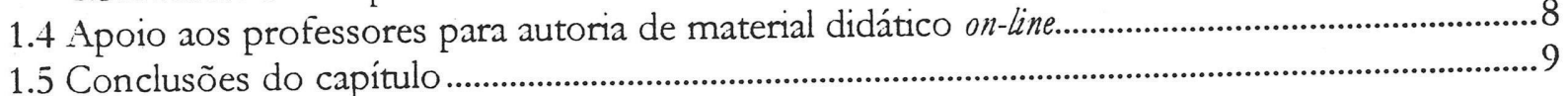

2. Sistemas didáticos e de apoio à autoria ...........................................................................10

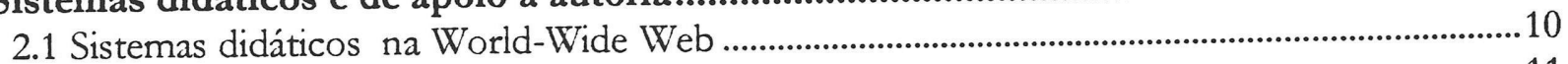

2.1.1 "Sites" de disciplinas.........................................................................................................11

2.1.2 Material didático na World-Wide Web ...............................................................................12

2.1.3 Sistemas didáticos baseados na comunicação via Internet.....................................................13

2.1.4 Sistemas cooperativos para exploração de informações na Internet...................................16

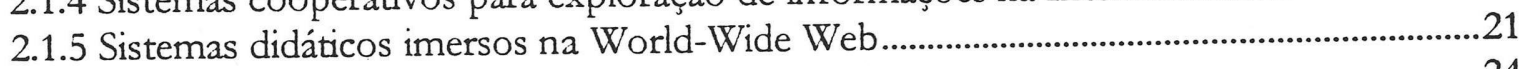

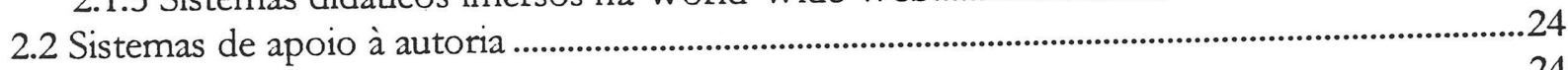

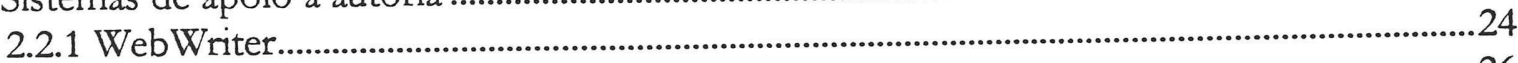

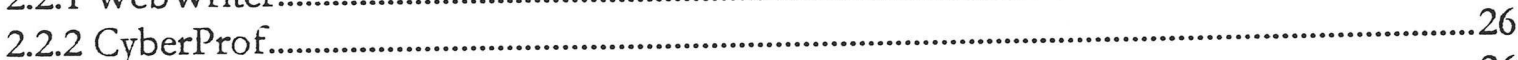

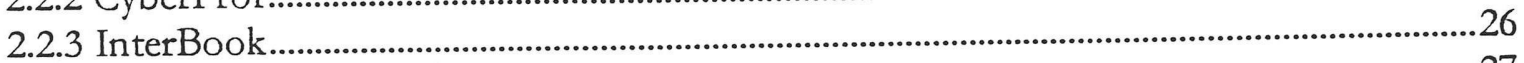

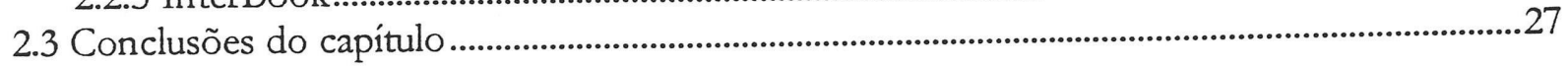

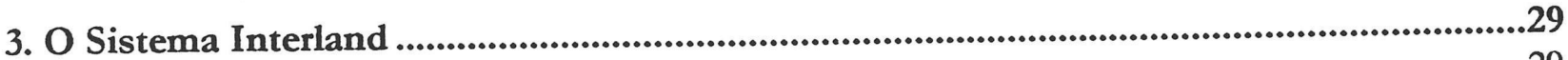

3.1 Fundamentos e Arquitetura do Sistema ......................................................................................29

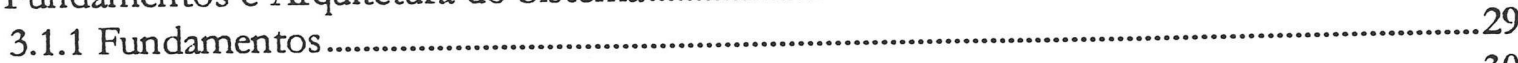

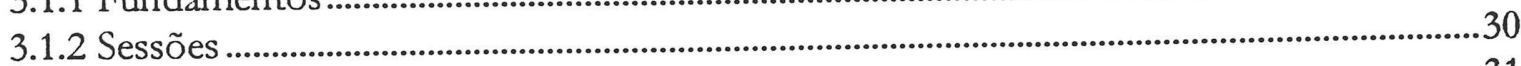

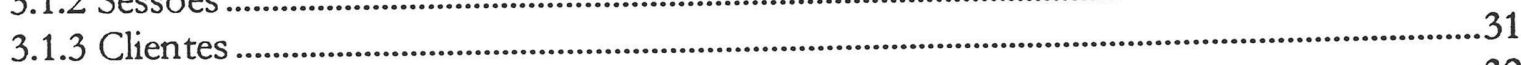

3.2 Funcionamento básico do sistema Interland ...........................................................................32

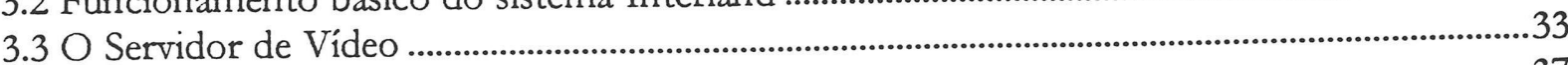

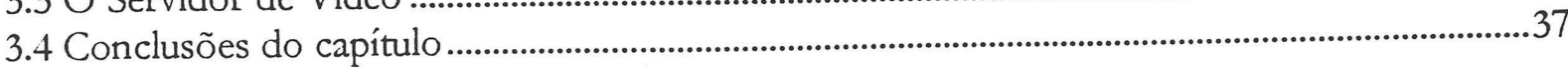




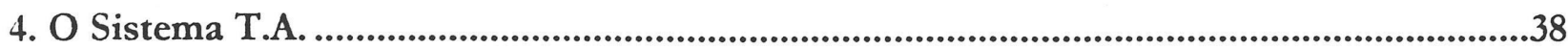

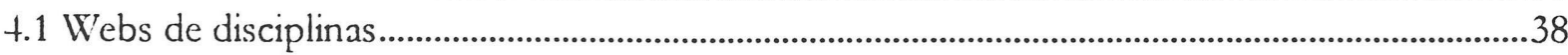

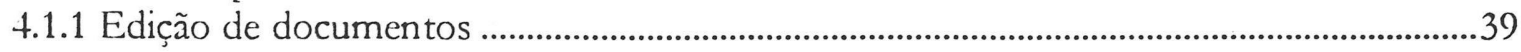

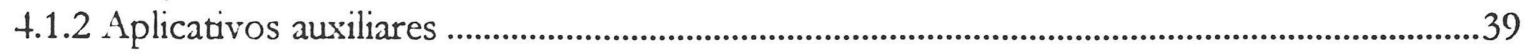

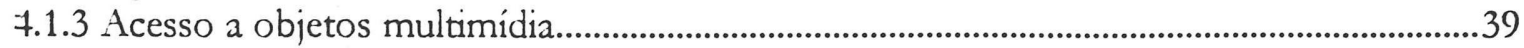

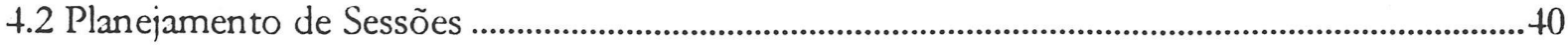

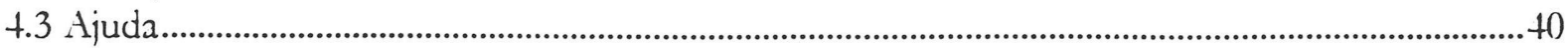

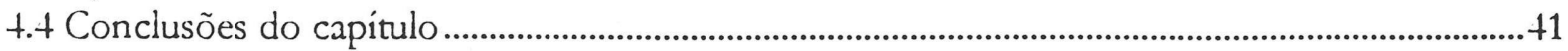

5. Implementação do Sistema T.A.....................................................................................42

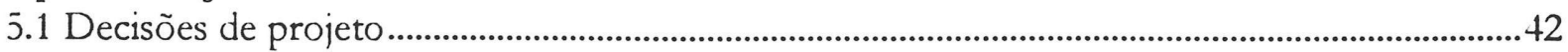

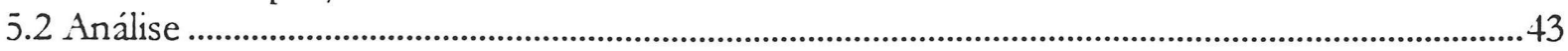

5.3 Projeto

5.3.1 Módulo de edição ....................................................................................................................44

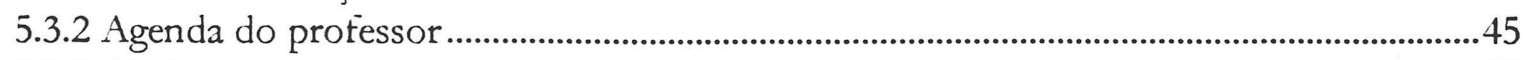

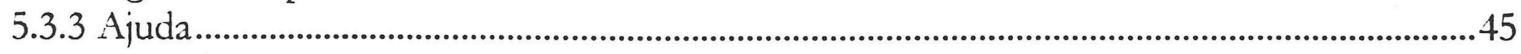

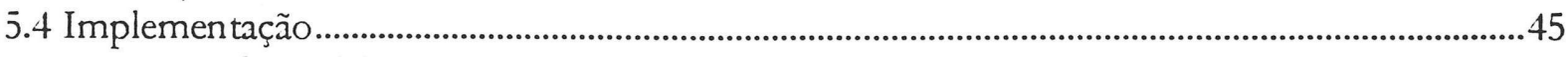

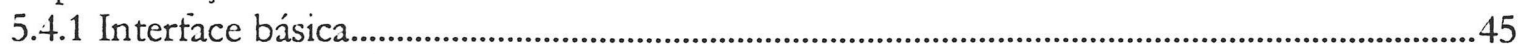

5.4.2 Interface de edição...............................................................................................................47

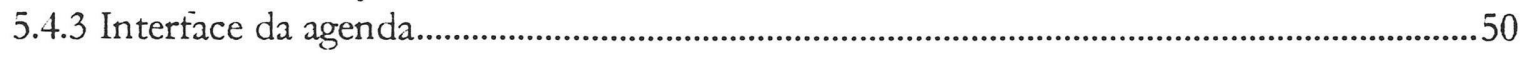

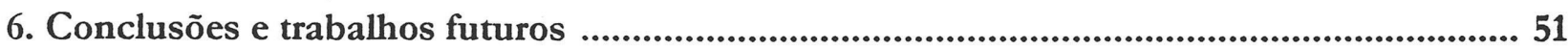

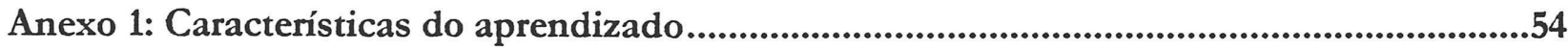

Anexo 2: Autoria de hipermídia para a World-Wide Web........................................................ 61

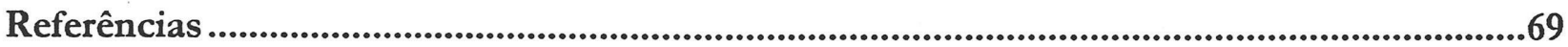

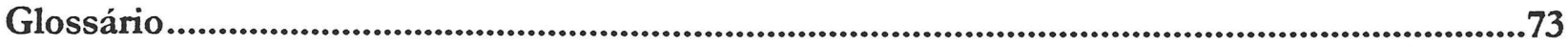

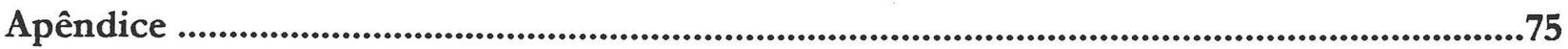




\section{ÍNDICE DE FIGURAS}

Figura 1: Possibilidades de educação e ambiente segundo combinações de tempo e lugar.....................

Figura 2: Níveis de sistemas pedagógicos com uso de computadores........................................................6

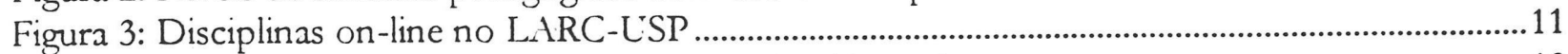

Figura 4: Exemplos de material didático na World-W'ide Web ..............................................................13

Figura j: "Site" da Escola do Futuro ..............................................................................................................14

Figura 6: Programa Educ@r..........................................................................................................................15

Figura 7: Softwares do sistema KIE ........................................................................................................18

Figura 8: Fórum de discussões no sistema KIE.....................................................................................19

Figura 9: Interface do professor no sistema KIE ..........................................................................................20

Figura 10: Curso de contabilidade no site da LOL ........................................................................................22

Figura 11: Fórum de discussão no curso de contabilidade na UOL .........................................................23

Figura 12: Frames do editor WebWriter ................................................................................................24

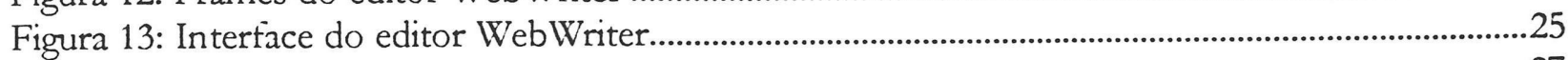

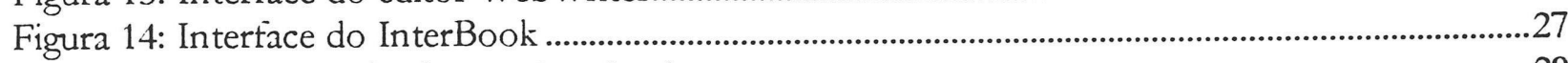

Figura 15: Visão geral do sistema Interland ............................................................................................29

Figura 16: Protótipo do sistema Interland, interface aluno .........................................................................33

Figura 17: Resultados de uma pesquisa.........................................................................................................34

Figura 18: Player apresentando um vídeo...............................................................................................35

Figura 19: Hiperdocumento com inserção de vídeo .....................................................................................35

Figura 20: Servidor de metadados in tegrado ao servidor de vídeo ............................................................36

Figura 21: Templates e instâncias de sessão.........................................................................................40

Figura 22: Página principal do T.A.....................................................................................................46

Figura 23: Módulo de ajuda do T.A.....................................................................................................46

Figura 24: Módulo de edição do T.A. .....................................................................................................47

Figura 25: Download de modelos para criação de "Web de disciplina" ......................................................48

Figura 26: Criação de documento segundo um modelo pronto...................................................................48

Figura 27: Modelo de arquivo para bookmarks ...................................................................................................49

Figura 28: Interface da agenda do professor ...............................................................................................50 


\section{RESUMO}

A presença de computadores e outros recursos tecnológicos no ambiente educacional sempre causou polêmica. Quando as máquinas de calcular entraram nas salas de aula, temia-se que as crianças - e, em pouco tempo, os adultos — perdessem a capacidade de realizar cálculos às custas de seu próprio raciocínio (preocupação antecipada em um conto de fícção de Isaac Asimov, A Sensação de Poder, publicado pela primeira vez em 1957). O cenário atual nos mostra não o receio, mas a necessidade de oferecer recursos tecnológicos aos estudantes, o mais cedo possível.

Neste contexto, focalizamos o sistema Interland (Moreira, Nunes \& Pimentel, 1995), que propõe um ambiente de auxílio ao aprendizado no sistema World-Wide Web, com facilidades para exploração de recursos interativos e de multimídia.

O objeto deste trabalho é a interface do professor no sistema Interland: o Teaching Assistant ou T.A. O sistema T.A. implementa um conjunto de recursos de autoria com modelos e ferramentas para a produção de documentos relacionados a disciplinas. Os modelos de páginas contribuem para uma menor necessidade de decisões de projeto por parte do professor e menos problemas de autoria, embutindo conceitos importantes na produção de documentos para a World-Wide Web. Essa preocupação também tem em vista evitar problemas para os usuários das páginas em hipertexto (os alunos). Um dos pontos principais do sistema T.A. é permitir a introdução de recursos multimídia (no estágio atual, trechos de vídeo selecionados pelo professor) disponíveis em uma base de dados, eliminando a necessidade de se aprender a manipular outros programas específicos para esse fim.

Os protótipos já desenvolvidos oferecem modelos de documentos, e permitem a introdução de interações simples e trechos de vídeo em páginas, de maneira transparente para o usuário. 


\begin{abstract}
The presence of computers and other technological resources on the educational environment was always a subject of controversy. When calculators entered the classrooms, there was the concern that children - and, into a short period of time, also adults - could lose their ability of making counts with their own brains (such concern was anticipated in a fiction story by Isaac Asimov, first published in 1957). The current scenery shows not the concem but the need to offer technological resources to the students, as soon as possible.

In such context, we focus on the system Interland (Moreira, Nunes \& Pimentel, 1995), which proposes an environment for learning support on the $\mathbb{W}^{\prime}$ orld-Wide Web, with tools that explore interactive and multimedia resources.

The subject of this work is the teacher's interface on the Interland system: the Teaching Assistant or T.A. The T.A. system implements a set of authorship resources with models and tools for the production of documents related to disciplines. Document models contribute for a minor need of project decisions by the side of the teacher, and also diminishes authorship problems, embedding important concepts of documents production for the World-Wide Web. Such feature also tries avoiding problems for the users of the hypertext (the students). One of the main features of the TA. is the insertion of multimedia resources (at its current development, video pieces selected by the teacher) from a data base, with no need of learning how to work with specific programs for manipulating video or data bases.
\end{abstract}

Developed prototypes offer document templates, allowing the insertion of simple interactions and video pieces on the pages, in a transparent way to the user. 


\section{Informática no apoio à Educação}

I educação está passando por uma revolução Norman \& Spohrer, 1996). Essa revolução (ou evolução) abrange os vários fatores psicológicos, filosóficos e físicos envolvidos no processo de aprendizado, além de diretrizes curriculares. A justificativa para tais mudanças é composta por motiros sociais e econômicos, segundo tendências mundiais: cortes nas verbas destinadas às universidades, competição entre universidades e outros órgãos educacionais, mudança no perfil dos estudantes universitários, e a recente capacidade de aquisição de computadores mais baratos e poderosos (Barker \& Manji, 1992; Litto, 1996; Norman \& Spohrer, 1996; Pozzembom, 1996; Skilicom, 1996).

Comenta-se que, atualmente, as mídias e meios eletrônicos oferecem muito mais informação em um único dia, do que um homem da Idade Média aprenderia durante toda sua vida. A integração intemacional e o desenvolvimento tecnológico enfatizam cada vez mais a necessidade de "aprender a aprender" (Pinciroli, 1996). A tendência desta Era da Informação é a personalização (Barreira, 1994): em vez de consumir produtos e informações produzidos em massa, existe a liberdade de escolha conforme preferências individuais. Os reflexos dessa tendência no ensino - a capacidade de interagir, definir as próprias lições de aprendizado e pesquisar informações em bancos de dados do mundo todo - contribuem para a revolução apontada por Norman e Spohrer (1996). Pinciroli (1996) conclui: saber localizar, compreender e utilizar as informações na era da Internet significa a diferença entre ser um navegador e ser um náufrago.

\subsection{Recursos eletrônicos no suporte ao ensino e aprendizado}

As aplicações de computadores no ensino têm sido classificadas em duas grandes categorias: a instrução assistida por computador (computer-aided instruction - $C A I$ ) e o treinamento baseado em computador (computer-based training - CBT) (Barker \& Manji, 1992; ver também Harmon, 1987).

A instrução assistida por computador (CAI) enfatiza o uso de computadores para a iniciação e promoção dos processos de aprendizado. Aplicações avançadas incluem mecanismos de Inteligência Artificial em sistemas de ajuda e tutores (sistemas tutores inteligentes: STI — ou sistemas de instrução inteligente assistida por computador: ICAI - Intelligent Computer-Aided Instruction).

O treinamento baseado em computador (CBT) trabalha com ambientes computacionais que visam 
facilitar o desenvolvimento e aperfeiçoamento de habilidades em domínios especificos de tarefas e procedimentos. Esses ambientes, em especial, exploram o uso de simulações.

\subsubsection{Simulações}

A aplicação de simulações no aprendizado procura estimular os processos que transformam informações em conhecimento. Várias abordagens (Goodyear et al., 1991) propõem que as simulações por computador podem servir como um processo de investigação (pela proposição e teste de hipóteses, análises heurísticas); como ferramenta de aprendizado indutivo e/ou dedutivo; ou como um ambiente para aquisição de conhecimento, ou voltado para a resolução de problemas.

\subsubsection{Hipertexto}

O hipertexto, como uma aplicação de armazenamento e recuperação de informações, foi previsto por Vannevar Bush em 1945. Bush descreveu um dispositivo chamado MENEX, no qual um indivíduo armazenaria todas as informações que possuísse: livros, anotações, registros, comunicações. Através de microfilmes, alavancas, botões e sistemas de índice, seria possível localizar as informações requisitadas, visualizando-as pela projeção em telas e realizando buscas progressivas e regressivas. A idéia da projeção progressiva, de acordo com Bush, era oferecer uma facilidade de indexação associativa, segundo a qual cada item poderia sempre selecionar outro. Essa seria a característica essencial de MEMEX (Baeker \& Buxton, 1987).

Pela representação de conhecimentos em sistemas de hipertexto, diversos elementos de informação podem ser montados de maneiras diferentes, de acordo com as diferentes perspectivas dos usuários do sistema. Através de ligações (links), o hipertexto oferece mecanismos para se descobrir as ligações conceituais entre seções de assuntos relacionados (Duncan, 1989). Uma de suas vantagens é permitir a exploração através dessas ligações conceituais. Em outras palavras, o hipertexto procura simular o processo de pensamento associativo realizado pela mente humana, sendo um de seus objetivos melhorar estratégias de aprendizado existentes (McAleese, 1989; ver também Nielsen, 1990).

\subsubsection{Multimidia e Hipermidia}

Multimídia é o uso simultâneo de dados em diferentes formas de mídia (voz, vídeo, texto, animações, e outras) (Buford, 1994). A associação entre hipertexto e multimídia define a hipermídia: textos, imagens e sons tomam-se disponíveis à medida em que o usuário percorre as ligações existentes entre eles. 
A World-Wide Web (Berners-Lee et al., 1994) é o sistema hipermidia mais conhecido na atualidade. Sua indèpendência de plataforma e a possibilidade de agregar diversos recursos e serviços aos documentos apresentados, implicam na facilidade de execução dos vários recursos pedagógicos, incluindo simulações e interações.

\section{$1.2 \mathrm{O}$ ensino on-line}

A Intemet vem sendo considerada um sinônimo de "comunicação sem fronteiras": uma poderosa ferramenta através da qual pode-se diminuir diferenças regionais, em termos de educação e desenvolvimento científico ${ }^{1}$, seja em parâmetros nacionais ou intemacionais. O professor Frederic Litto (1996) descreve algumas experiências da Escola do Futuro (Universidade de São Paulo - USP), uma delas com o desenvolvimento de atividades entre estudantes brasileiros, norte-americanos e israelenses. Um dos pontos importantes da "exploração didática" dessa comunicação é a oportunidade dos alunos desenvolverem o senso crítico diante do que o professor lhes apresenta em sala de aula, pois passam a ter acesso fácil a fontes de informação ricas e diversificadas, não importando sua localização geográfica (Bizzo, 1996).

A presença da Internet nas universidades e sua utilização como ferramenta de pesquisa são discutidas nas entrevistas feitas por Castro (1996). Entre os diversos fatores positivos, não se espera mais pela importação de livros e pela impressão de periódicos, sendo imediato o acesso a informações atualizadas e recursos prontos para utilização. Uma interface gráfica amigável, surgida com o sistema World-Wide Web (Berners-Lee et al., 1994), aproxima da Internet as pessoas que antes não dominavam os diversos protocolos de acesso a informações. Em comparação com outros serviços de pesquisa bibliográfica, o ambiente é muito mais ágil, oferecendo acesso a muita informação que não se encontra em mídias convencionais.

Por outro lado, as buscas em catálogos de informações geram a dificuldade em encontrar sites com informações científicas realmente interessantes, entre o "lixo cibernético". É difícil de se chegar à informação desejada. Muitas vezes, a decepção vem na forma de páginas com ênfase no tratamento gráfico e informações pouco relevantes, escassas ou desatualizadas. Chegamos ao paradoxo de termos muitos, e ao mesmo tempo poucos sites. $\mathrm{O}$ entusiasmo pelo acesso à Intemet também esbarra na preocupação com o conteúdo: o estudante pode acabar baseando suas pesquisas em

\footnotetext{
1 Mesa redonda: Pesquisa Científica e os Novos Ambientes Eletronicos, 48². Reunião Anual da SBPC - PUC-SP - 8 de julho de 1996.
} 
informações que não passaram pelo crivo de um referee, arriscando-se a propagar erros científicos (Castro, 1996)

Segundo Skillicom (1996), os cursos on-line tomam possível oferecer aprendizado de melhor qualidade devido aos seguintes fatores:

- O material on-line pode ser mais rico que o oferecido através da combinação de palestras e consultas a bibliotecas, mostrando facilmente as conexões entre os assuntos.

- O material pode ser mais consistente. Recursos de multimídia podem tomar permanentemente disponiveis as melhores explicações, apresentações e soluções, não apenas para os atuais alunos, mas também para os futuros.

- O material pode oferecer caminhos altemativos, respondendo a variados estilos de aprendizado dos estudantes. É possível ajustar o curso ao ritmo de aprendizado, fazendo avaliações e utilizando explicações mais simples nos pontos de dúvida.

- Cursos on-line podem ensinar a encontrar informações apropriadas em sistemas com grande volume de dados. O material do curso pode agir como um filtro, apontando boas fontes de informação na World-Wide Web.

Essas possibilidades dependem de vários fatores de implementação, apresentados nas seções seguintes.

\subsubsection{Modelos de ambientes e sistemas educacionais}

Kent L. Norman (1996) apresenta um estudo sobre a sala de aula on-line (ou eletrônica), com a exploração de recursos tais como tutores inteligentes e instrução assistida por computador. Ao analisar as características desse ambiente educacional, Norman o compara aos outros ambientes possíveis, segundo combinações de tempo e lugar que oferecem diferentes possibilidades de estudo em grupo e individual (Figura 1).

A sala de aula eletrônica é proposta como um ambiente no qual os participantes estão ao mesmo tempo no mesmo lugar, da mesma forma que a sala de aula tradicional, explorando recursos eletrônicos para dar ênfase ao envolvimento dos alunos e ao relacionamento professor-alunos. 


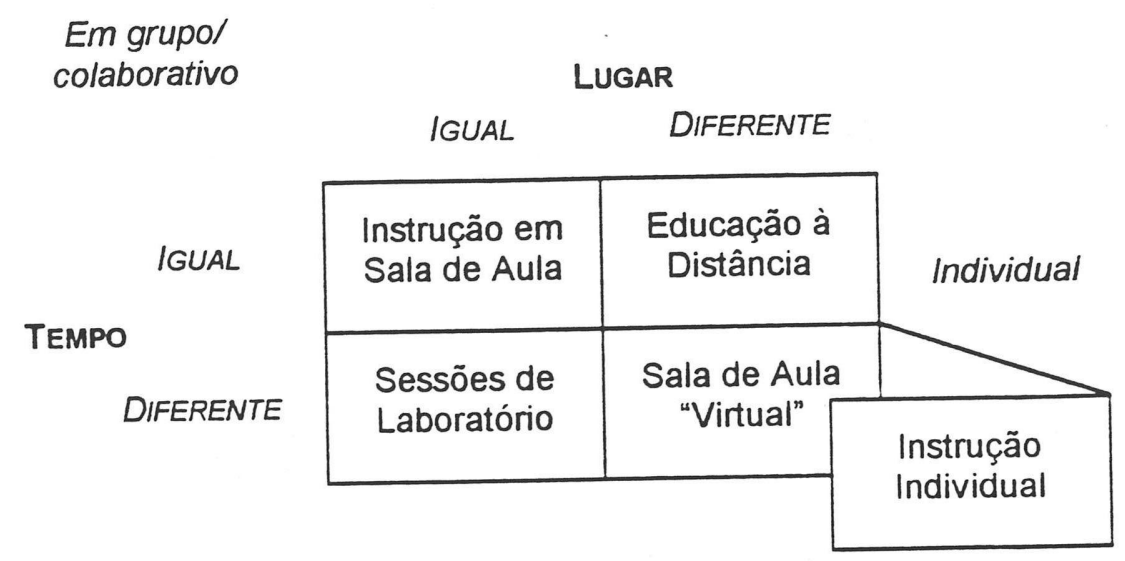

Figura 1: Possibilidades de educaçào e ambiente segundo combinaçŏes de tempo e lugar (Norman, 1996) ${ }^{2}$

A situação em que os envolvidos ocupam um mesmo lugar, em tempos diferentes, revela a situação de compartilhamento de recursos: uma mesma turma de alunos precisa ser dividida em grupos para aulas práticas ou exercícios que explorem em períodos diferentes os mesmos recursos.

A educação à distância, quando implementada sobre televisão ou rádio, é um ambiente que reúne pessoas a um mesmo tempo em lugares diferentes.

O ensino via correio comum, ou através de rede de computadores, origina o ambiente em que alunos e professores interagem mesmo quando em tempos e lugares diferentes; neste último caso, temos a sala de aula virtual. Tal modelo inclui a instrução individual, na qual cada estudante trabalha em seu próprio ritmo e de acordo com seus próprios interesses e habilidades.

Norman adota para suas experiências o conceito de sala de aula eletrônica, aliado à instrução individual; tal abordagem combina o envolvimento e trabalho conjunto dos alunos da sala de aula e o acompanhamento do ritmo individual de cada um deles ${ }^{3}$.

A classificação de Barker e Manji (1992) considera diversos níveis de CAI e CBT de acordo com a abrangência do sistema on-line de ensino (Figura 2).

2 Norman, K. L. - Teaching in the switched on classroom: An intraduction to electronic education and bypercourseware, figura 1.2 (capitulo 1): http://www.lap.umd.edu/SOC/Ch1/Ch1.html

3 Vide Anexo 1. 


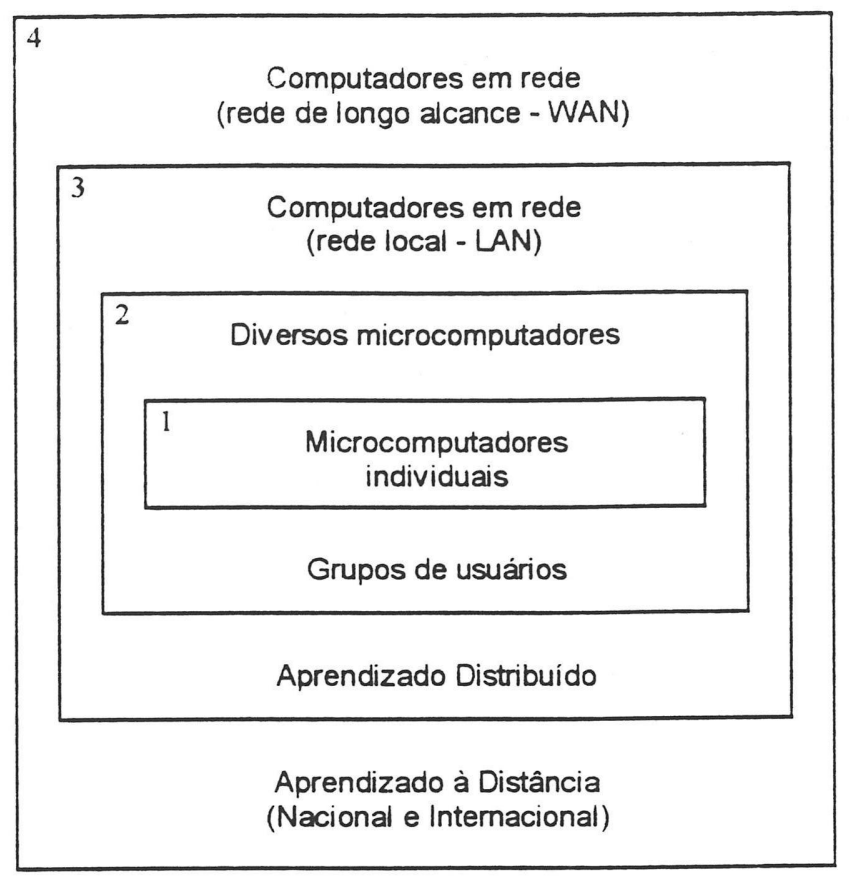

Figura 2: Niveis de sistemas pedagógicos com uso de computadores [baseado em (Barker \& Manji, 1992)]

\subsubsection{Tecnologia e pedagogia}

Um estudo realizado na Universidade do Estado da Califómia em Northride ${ }^{4}$ indicou que os estudantes em uma sala virtual obtiveram um rendimento $20 \%$ superior ao daquele conseguido pelos que aprenderam o conteúdo em uma sala de aula tradicional. O sucesso desse e de outros casos não vem da tecnologia em si: nas várias experiências bem sucedidas, os recursos tecnológicos foram explorados segundo estratégias pedagógicas adequadas ${ }^{5}$. Esse fato traz diversas questões sobre o papel da tecnologia no ensino: há quem considere a tecnologia da informação como uma alavanca para a transformação do ensino, e há quem a veja como um fator de perturbação, devido às mudanças que acarreta no ambiente educacional - o corpo docente amplia suas atribuições para unir currículo e pedagogia à tecnologia e à administração de recursos. $\mathrm{O}$ aprendizado e adaptação de técnicas novas demanda tempo e, em diversas situações, alunos e professores se encontram no patamar de aprendizes de um sistema computacional (DeSieno, 1995; Heterick Jr., 1994; Ruth, 1997).

\footnotetext{
${ }^{4}$ Edupage em português (19 de janeiro de 1997). [Mailing-list]. EDUCOM - RNP - MCT

5 Vide Anexo 1.
} 


\subsection{A produção de material didático eletrônico}

Além da essencial formação dos professores para o uso da tecnologia, a qualidade dos recursos utilizados (programas e mídias) é outro fator de grande importância. No Brasil, ainda não existe suficiente motivação de alunos e professores para assimilar o uso da nova ferramenta - bem como condições adequadas para tal. Também há falta de material didático; em especial, a importação de CD-ROMs em geral exige dos alunos a compreensão de outra língua (em geral o inglês) para estudar matérias como geografia e história, além do material não se mostrar adequado a características regionais (Pozzembom, 1996; Valente \& Almeida, 1997).

\subsubsection{Projeto de simulaç̃es}

As simulações devem permitir a exploração e experimentação de situações, oferecendo condições apropriadas de controle e critérios de avaliação adequados aos efeitos reais da simulação. Por serem sistemas complexos, exigem um bom ambiente de produção. Além disso, devem ter um compromisso entre fidelidade de representação da situação real e valor educacional da simulação (Goodyear et al., 1991).

\subsubsection{Autoria de bipermídia}

Existe uma longa tradição no projeto de documentos em papel, mas há pouca ou nenhuma para o projeto de documentos ou outras aplicações com hipermídia (Streitz, 1994). O sucesso ou fracasso de nossa interação com um hiperdocumento será determinado pelas decisões feitas pelo autor sobre quais nós (pedaços de informação, documentos hipertexto) devem ser unidos por ligações. $O$ hipertexto é não-linear, assim como as idéias; o problema da autoria de hipertexto é escolher o melhor "caminho de pensamento" para os documentos, através das ligações (McKnight et al., 1989).

Os problemas enfrentados pelos usuários de hipertexto são conhecidos (desorientação ou dificuldades em localizar a informação desejada, sobrecarga cognitiva $\left.{ }^{6}\right) . O$ autor, por sua vez, precisa aprender a expressar suas idéias no novo meio - a expressão de idéias não mais se limita às palavras, mas deve incluir as conexões entre nós. O autor precisa antecipar os usos que o leitor irá fazer da informação apresentada, prevendo os links (ligações ou biperlinks) necessários. De outra forma, o usuário poderá ficar apenas "passeando" pela base de conhecimentos, de maneira desmotivada e ineficiente. (McKnight et al., 1989; veja também Allinson \& Hammond, 1989). 
() suporte à navegação, o uso de metáforas e a combinação de ícones e cores, devem ser usados de modo que o leitor possa reconhecer facilmente o ambiente e sua localização no conjunto de hiperdocumentos; dessa forma, o usuário focalizará menos energia na interação com o hipertexto, concentrando-se nas tarefas que the interessarem (por exemplo: pesquisar um texto, resolver questões, realizar uma simulação) (Castro et al., 1997).

\subsection{Apoio aos professores para autoria de material didático on-line}

Com a popularização da World-Wide W'eb, foi aberta a possibilidade de se organizar sites para a divulgação de textos didáticos e oferecimento de cursos à distância através da Internet. Porém, considerando o acesso facilitado a esse meio de divulgação, a autoria de documentos adequados ainda não é simples. O conhecimento formal do sistema, e a aplicação de conceitos relacionados a Engenharia de Software e Interação Ĺsuário Computador, podem proporcionar melhor qualidade e aproveitamento do material produzido. A falta dessas técnicas, embora não seja sentida pelos autores, atinge diretamente os leitores (Castro et al., 1997).

Sistemas didáticos na World-Wide Web variam dos mais simples (publicação de material didático) aos mais complexos (sistemas tutores inteligentes). Neste trabalho, alguns sistemas atuais foram analisados para um estudo dos elementos mais importantes na implementação de tais aplicações, proporcionando uma visão geral dos sistemas que se tem produzido atualmente, e como (ver Capítulo 2).

Apesar da grande preocupação em implementar um conjunto de ferramentas de apoio ao ensino, boa parte dos sistemas deixa o trabalho da produção do material on-line sem muito suporte. Dessa forma, temos o conhecido panorama no qual a tarefa de publicar o curso na Internet não é executada pelos professores, mas por monitores de uma disciplina, por webmasters ou por terceiros. Isso leva o professor a depender diretamente de outras pessoas para trabalhar com seu próprio material. Outro fato indesejável é que algumas modificações necessárias, introduzidas pelos autores dos hiperdocumentos, podem interferir no resultado planejado pelo professor e, ao perder contato com o material eletrônico, como autor original, esse material on-line acaba perdendo qualidade e confiabilidade ${ }^{7}$.

\footnotetext{
${ }^{6}$ A sobrecarga cognitiva acontece quando o usuário precisa saber e se lembrar de muitos detalhes sobre sua navegação - ou sobre o sistema - para conseguir se orientar no conjunto de informaçōes.

${ }^{7}$ Edupage em português (5 de outubro de 1997). [Mailing-list]. EDUCOM - RNP - MCT
} 
lo dar suporte à autoria para o professor, pretende-se facilitar seu acesso aos recursos que podem ser explorados no material didático on-line. Pensando no esforço de adaptação do material já existente, tal suporte deve permitir a reutilização desse material, deixando o professor livre de preocupações com os vários detalhes de autoria do hipertexto - linkes, elementos de HTML, recursos interativos, navegação, estilo de documentos, entre outros. A interface deve facilitar o trabalho para que o professor, mesmo sem ter intimidade com as ferramentas envolvidas, produza bons documentos e ao mesmo tempo tenha ampla liberdade de criação.

\subsection{Conclusões do capítulo}

Is mudanças sociais e econômicas no mundo atual demandam métodos de ensino eficientes para a habilitação das pessoas ao aprendizado contínuo. O acesso cada vez mais fácil a grande número de informações de nada serve se o indivíduo não souber trabalhar tais dados para assimilá-los de maneira produtiva — na era da Internet, é ainda mais importante "aprender a aprender".

Os novos recursos de comunicação liberam estudantes e professores das limitações de tempo e espaço, enriquecendo o ensino com recursos de multimídia, interação, simulações, permitindo o estudo individualizado e colaborativo.

Empregar novas tecnologias no ensino não implica em sucesso no aprendizado. Acima de tudo, é necessário haver motivação e abertura das pessoas envolvidas com a nova ferramenta, dando oportunidade ao surgimento de uma nova maneira de ensinar e aprender.

Os sistemas didáticos on-line, por sua vez, precisam ser bem elaborados, contando com uma estrutura básica que ofereça facilidades para alunos e professores. A produção do material pedagógico deve facilitar a exploração de recursos, levar à composição de bons hiperdocumentos e, ao mesmo tempo, permitir a autonomia do professor no desenvolvimento de suas aulas e materiais de apoio.

Exemplos de sistemas didáticos disponíveis atualmente são discutidos no próximo capítulo. 


\section{Sistemas didáticos e de apoio à autoria}

Diversas abordagens são utilizadas para o uso de material didático on-line; selecionamos algumas implementações para detectar características desejáveis para tais sistemas. L'm conjunto de sistemas de apoio à produção de material didático também é analisado neste capítulo ${ }^{8}$.

\subsection{Sistemas didáticos na World-Wide Web}

Sistemas de hipermídia vêm sendo cada vez mais usados como ferramentas de aprendizagem. Quando esses sistemas ganham uma "inteligência" que os permita monitorar as atividades dos usuários, podem englobar Sistemas Tutores Inteligentes (STIs). Esses sistemas tutores são programas destinados ao ensino, sendo sua forma mais simples os recursos de auxílio interativo. Os sistemas de hipermídia, que visam o suporte ao aprendizado, ganham uma arquitetura que abrange alguns módulos especiais (Park, 1987; veja também Tedesco, Barros \& Souza, 1997):

- o modelo do aluno, que acompanha sua evolução dentro do domínio de conhecimento, atividades desenvolvidas e desempenho;

- um conjunto de recursos relacionados ao assunto a ser explorado pelo estudante;

- o módulo pedagógico, que trabalha com o modelo do aluno, relacionando atividades e conteúdos que devem ser apresentados de acordo com seu desempenho;

- um componente que controla a in teração entre o aluno e o sistema.

Além dessas características, os sistemas didáticos com hipermídia na Internet devem dar suporte a recursos de comunicação, pelo excelente motivo de estarem implementados em uma rede de comunicação e, assim, oferecerem facilidades de trabalho cooperativo.

Neste capítulo, procuramos identificar características desses sistemas didáticos em algumas implementações encontradas na Internet. Foram analisadas diversas experiências, aqui organizadas informalmente segundo a presença de interações, acompanhamento de usuários e suporte ao trabalho cooperativo.

\footnotetext{
s Para melhor compreensão das análises, que envolvem conceitos do sistema World-Wide Web e itens importantes de produção de hipermidia para uso on-line, consulte o Anexo 2.
} 


\subsection{1 "Sites" de disciplinas}

. ggumas implementações se utilizam da estrutura da rede (sistema World-Wide Web) para manter informações sobre disciplinas: ementas, datas de provas e entrega de trabalhos, listas de exercícios. Vormalmente, esse "site" é uma iniciativa do professor. Manter um conjunto de informações desse tipo não é "ter um curso na Internet", embora possa ser o início de um sistema didático.

L'ma experiência no Laboratório de Arquitetura e Redes de Computadores (LARC-USP http://www.larc.usp.br/) insere diversos "sites" de disciplinas, utilizando o suporte à restrição de acessos do servidor HTTP (Figura 3). Os alunos registrados nas matérias têm acesso às informações referentes a ela, tais como datas para entrega de trabalhos e enunciado de exercícios, porém o conteúdo das aulas ainda não se encontra disponível. Os professores são responsáveis pela manutenção dos dados e notas, atualizando as páginas por FTP.

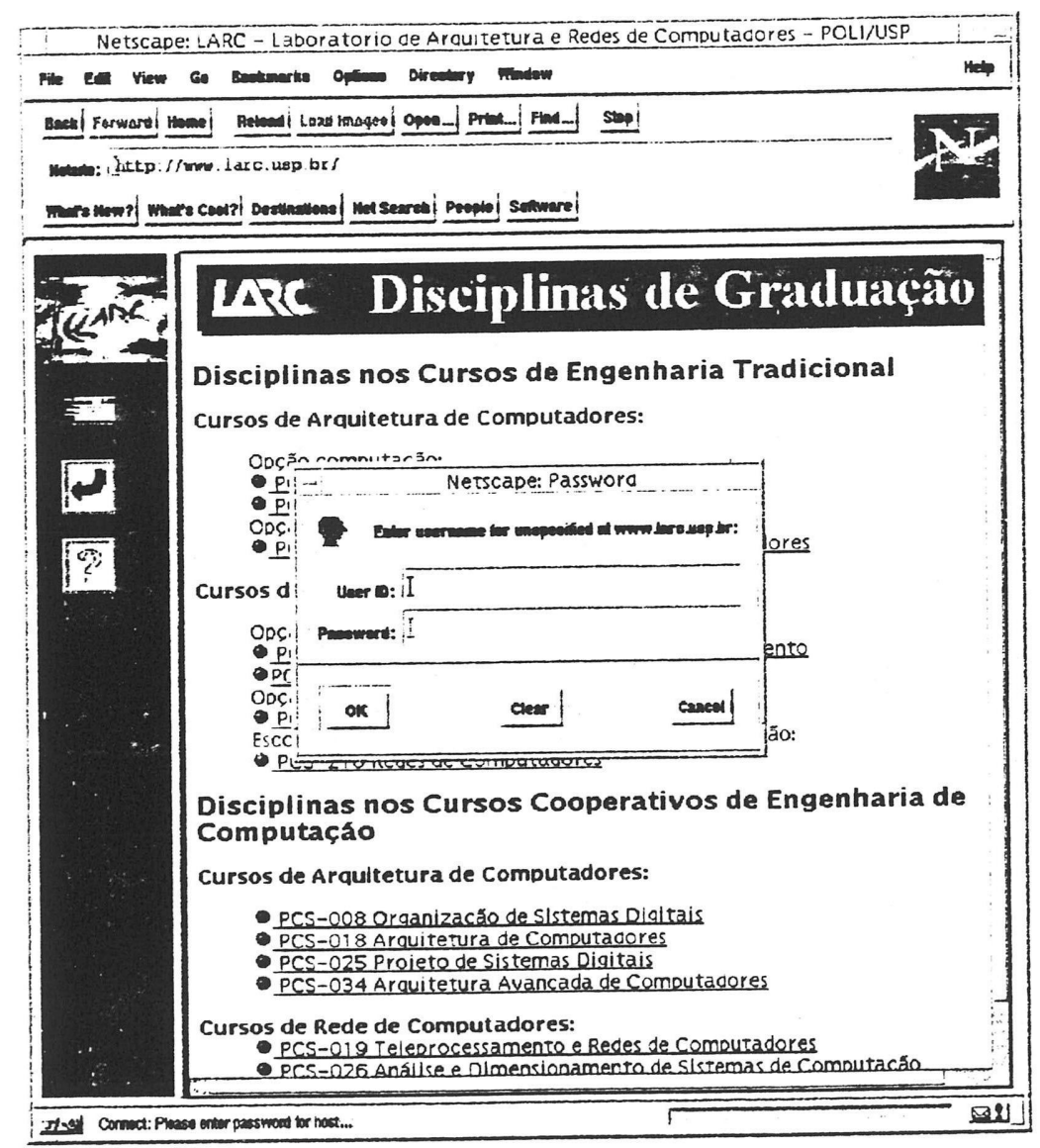

Figura 3: Disciplinas on-line no LARC-USP: ementas, exercicios e notas

Um aluno cadastrado pode ver suas notas (apenas suas próprias notas) através do sistema e, através de um programa de notas, acompanhar seu desempenho com relação à classe. Este projeto de tele- 
¿¿ucação está em desenvolvimento?.

\subsection{Material didático na World-Wide Web}

É comum encontrarmos material didático na World-Wide Web; em geral, eles são localizados sob a Eenominação de "curso", "manual de referência", ou "tutorial". Tais conjuntos de documentos żzem uso da hipermídia como ferramenta de apresentação do material, seguindo algum método idático.

A interação existente nesse material se resume ao acionamento de ligações do hipertexto; కeralmente, há também a possibilidade de enviar mensagens de e-mail para o autor (que não é, necessariamente, um professor). Os tutoriais se diferenciam dos manuais de referência pelo fato de implementarem alguma interação do leitor com o material sendo apresentado — por exemplo, com Formulários através dos quais se experimentam comandos ou formatações, e cujos resultados são apresentados imediatamente após a submissão dos dados ${ }^{10}$. Implementações avançadas embutem sistemas tutores (Tedesco, Barros \& Souza, 1997).

I abordagem não-interativa surte efeito para a divulgação das informações e as pessoas conseguem aprender pela consulta a esse material. Porém, como material on-line, é uma implementação ineficiente: o leitor interessado costuma imprimir o material, utilizando-o como um livro comum este fato vem ocorrendo com o "Tutorial HTML" e o curso de Estruturas de Dados (Figura 4), ambos no site do ICMSC-USP (respectivamente, em http://www.icmsc.sc.usp.br/manuals /SCE182/ e http://www.icmsc.sc.usp.br/manuals/HTML/).

Algumas características indesejáveis dos "cursos" disponiveis no sistema World-Wide Web são sintetizados em (Romanatto, Torres-Alamilla, \& Monard, 1996):

- Apresentam pouca informação sobre como navegar pelo material. A maioria dos cursos é implementada pelo próprio pesquisador, o que faz desses sites meros reservatórios de informação, carentes de uma estrutura didaticamente ordenada e compreensível para os internautas ${ }^{11}$.

\footnotetext{
${ }^{9}$ Femando Frota Redigolo (1997). Comunicação pessoal.

10 Alguns "tutoriais" encontrados na Web são, na verdade, manuais de referência (por exemplo, o "Tutorial HTML" implementado no site do ICMSC). Os tutoriais de fato ainda säo raramente encontrados.

11 Internauta é um dos termos utilizados para designar os usuários "navegantes da Internet".
} 

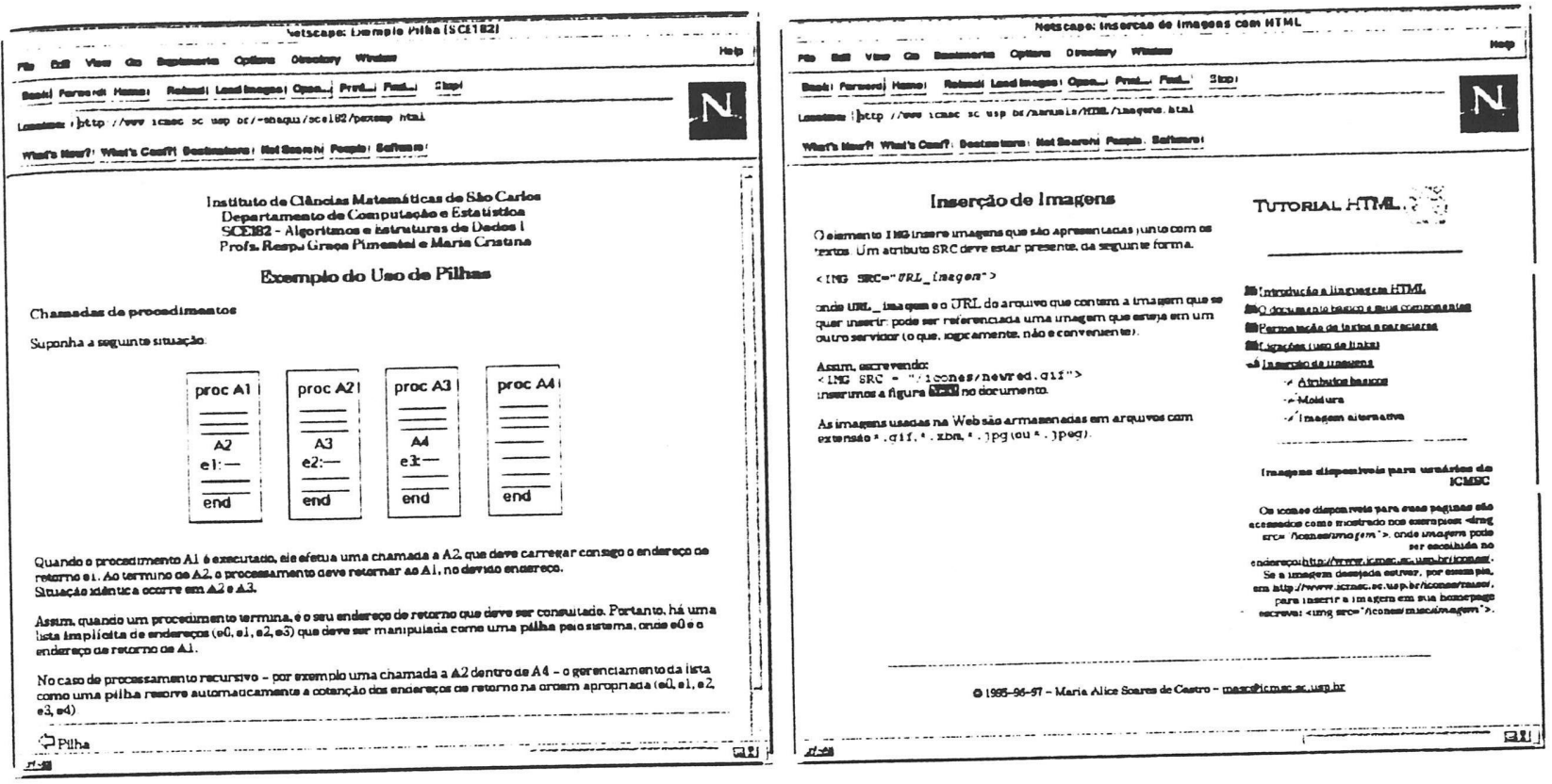

Figura 4: Curso de Estruturas de Dados e "Tutorial HTML": exemplos de material didático na World-Wide Web

- Atrás de um título interessante, nem sempre se chega a informações correspondentes. Em boa parte dos sites, a informação oferecida é pontual, apenas com recomendações ou referências (links) para arquivos.

- Foi observado também que muitos sites não fornecem a origem das informações, nem a data da última atualização.

Portanto, além da simples transposição de material didático para documentos da World-Wide Web não produzir um sistema de Educação à Distância, muitas vezes toma-se dificil lidar com essas fontes de informação para o aprendizado de algum assunto. Esses problemas são devidos à não aplicação de conceitos relacionados a interação e apresentações em hipermídia, em particular no ambiente da World-Wide Web.

\subsubsection{Sistemas didáticos baseados na comunicação via Internet}

Algumas implementações, ainda que não constituam um sistema didático completo, usam a comunicação via Intemet para exploração de informações e desenvolvimento de trabalho cooperativo. Descrevemos brevemente algumas características de implementação de cursos na Escola do Futuro (http://www.futuro.usp.br/; Litto, 1996) e no Programa Educ@r 
http://www.ifqsc.sc.usp.br/educar/educar.html).

\subsubsection{Escola do Futuro}

I Escola do Futuro nasceu como um centro difusor e de orientação técnico-pedagógica de tecnologias avançadas de comunicação aplicadas à educação (Litto, 1996). Diversos grupos de pesquisa trabalham em várias frentes de investigação, envolvendo a produção de material interativo (videodiscos e CD-ROMs educativos) e ensino via Telemática (uso das redes Bitnet e Internet para pesquisas sobre Ciências e Humanidades), entre outros. As atividades visam principalmente o nível de $1^{\circ}$. e $2^{\circ}$. graus. Nas experiências científicas há trabalhos práticos e os computadores são usados para o registro dos dados em planilhas, para a confrontação dos dados, acesso a fontes internacionais (tais como bibliotecas e bases de dados on-line), geração de relatórios e intercâmbio desses relatórios através de e-mail. Algumas dessas atividades envolvem escolas do Brasil, Israel, Inglaterra, Portugal e Estados Unidos. O material das atividades ainda não se encontra disponível para acesso on-line (Figura 5).

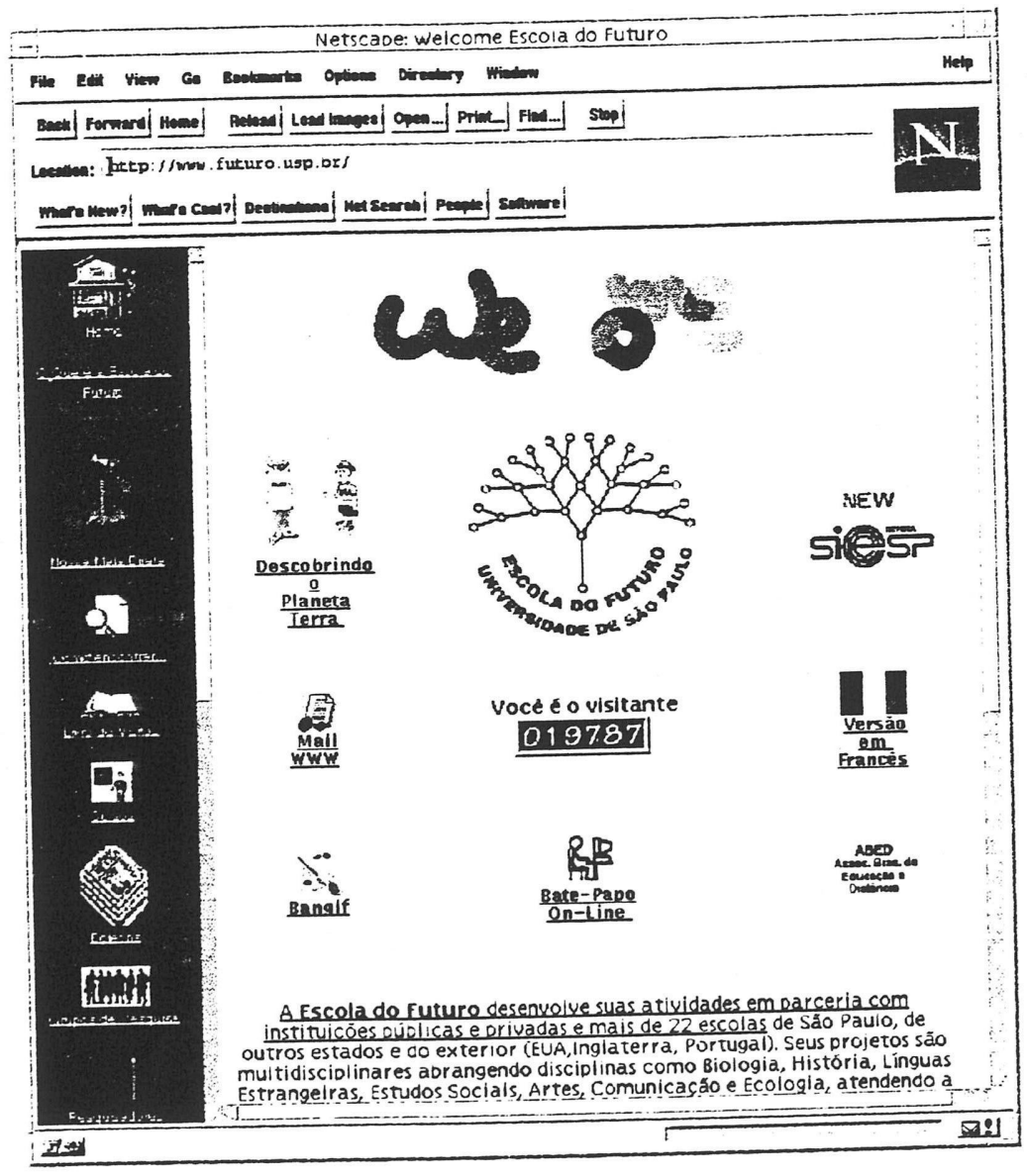

Figura 5: "Site" da Escola do Futuro 
1 Escola mantém um BBS que se dedica à questão de Inovações em Educação, organizando também alguns cursos livres à distância via rede. Devido a um convênio com a Agência Estado, os usuários do BBS têm acesso às informações veiculadas por aquela agência noticiosa; essas informações são utilizadas como fonte de atividades em sala de aula, tais como a criação de jomais murais, e análise crítica de acontecimentos.

\subsubsection{ProgramaEduc@r}

O programa Educ@r iniciou suas atividades no ano de 1997, com três cursos disponíveis na primeira fase: Matemática para professores de $1^{2}$. a $4^{2}$. séries, Mecânica Gráfica para alunos de $2^{\circ}$. grau, e Educação Ambiental.

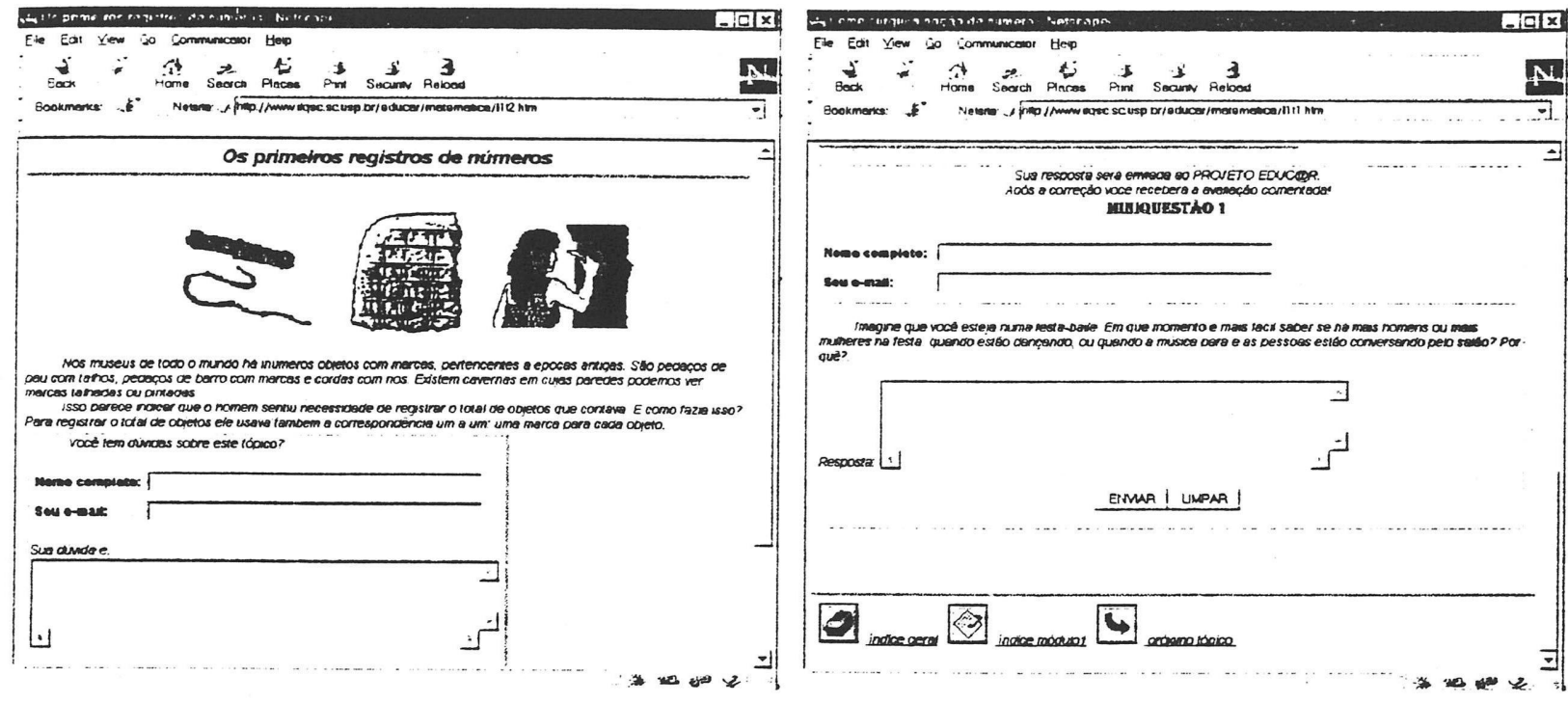

Figura 6: Programa Educ@r. Formulários on-line para envio de dúvidas , respostas a questōes, submissão e consulta a dados

O conteúdo básico dos cursos está disponível em páginas na World-Wide Web, complementado por atividades de laboratório acompanhadas pelo Programa. Através de formulários on-line, os participantes do curso de Educação Ambiental podem submeter os dados coletados nas atividades práticas; esses dados são armazenados e deixados à disposição para consulta pelos outros grupos participantes. Dúvidas e respostas de questionários são submetidas também por formulários nas páginas dos cursos, fazendo o ponto de comunicação entre os estudantes e os coordenadores do Programa (Figura 6). 
Este projeto está em desenvolvimento, sendo prevista a implementação de um "chat" para oferecer comunicação entre os participantes das diversas escolas.

\section{1.t Sistemas cooperativos para exploração de informações na Internet}

Lma característica importante dos sistemas didáticos é a capacidade de oferecer tratamento personalizado para estudantes ou grupos de estudantes. Duas abordagens interessantes são vistas aqui: a primeira utiliza o sistema Hyper-G (Skilicom, 1996), e a segunda focaliza a exploração da Internet dentro de um sistema didático (Linn, 1996; http://www.kie.berkeley.edu/KIE.html).

\subsubsection{Lma experiência com Hyper-G}

A World-Wide Web apresenta diversas limitações que se tomam aparentes quando se considera tarefas mais complexas; faltam características de autorização de acesso, buscas que ultrapassem os limites do sistema Web, entre outras. Além disso, os linkes são unidirecionais; a bidirecionalidade é essencial para se descobrir quais documentos estão apontando para o documento atual - essa é uma informação crítica para a atualização de link,s.

Considerando os conceitos que faltam na Web, foi desenvolvido o Hyper-G, projeto da Universidade de Tecnologia de Graz (Áustria) em $1993^{12}$. A diferença principal entre servidores World-Wide Web e Hyper-G é que o Hyper-G provê muito mais funcionalidade integrada e, portanto, uniforme. Outras características são (Skilicom, 1996):

- O conceito de conjuntos (clusters) e coleções (collections) de documentos. As hierarquias de coleções podem conter outras coleções de documentos e, dessa forma, um usuário pode mover-se dentro de uma hierarquia (para cima e para baixo) ou seguindo links (para frente e para trás). Essa estrutura ajuda a reduzir o efeito de desorientação, oferecendo uma maneira natural de organização do material.

- Em Hyper-G todos os links para ou de algum documento são conhecidos (sem que se veja o conteúdo dos documentos). Assim, é possível seguir links em qualquer direção, através de qualquer número de servidores.

- As ligações de hipertexto são armazenadas de maneira independente dos documentos. Quando uma âncora é colocada em um documento, o sistema o retira, armazenando-o

12 Atualmente, o projeto è denominado Hypervave (http:/ fiicmpc21.tu-graz.ac.at/hyperwave, http://www.ïcm.edu/hgbook) 
separadamente, com seu status de visibilidade. Dessa forma toma-se possível adicionar um link, de um documento sem editá-lo: a inserção de um link não altera o documento original.

- Os servidores Hyper-G trabalham sobre uma plataforma realmente distribuída: um usuário pode acionar diversos servidores Hyper-G de modo que a união de todos os bancos de dados envolvidos aparece como se fosse um único banco de dados. Assim, não é preciso ter um servidor central dedicado com grande capacidade de armazenamento.

- É possível lidar com contas de usuários: estabelecer quem pode ter acesso a que recurso, onde, e por quanto tempo; isso se toma útil para pesquisas, análise de acessos, entre outras aplicações.

- O autor é capaz de especificar a vida útil de documentos no momento da criação, tomandoos visiveis ou invisiveis de acordo com a data.

İ semelhança da Web, Hyper-G pode invocar outros programas para execução, e tem acesso aos vários sistemas de informação da Internet com uma interface consistente.

A experiência apresentada por Skillicom em (Skilicom, 1996) foi realizada na Queen's University (Canadá). Inicialmente, o material on-line oferecia textos e sugestões de referências na Intemet, bem como anúncios relacionados a aulas e exercícios. As atividades desenvolvidas com o auxílio do sistema envolveram também a produção de hipertextos pelos estudantes e, ao final do semestre, os cursos apresentavam material produzido pelo professor, monitores e alunos.

Uma vez que o sistema permite a declaração de documentos e coleções públicas e particulares, algumas sessões permitiam a introdução de links para referências na Intemet sugeridas pelos alunos; sessões de dúvidas foram compostas pelas perguntas dos alunos e respectivas respostas de monitores ou do professor. Algumas questões de revisão, propostas pelo professor, fizeram parte do conjunto de material de revisão do curso. Como todo material inserido no sistema é autenticado com o nome do autor, data e hora de inserção, a participação dos alunos era facilmente verificada.

Skillicom não relata maiores detalhes da implementação, porém comenta que os alunos acharam dificil resistir ao impulso de imprimir o material disponível on-line, não somente devido à necessidade de se aprender de uma maneira diferente, como também pela baixa qualidade da apresentação dos textos. Alguns alunos que perderam as aulas iniciais tiveram problemas em lidar com o sistema; como boa parte do curso estava on-line, esses alunos não acompanharam o desenvolvimento de 
atividades, perdendo prazos e gastando mais tempo para atingir o progresso dos colegas.

Os estudantes anotaram, como pontos positivos, a capacidade de acompanhar os trabalhos de seus pares (introduzindo críticas e comentários sobre esses trabalhos), a possibilidade de trabalhar em casa e de lidar com hipertexto. U'm maior contato entre alunos, professores e monitores também foi uma das conseqüências percebidas durante as experiências desenvolvidas.

\section{1.t.2 KIE - Ambiente de Integração de Conbecimentos}

KIE (Knowledge Integration Environment - Ambiente de Integração de Conhecimentos) é um sistema desenvolvido na Berkeley University para estudantes de $1^{\circ}$. grau $(\mathrm{K}-12$ no sistema educacional americano). No sistema KIE, os alunos desenvolvem idéias cientificas a partir da experiência pessoal, de aprendizado na escola, exploração pela Intemet e outras atividades.

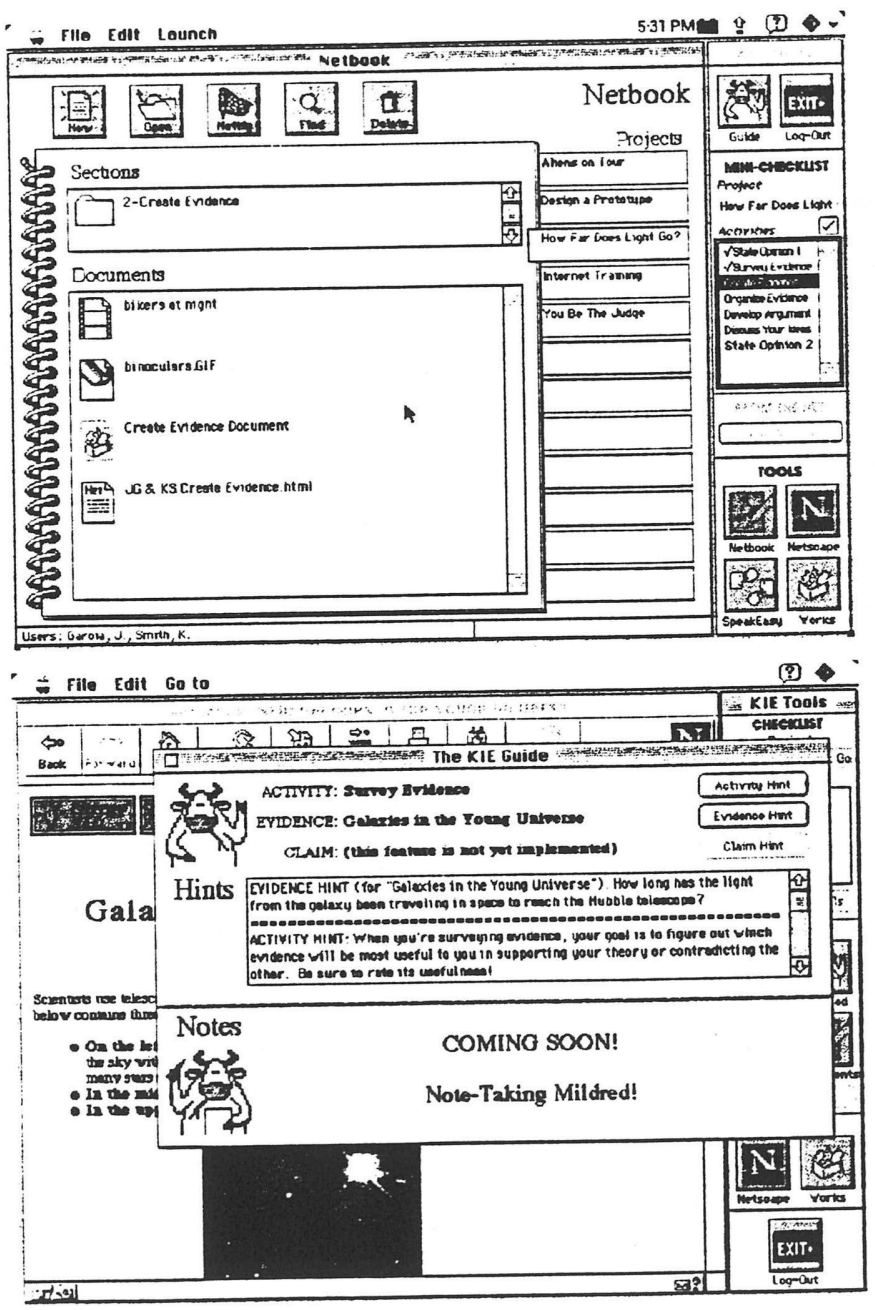

Figura 7: Softwares do sistema KIE: Netbook (para organização de informaçōes) e Guide (dicas para desenvolvimento de atividades) 
Em particular, a estrutura Scuffolded Knowledge Integration (Integração Estruturada de Conhecimento) enfatiza tornar visível a necessidade dos estudantes em integrar conhecimentos e ao mesmo tempo encorajá-los a tomarem-se responsáveis pelo próprio aprendizado (Linn, 1996). Cada atividade do sistema KIE apresenta uma coleção de evidências incluindo fotos e dados. Auxílios para estudantes incluem o guia da vaquinha Mildred (com dicas e exemplos associados às atividades em desenvolvimento), um ihecklist de atividades, e ferramentas de navegação (Figura 7). Os professores adicionam novas atividades e projetos usando a interface do professor.

O material básico de consulta on-line é desenvolvido dentro de uma base de dados do sistema. Outros documentos podem ser inseridos não somente pela equipe de desenvolvimento do projeto, como também por professores, cientistas e pelos próprios alunos.

Um fórum para troca de idéias (em formato de News) é implementado em um software que permite tanto a participação com identificação do autor, como a participação anônima (Figura 8). Esta segunda opção, segundo (Linn, 1996), oferece a oportunidade do professor participar das discussões como um aluno e, assim, obter opiniões mais francas sobre seus comentários.

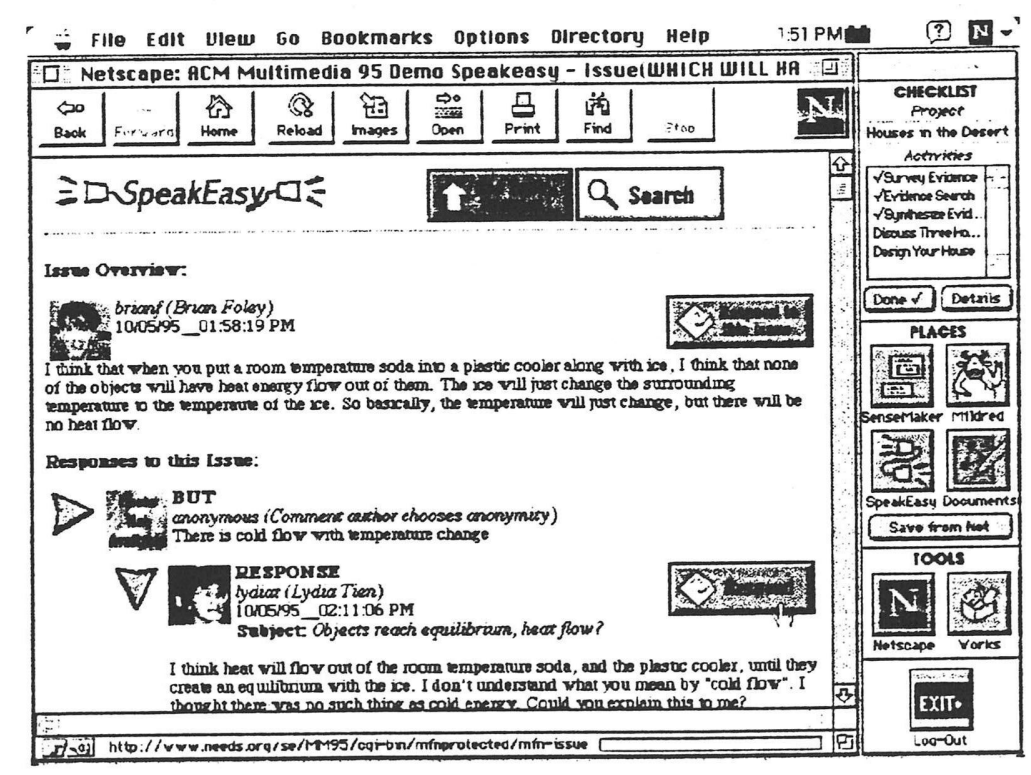

Figura 8: Fórum de discussões no sistema KIE

A ferramenta do professor - SKIPP (Student Knowledge Integration Profiler and Planner) - é composta por duas partes principais: o planejador de atividades e o gerenciador de dados dos alunos (profiler). Esse software ainda está em desenvolvimento (Figura 9). 
() planejador de atividades tem por objetivo oferecer aos professores um conjunto padrão de projetos, cada qual com atividades associadas e modelos para os respectivos trabalhos dos alunos. Os professores também poderão planejar seus próprios projetos, ou modificar atividades, modelos, estruturas, e outras características de projetos já existentes.

As atividades e projetos desenvolvidos pelos alunos, bem como o conteúdo visitado por eles, são acompanhados pelo profiler. Todas as informações entradas pelos alunos também são mantidas por ele, oferecendo material que permita uma personalização de projetos e atividades de acordo com as necessidades de aprendizado de cada aluno. O professor poderá decidir quais aspectos do aluno serão usados, e em que extensão; além disso, suas decisões poderão sobrepor o que for indicado pelo profiler.

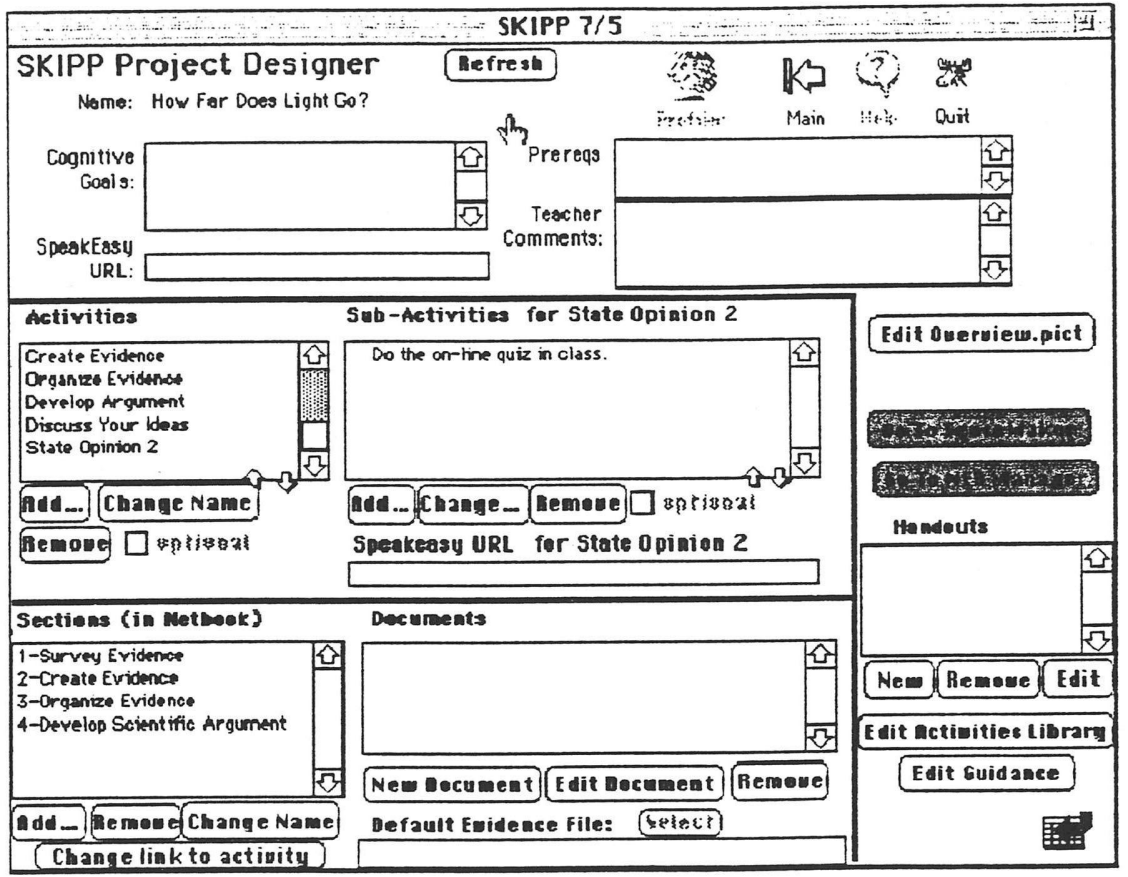

Figura 9: Interface do professor no sistema KIE

Sendo um projeto voltado para crianças, o KIE apresenta itens relevantes como sistema de apoio ao aprendizado, em especial com relação ao processo cognitivo. Ele é um modelo de ambiente didático completo, do ponto de vista abordado no presente trabalho. A solução encontrada para a autenticação e acompanhamento de usuários foi a implementação de softwares específicos, deixando a World-Wide Web como fonte de informações a explorar segundo um assunto determinado pelo professor. A interface é simples e consistente, mantendo sempre à disposição o acesso aos vários softwares do sistema - incluindo browsers e editores especiais para gerar 
documentos HTML e apresentações em diversas mídias.

\subsubsection{Sistemas didáticos imersos na World-Wide Web}

No item anterior, vimos dois exemplos de sistemas didáticos com diversas características desejáveis; porém, os recursos utilizados não estão inseridos no ambiente do presente trabalho, que é a WorldWide W'eb. Sendo assim, procuramos alguns exemplos de sistemas didáticos totalmente "imersos" na Web, que explorem seus recursos para oferecer material didático, interação, autenticação e acompanhamento de usuários, ambientes de trabalho cooperativo, e aplicações de multimídia.

Foram visitados alguns sites com implementação de recursos didáticos, em especial no Canadá e Estados Unidos. Em geral, os trabalhos apresentaram a preocupação em treinar professores para a adaptação aos novos métodos de ensino, introdução às novas ferramentas de preparação de aulas e material didático.

Diversas empresas americanas vêm se especializando na preparação de coursewares, deixando disponíveis na rede algumas demonstrações dos recursos utilizados. Lma dessas empresas University Online Publishing, Inc. (UOL - http://www.uol.com/) - oferece um passeio por algumas páginas, como visitante cadastrado com login e senha pessoais. $\mathrm{Na}$ época da realização do acesso ao site, um dos cursos disponíveis era o de contabilidade, sendo possível analisar a exploração de vários recursos do ambiente Web para a composição do material. Alguns desses recursos dependem da plataforma utilizada pelo aluno, o que não é uma característica grave quando se considera que o público-alvo é conhecido e utiliza a plataforma necessária para a habilitação de tais características.

Uma análise das principais características da implementação do curso (Figura 10) está a seguir.

- Interface: as páginas seguem um padrão de apresentação (cores, ícones e organização do conteúdo) que permite a rápida familiarização do usuário com o ambiente do curso.

- Navegação: a lista de links principais, sempre presente, marca em cor diferente o nome da página sendo mostrada, possibilitando ao usuário ver sua localização no conjunto de documentos. Essa lista permite acesso imediato a diversos recursos do curso: página inicial (Home), introdução ao curso e critérios de trabalho (Syllabus), aulas (Lectures), referências (References), exercícios (Exercises) e testes (Tests), fórum de discussão (Conference), configuração da apresentação (Display) e ajuda para utilizar o sistema (Help, não implementado).

- Recursos multimídia: grande parte dos itens vistos apresenta somente textos, alguns com 
ilustrações. Tópicos mais complexos, relacionados ao uso de recursos computacionais (planilhas), oferecem trechos de apresentações em Lotus ScreenCiam, alertando para a necessidade de se utilizar plataforma Windows para sua execução. Alguns recursos multimídia estão presentes também nos exercícios.

- Exercícios: pode-se ter acesso a pelo menos um exercício relacionado ao tópico visto em determinada semana. Os exercícios testados foram implementados em linguagem Java, mostrando a evolução de determinada condição tinanceira, juntamente com controles para simulações e análises.

- Testes: exercícios baseados em formulários de múltipla escolha ou respostas simples (falso/verdadeiro, ou inserção de uma palavra). Cada questão é apresentada em uma página separada; o aluno pode pular questões, revisar as respostas dadas e, ao final, submeter o conjunto de respostas para avaliação. A correção é recebida em seguida, em uma página que compara as respostas corretas com as que foram oferecidas pelo aluno. É possível rever as questões com os resultados, mas as respostas submetidas não podem ser alteradas após a correção. Breves comentários sugerem a revisão de conceitos em um livro-texto.

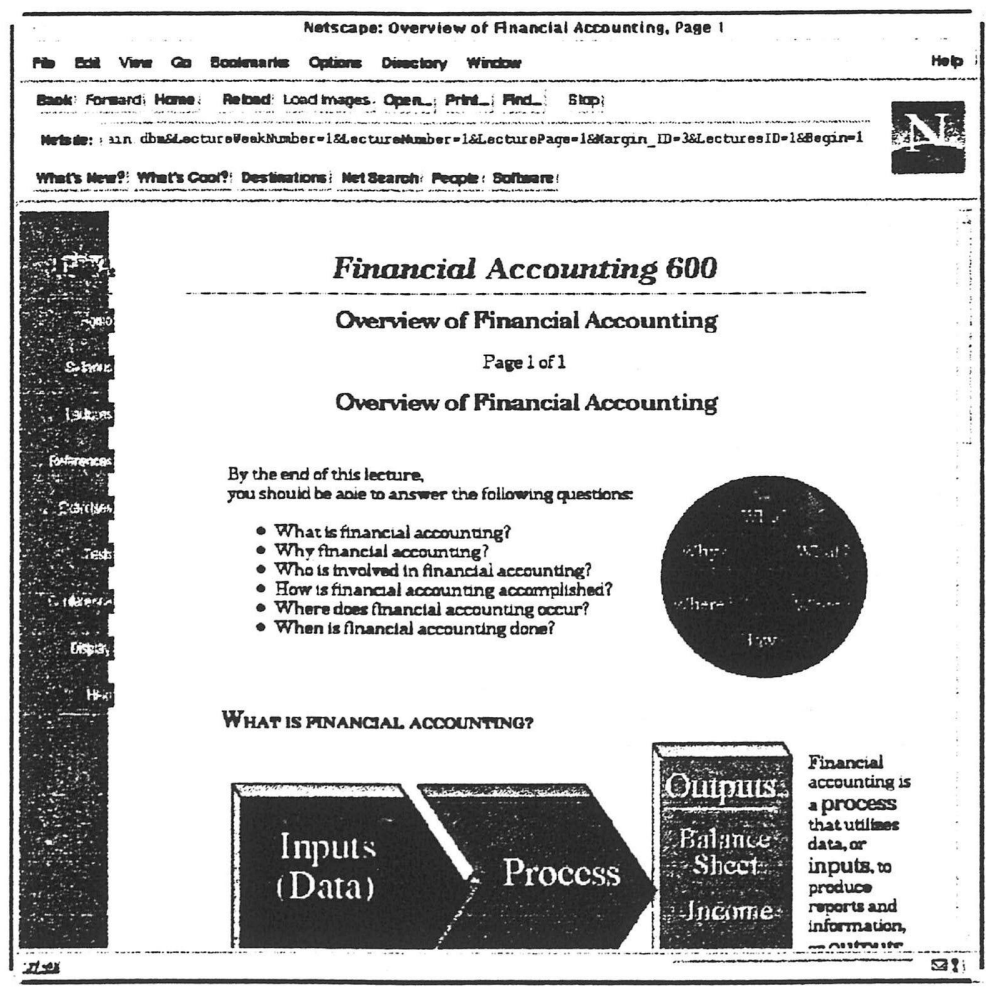

Figura 10: Curso de contabilidade no site da UOL 
- Fórum de discussão: em formato de Nen's, o fórum é aberto a discussões gerais sobre a matéria, o desempenho de trabalhos, soluçào de dúridas e consultas ao professor. A implementação desse fórum foi feita em Cold Fusion ${ }^{13}$ (Figura 11).

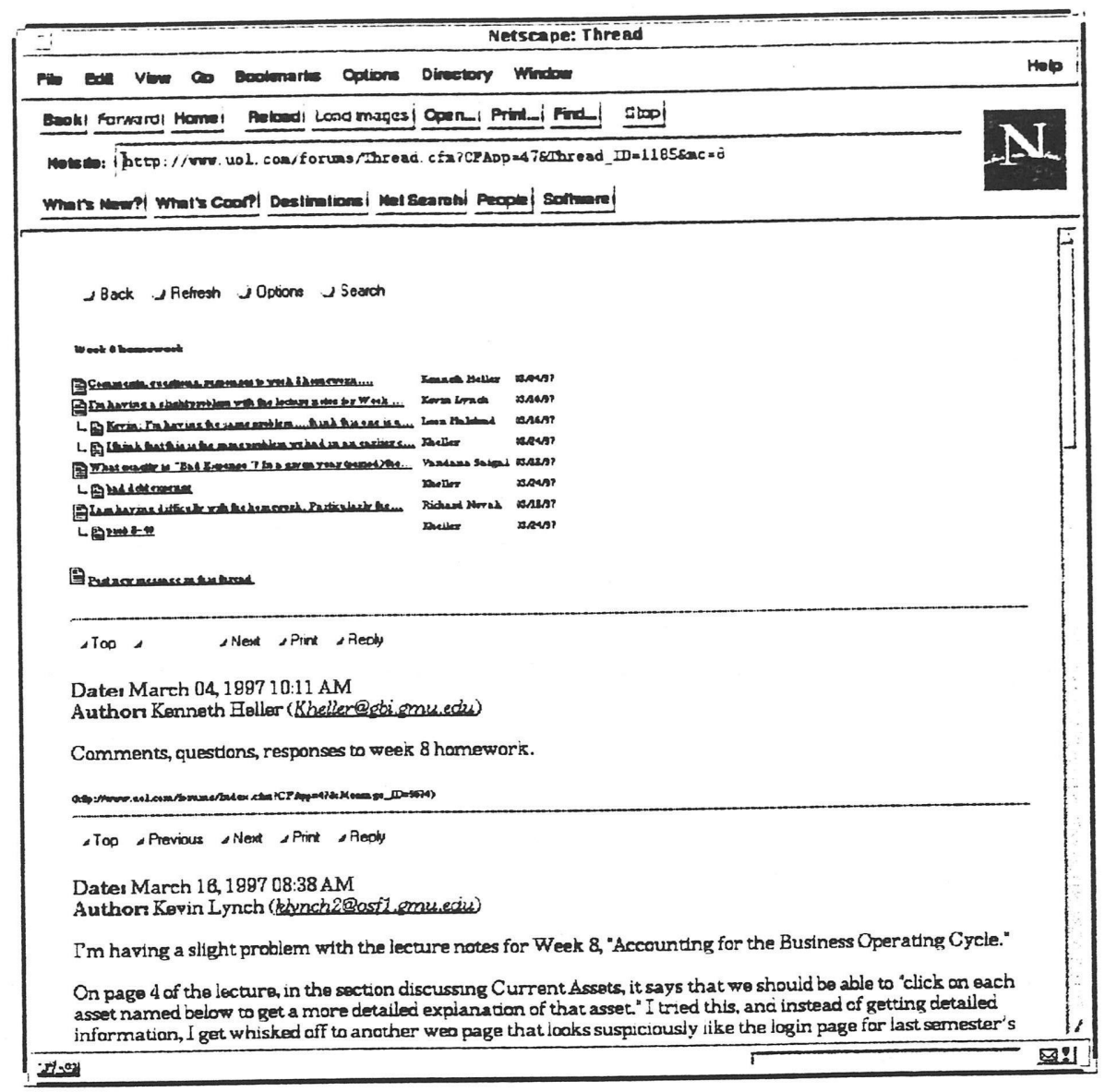

Figura 11: Fórum de discussäo no curso de contabilidade na UOL

A navegação foi planejada da maneira mais simples possível, seguindo uma ordem seqüencial de aulas e, dentro de cada aula, páginas associadas aos links principais (referências, exercícios, e outros indicados no primeiro item acima). Os recursos utilizados para apresentar o conteúdo foram vários e bem explorados. Todas as páginas foram acionadas através de scripts, sendo realizado o acompanhamento do progresso dos alunos dessa forma. Não foi possível ter acesso a informações mais detalhadas sobre a avaliação do aluno, ou sobre a interface do professor, apenas que são oferecidos kits de softwares para a integração dos recursos dentro de um modelo básico de curso. 


\subsection{Sistemas de apoio à autoria}

I maioria dos sistemas didáticos analisados não possui suporte direto à produção de documentos. Em geral, tais sistemas propõem a adoção de ferramentas já existentes, como editores para HTML (tipo texto ou WYSIWYG ${ }^{14}$ ), filtros para transformação de documentos MS Word, ou então editores que exploram a interface do próprio browser.

\subsubsection{WebWriter}

O sistema WebWriter (Crespo, Chang \& Bier, 1997), é um editor de HTML que utiliza processamento do lado do cliente, isto é, pelo browser (através de JavaScript), e também do lado do servidor (pela invocação de CGI scripts). O WebWriter permite a composição de aplicações simples para a Web, sem que o usuário precise aprender HTML ou programação CGI. Seguindo o modelo HyperCard (Apple, Inc.), esse editor oferece uma visão de pilhas (stacks) de páginas; cada página, por sua vez, é um documento Web comum, podendo apresentar texto, imagens, elementos de Formulários e conteúdo produzido por scripts.

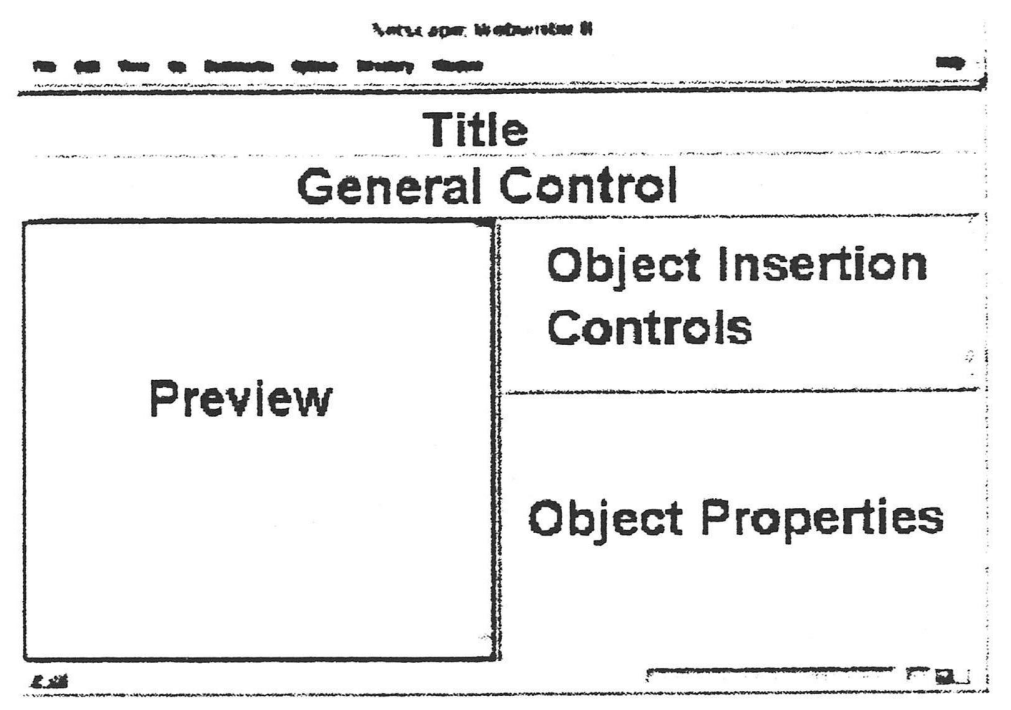

Figura 12: Frames do editor WebWriter [Figura 2 de (Crespo, Chang \& Bier, 1997)]

A organização da interface em frames dá uma visão dos controles e propriedades relacionados à página em edição. O uso de JavaScript explora o processamento local para o preview da edição,

13 Cold Fusion è uma ferramenta que permite a criação de páginas dinâmicas e interativas, integrando bases de dados e outros protocolos. Qualquer cliente Web tem acesso a um servidor Cold Fusion, mas o servidor roda apenas em ambiente Windows.

${ }_{14}$ WYSIWYG: "What You See Is What You Get" - ambiente no qual o usuário edita documentos (textos, imagens) visualizando o resultado final. 
evitando os tempos de espera causados pelo acionamento de scripts CGI no servidor. Os roteiros CGI são ativados apenas para as tarefas que não poderiam ser efetuadas localmente.

A arquitetura do WebWriter é composta por quatro (4) módulos em CGI e dezenove (19) módulos em JavaScript. Os módulos de CGI oferecem serviços tais como carregamento de arquivos, parsing de arquivos HTML, armazenamento de arquivos, e preparação do ambiente de edição para os módulos de HTML ao iniciar o editor. Os módulos em JavaScript apresentam o preview da página editada, selecionando o objeto que estiver em edição, fazendo a edição, inserção, cópia e transferência de elementos HTML.

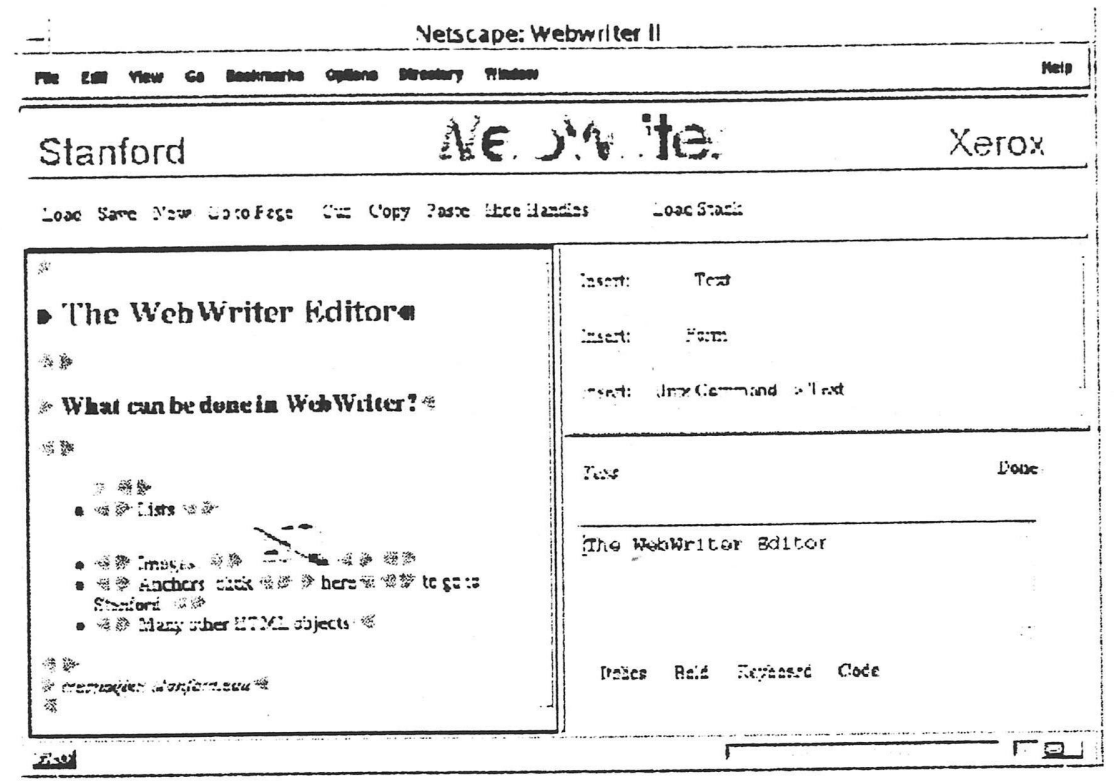

Figura 13: Interface do editor WebWriter [Figura 1 de (Crespo, Chang \& Bier, 1997)]

O arquivo principal do WebWriter é um programa CGI que cria uma página HTML com três (3) componentes: funções globais de JavaScript, estruturas de dados globais de JavaScript e a definição do conjunto de frames.

Uma requisição básica do sistema é que o usuário se utilize de um browser que apresente frames e interprete JavaScript. A escolha por esse conjunto de JavaScripts e frames, foi motivada pela possibilidade de oferecer uma interação rápida (necessária em uma edição), evitando ao máximo a necessidade de recarregar páginas para conferir resultados finais. Também através de JavaScript, é possivel selecionar na tela as frases ou elementos que se deseja editar, tomando a interface ainda 
mais leve por não empregar elementos de formulário para esse fím.

Das desvantagens citadas pelos autores, estão a falta de controle sobre o editor como produto pois os roteiros JavaScript são sempre enviados para a máquina do usuário - e a complexidade dos módulos JavaScript que o compõem. Diminuir ainda mais o tempo ainda gasto na interação entre cliente e servidor é um dos trabalhos futuros pretendidos para este editor.

\subsubsection{CyberProf}

O CyberProf (Hubler \& Assad, 1996) é um pacote didático completo que oferece interfaces para alunos e professores. Os programas que o compõem são scripts que agem do lado do servidor, e permitem a avaliação de exercícios feitos pelo aluno, de maneira automática.

A interface do professor permite que ele crie conjuntos de problemas através de um editor específico, utilize ferramentas específicas para montar problemas de determinada área, organize apostilas de aulas on-line e se comunique com os estudantes por uma central de mensagens. Seu módulo de edição é bem complexo, apresentando grande número de funções na janela do browser. exigindo que o usuário tenha algum conhecimento sobre o funcionamento do sistema e de suas ferramentas. A formulação de questões e produção de textos é feita via formulários de entrada, e alguns recursos solicitam a programação de roteiros cursos em um pseudo-código específico.

Este sistema ainda está em desenvolvimento, e pode ser visitado on-line através do URL: http://www.ccsr.uiuc.edu/cyberprof-docs/general/.

\subsubsection{InterBook}

O sistema InterBook (Brusilovsky, Schwarz \& Weber, 1996) oferece ferramentas para a autoria e publicação de livros-texto eletrônicos na World Wide Web. O InterBook gera índice, glossário e uma interface de busca.

Uma forte característica do InterBook é o suporte à navegação. Usando bullets coloridos, os links têm seu status marcado, com base no histórico da navegação, da etapa de conhecimento e dos prérequisitos.

A autoria tem vários passos, desde um texto preparado como um arquivo MS Word, até que ele possa ser usado pelo InterBook: o InterBook reconhece a estrutura do documento através de cabeçalhos. Reconhecida a estrutura, é empregada uma anotação baseada em conceitos para que o 
InterBook saiba os conceitos relacionados a cada seção; este passo produz um arquivo MS Word estruturado e anotado, que é armazenado em formato RTF. Lm filtro transforma esse arquivo RTF em HTML com algumas modificações. Quando o servidor InterBook é iniciado (acionamento de script), ele analisa todos os arquivos de seu diretório de textos e compõe um conjunto de frames.

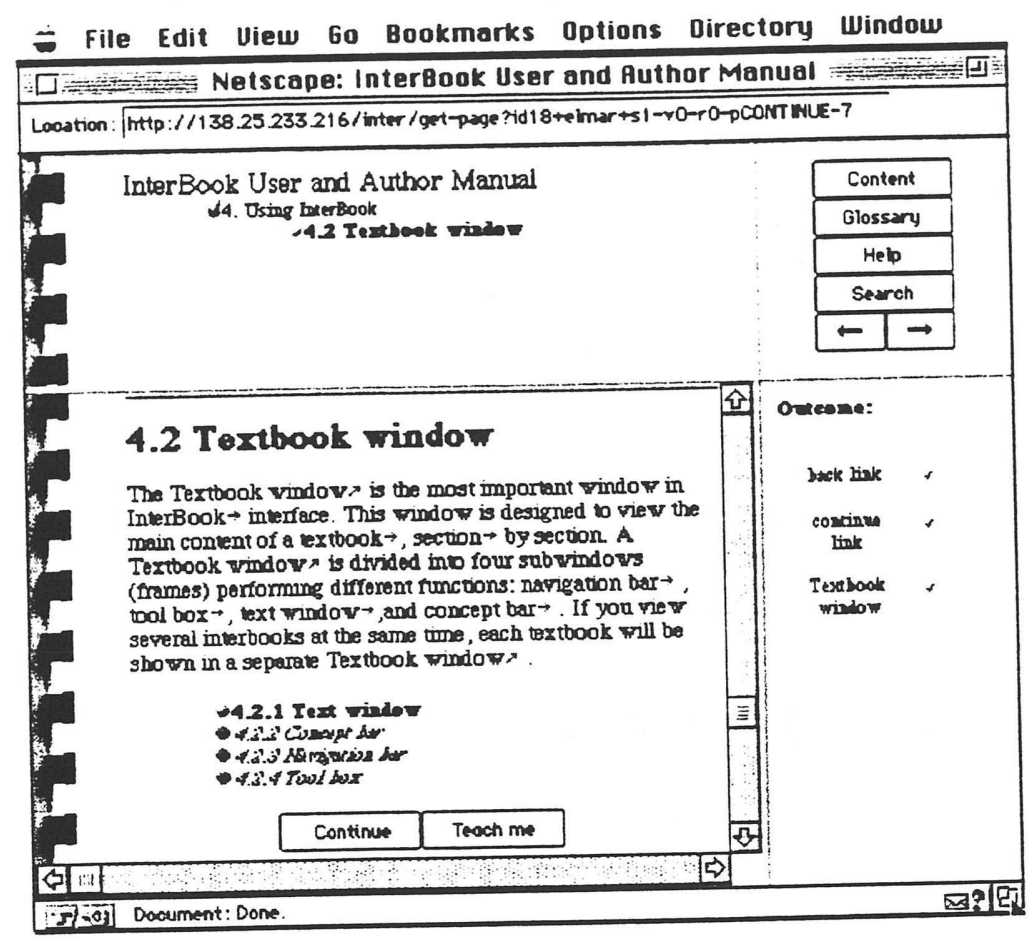

Figura 14: Interface do InterBook

\subsection{Conclusões do capítulo}

Neste capitulo, vimos diversas experiências relacionadas a cursos disponiveis na Internet, buscando identificar implementações de sistemas didáticos e características desejáveis para tais sistemas.

Os "sites" de disciplinas são confundidos, muitas vezes, com a idéia de "curso na Intemet"; na verdade, funcionam somente como ponto de referência sobre uma determinada disciplina e, em geral, não evoluem além da apresentação da ementa. Algumas iniciativas acrescentam recursos interessantes: consulta a notas, comparação de desempenho e exercícios desenvolvidos por alunos.

Grande parte da utilização didática da Internet está baseada na simples divulgação de material didático (em manuais de referência e tutoriais). Essas implementações exploram a capacidade de divulgação pelo sistema World-Wide Web, mantendo forte identidade com o material impresso; embora os manuais e tutoriais cheguem a ser eficientes, costumam sofrer com a falta de adequação do 
conteúdo ao meio: hipertextos com problemas de apresentação e navegação, entre outros.

Agumas experiências utilizam a Intemet como elemento de comunicação para o trabalho cooperativo, no complemento das aulas tradicionais. Esses projetos são um passo importante em direção à idéia de exploração de informações para construção do conhecimento, quebrando o isolamento das salas de aula e oferecendo oportunidades para o desenvolvimento do senso crítico dos alunos.

Outros sistemas oferecem um ambiente de exploração de informações na Internet; nos sistemas aqui abordados, encontramos a preocupação em implementar elementos de sistemas tutores - modelo do aluno, recursos relacionados aos assuntos explorados, módulo pedagógico, controle de interação - e, adicionalmente, recursos para o trabalho cooperativo. Uma abordagem é implementar tais elementos em um sistema próprio (como na experiência de Berkeley, com o sistema KIE); outra forma é utilizar um ambiente que já possua grande parte dessas facilidades (no exemplo visto, o sistema Hyper-G).

Sistemas didáticos imersos na World-Wide Web procuram oferecer os elementos de sistemas tutores através de recursos adicionais desenvolvidos na própria Web: servidores HTTP comunicando-se com bancos de dados (para o módulo do aluno), desenvolvimento de scripts (acompanhamento de desempenho) e aplicação de diversas tecnologias (recursos de interação e simulações). Um bom projeto de interface, bem como a adoção de uma estrutura simples de navegação, garantem uma apresentação leve e eficiente.

As ferramentas de autoria on-line apresentam diversas funções interessantes, geralmente escondendo do usuário os mecanismos subjacentes da edição. Enquanto alguns editores se preocupam com a estrutura de navegação (InterBook), outros dão ênfase à geração de recursos que exigem maior conhecimento do sistema pelo usuário (CyberProf), ou simplesmente oferecem uma ferramenta simples para edição de textos (WebWriter).

$\mathrm{Na}$ pesquisa realizada não se encontrou uma ferramenta, totalmente inserida na World-Wide Web, que lide com os problemas de organização e produção de bons documentos e também suporte facilidades para inserção de elementos de multimídia, como propomos neste trabalho. 


\section{O Sistema Interland}

() sistema HyDTS (Hypermedia Distributed Teaching System) (Moreira, Nunes \& Pimentel, 1995), atualmente denominado Interland, propõe um sistema direcionado para funções de treinamento e ensino assistido, no qual animações, vídeo clips e hiperdocumentos são fartamente utilizados como ferramentas de auxílio ao aprendizado.

Diversos estudos em desenvolvimento compõem o projeto do sistema Interland. O conjunto de informações sobre o sistema pode ser obtido pela consulta às seguintes referências: (Castro et al., 1997), (Galli \& Moreira, 1997), (Goularte, 1998), (Guimarães, 1997), (Hachisuca, 1997), (Moreira, Nunes \& Pimentel, 1995) e (Reami, 1997).

\subsection{Fundamentos e Arquitetura do Sistema}

O sistema Interland é distribuído entre um servidor e vários clientes, sendo atualmente implementado sobre a plataforma World-Wide Web.

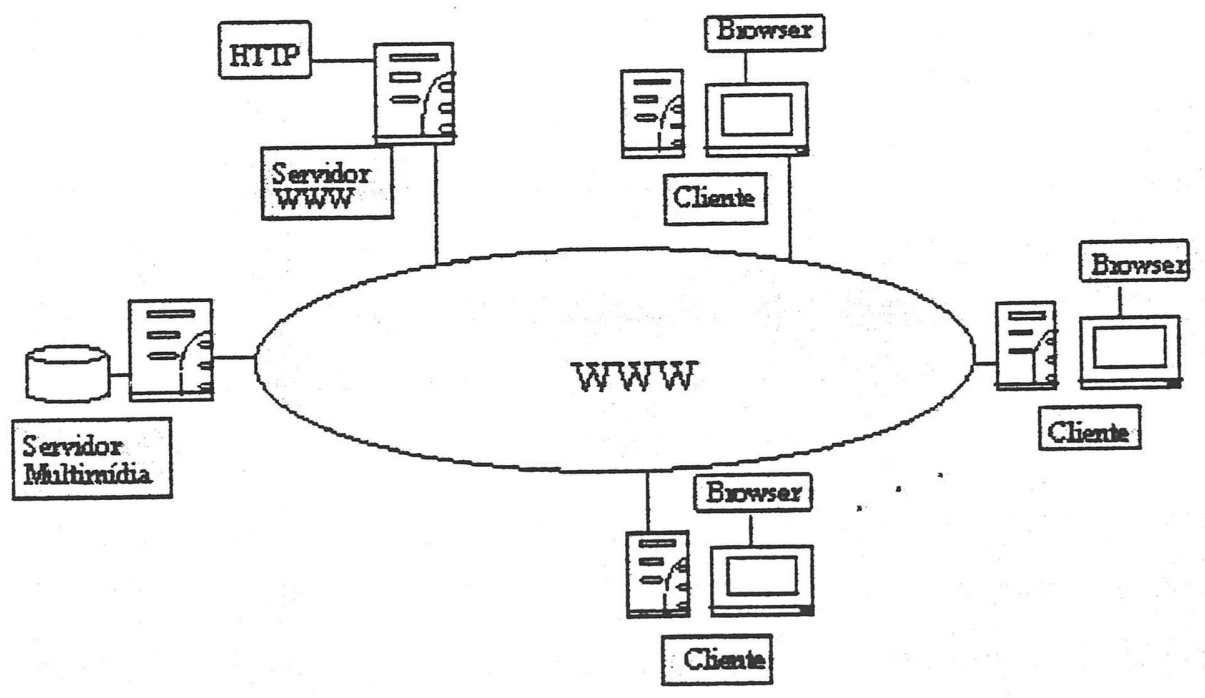

Figura 15: Visão geral do sistema Interland (Goularte, 1998)

\subsubsection{Fundamentos}

O primeiro objetivo do sistema Interland é oferecer toda a infra-estrutura básica para um ambiente 
centrado no usuário (Galli \& Moreira, 1997; veja também Guimarães, 1997):

- Autenticação e monitoramento de usuários.

- Restrições de acesso a recursos e diretórios.

- Interface personalizada como mesa de trabalho.

- Registro em banco de dados, de usuário e sessão de usuário.

- Comunicação entre as partes.

Através da autenticação, toma-se possível a construção de um mapa das ações do usuário. O monitoramento exige um módulo de gerenciamento baseado na especulação das ações do usuário (tempo de acesso, recursos utilizados, páginas visitadas) que consiga armazenar estes dados para uma futura análise do comportamento do estudante.

Para as restrições de acesso são criadas ACLs (Access Control List) pelo servidor do Interland, utilizadas para cadastrar usuários e a eles associar os recursos aos quais o aluno poderá ter acesso (Guimarães, 1997).

A imagem que os usuários têm do sistema é formada pelo conjunto de características da interface, seu comportamento e sua documentação; essa imagem também inclui o modo como ele é utilizado: os usuários aprendem não apenas analisando o sistema, mas também através da experiência que vão adquirindo ao utilizá-lo (Preece et al., 1994). No Interland, interfaces personalizadas do sistema darão acesso a atividades e recursos conforme o desempenho do aluno e de acordo com a programação de estudos delineada pelo professor (Galli \& Moreira, 1997).

\subsubsection{Sess̃̃es}

Cada sessão é formada por um conjunto de recursos educacionais, restrições de acesso, entre outros objetos. Uma sessão é preparada por um professor através de ferramentas de autoria associadas à interface do professor, podendo estar associada a uma lista de alunos, que terão seu desempenho registrado e avaliado.

Independentemente do conceito de sessões, os materiais de curso que não têm controles associados poderão estar disponíveis de forma livre, de modo que usuários não cadastrados no sistema terão esso a eles. 
O usuário aluno pode receber diversas instâncias de sessão, sendo cada uma o ambiente de trabalho de um contexto de estudo (aula, curso). A modelagem das sessões é feita pelo professor, que distribui aos alunos as instâncias de sessão com o auxílio de ferramentas de seu ambiente (Galli \& Moreira, 1997).

\subsubsection{Clientes}

O acesso aos recursos e sessões do sistema será feito através de uma série de clientes especiais. Foram definidos níveis de acesso para controlar quais informações cada usuário tem disponível para si (controle de sessões de vídeo, acesso aos conteúdos e resultados de provas, permissão para criar novas sessões, etc.), a saber: modo supervisor, modo professor e modo aluno. Os usuários são identificados pelo servidor HTTP através do módulo de identificação e classificados em uma dessas categorias (Moreira, Nunes \& Pimentel, 1995; veja também Reami, 1997).

\subsubsection{Cliente Supervisor}

Este cliente é a interface com o usuário responsável pelas configurações específicas do sistema e por manter a integridade e disponibilidade dos serviços do mesmo. O supervisor tem todos os direitos de gerenciamento do servidor, validação de usuários e acessos, gerenciamento das bases de usuários e cursos.

\subsubsection{Cliente Aluno}

Esta interface provê um ambiente de estudo personalizado, no qual cada estudante recebe uma instância de sessão correspondente a cada curso elaborado pelo professor. Os alunos podem ser distribuídos em grupos, para executarem uma mesma tarefa (que poderá ter relatórios individuais ou conjuntos), atribuindo-se a eles um determinado conjunto de atribuições e privilégios.

Este cliente pode ser utilizado de várias maneiras:

- Pode ser usado em aula para acompanhamento de exposição feita ao vivo pelo professor, que aciona, através de seu computador, procedimentos que são mostrados na tela das máquinas de cada aluno;

- Pode ser usado em aula, como o principal instrutor. Neste caso, o professor prepara a aula e deixa disponível aos alunos para ter uma "aula automática", possivelmente com a presença de monitores; 
- Pode ser utilizado para preparar documentos (relatórios, exercícios práticos, etc.);

- Pode ser utilizado como elemento de comunicação.

\subsubsection{Cliente Professor}

A interface do professor com o sistema Interland é o sistema T.A. (descrito com detalhes no Capítulo 4).

Os professores pertencem a um grupo especial, com privilégios excepcionais, que incluem acesso aos aplicativos de gerenciamento. Desta maneira, o professor poderá preparar um conjunto de objetos para serem utilizados assincronamente por ele durante a aula, ou para formarem o corpo de uma aula (através de scripts) que ficará disponivel no servidor para acesso pelos alunos durante uma sessão. Os scripts permitirão ao professor adicionar gráficos, textos, vinhetas, animações, vídeos, aplicações compartilhadas, entre outros recursos.

Quando um professor modela uma sessão, ele está também criando seu ambiente. Ele especifica a interface que ele terá durante uma aula, por exemplo. Esta interface pode incluir um conjunto de resultados de avaliações dos alunos, possíveis agentes de avaliação, controles gráficos para coordenação de sessões de exercícios e de vídeos, e outros recursos (Galli \& Moreira, 1997; veja também Guimarães, 1997).

\subsection{Funcionamento básico do sistema Interland}

O protótipo atual implementa uma visão de usuário aluno. Um formulário na página inicial solicita nome e senha do usuário, e a escolha de uma das disciplinas disponíveis no servidor (Figura 16). O módulo de autenticação realiza a verificação na base de usuários, validando-o ou não. Se o usuário for válido, ele receberá um cookie contendo várias informações do usuário (nome, nivel de acesso, tempo máximo de acesso, entre outras) recuperadas de uma base de dados em mSQL. Também é retomado um panel-guide com os tópicos relacionados à matéria selecionada, para acompanhamento do usuário.

Para um usuário professor, o sistema não estará exigindo a especificação de uma matéria, necessariamente; assim que sua entrada no sistema for validada, o sistema T.A. oferece seu ambiente com opções de trabalho. 


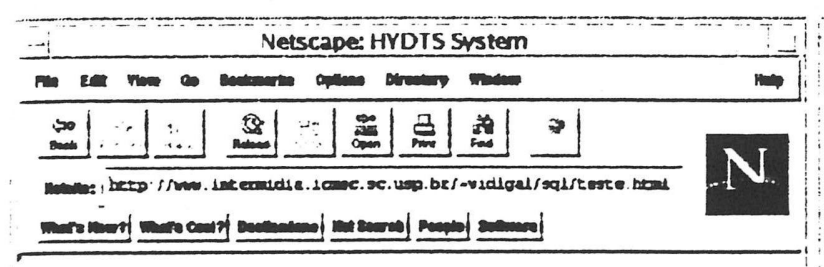

Xipola WebGuide

Xipola WebGuide v2.00.01alpha Msql based version "an HyDTS Guide"

(C)opyright 1996 by Intermidia Research Group

(C)opyright portions 1997 by JBE Research Group

User plict passwort jk1789 login Mowt

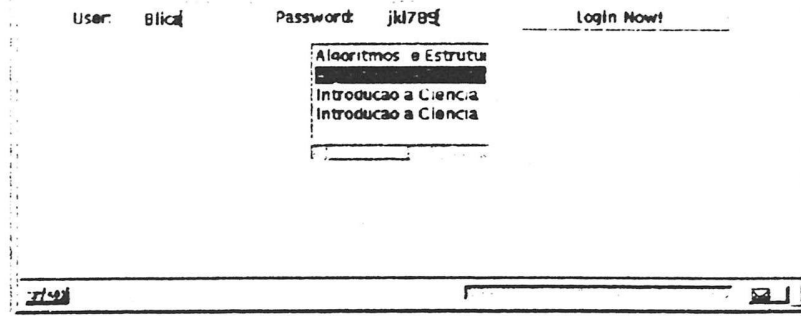

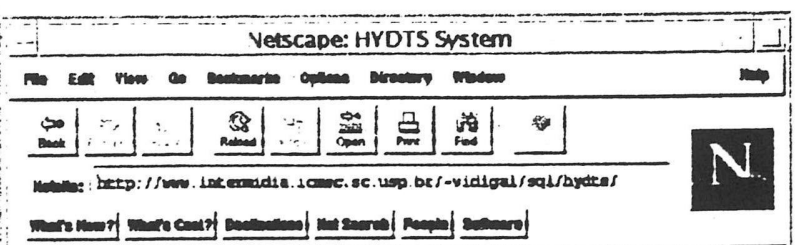

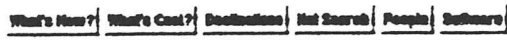

Intermidia Research Group presents

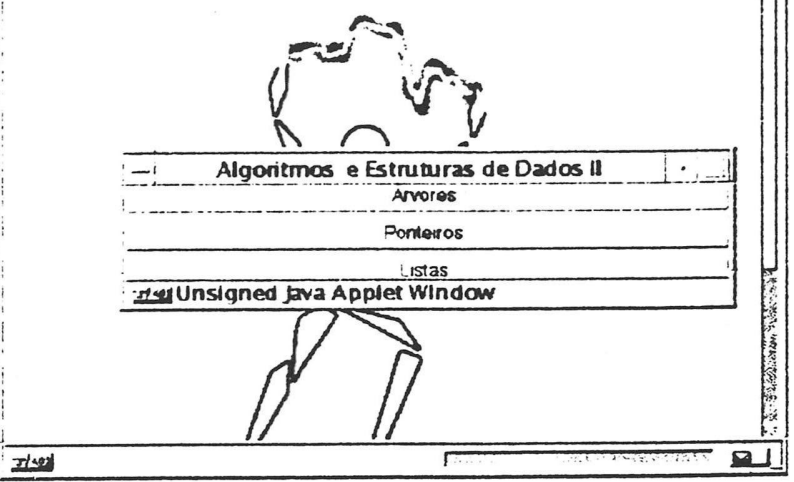

Figura 16: Protótipo do sistema Interland, interface aluno

\subsection{O Servidor de Vídeo}

O desenvolvimento de aplicações e servidores auxiliares às sessões de classe inclui, na maioria, módulos multimidia; por exemplo, on-line chats, vídeo conferência, visualizadores de vídeo digital ao vivo, servidores para acesso a objetos multimídia. Esses servidores farão o gerenciamento do material educacional utilizado por uma classe ou estudante.

Um desses servidores auxiliares é o servidor de vídeo (Hachisuca, 1997), que armazena objetos de som, vídeo, imagem e animação. Esse servidor tem por objetivo armazenar de forma eficiente os objetos multimídia e prover a entrega dos mesmos.

Para que o professor tenha acesso aos objetos, sem se preocupar com a estrutura de armazenamento, é necessário um mecanismo de gerenciamento dos objetos (tese em andamento: Goularte, 1998), com o objetivo de facilitar o trabalho de editoração, fornecendo agilidade no gerenciamento dos dados e dando suporte tanto a ferramentas interativas de busca e acesso aos dados quanto ao compartilhamento de dados multimídia. As atuais implementações trabalham apenas com vídeo; posteriormente, os conceitos serão aplicados aos outros tipos de mídia (áudio, imagens, texto e animações).

Esse mecanismo é inserido no sistema como um componente do cliente Professor, incorporando 
as funções de comunicação com o servidor de vídeo, agilizando o processo de inserção de objetos multimídia em um hiperdocumento.

Sem tal mecanismo, o trabalho que um professor realiza para inserir um vídeo envolve buscas em diretórios, abertura de vários arquivos para localizar cenas de interesse, copiar as cenas através de um programa específico, e somente então inseri-las em uma página. Nesses passos, o professor estaria utilizando programas diferentes, levando bastante tempo para localizar e compor as cenas, ocupando espaço de armazenamento.

Com o mecanismo proposto, o autor não necessita conhecer previamente o sistema de arquivos ou o seu conteúdo (diferente dos sistemas convencionais): ele pode simplesmente realizar uma consulta a um servidor de dados multimídia, descrevendo uma situação de seu interesse, e obtendo uma lista com nomes de arquivos contendo o vídeo, a cena ou o frame desejado (Figura 17). A partir dos resultados, o autor pode selecionar um dos arquivos (com a opção de visualizar seu conteúdo Figura 18) e, se desejar, inserir o objeto no hiperdocumento. $O$ hiperdocumento pode ser então visualizado em um Browser (Figura 19).

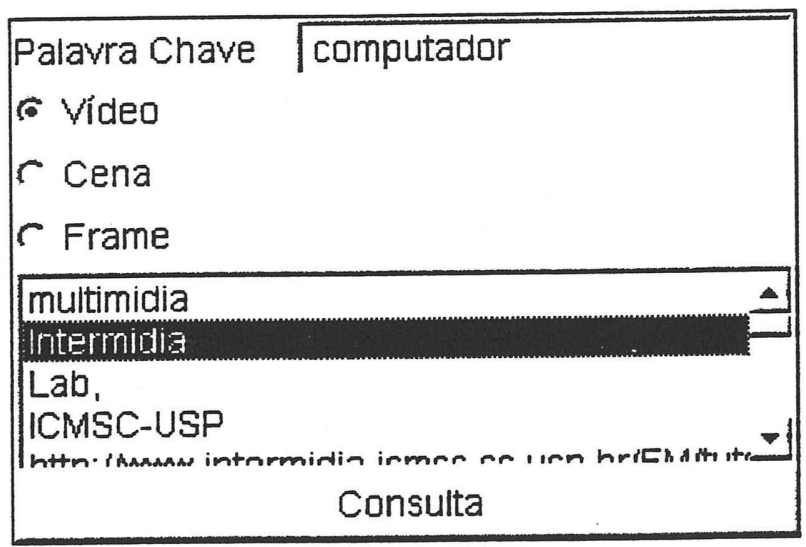

Figura 17: Resultados de uma pesquisa

O mecanismo oferece interatividade através de buscas baseadas nas características semânticas do objeto procurado. Através de uma interface adequada, é possível especificar o nível de detalhe da pesquisa, passando-se mais ou menos atributos como parâmetro. Também é possível definir como será a resposta da pesquisa: em forma de vídeos, cenas, frames, resumos dos vídeos, biografias das pessoas que atuam no vídeo, descrição de um objeto da cena, ou mesmo todos juntos 


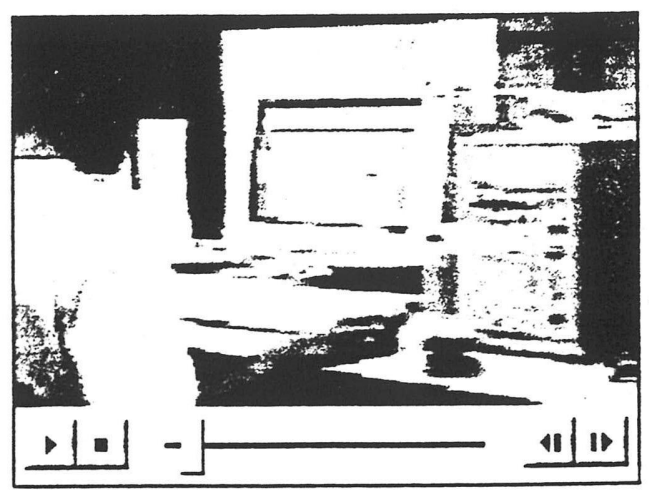

Figura 18: Player apresentando um video

\begin{tabular}{|c|c|c|c|c|c|c|c|c|c|}
\hline \multicolumn{9}{|c|}{ ro Netscape - [http://wrw.intermidia.i...sp.br/FH/tutorial/aqui/] } & \multirow{2}{*}{ - } \\
\hline File Exdit & View Go & Bor & & Dire & wy Wir & (us) $\underline{H}$ & & & \\
\hline $\begin{array}{l}\text { Pock } \\
\text { Back }\end{array}$ & Foryard & 岱 & & Reload & $\frac{17 y}{\text { Irrages }}$ & $\begin{array}{l}\Rightarrow 0 \\
\text { mastis } \\
\text { Open }\end{array}$ & Print & $\begin{array}{l}\text { 速期 } \\
\text { Find }\end{array}$ & \\
\hline
\end{tabular}

Netsite: $\sqrt{\text { http://www.intermidia.icmsc.sc.usp.br/FM/tutorial/aqui// }}$

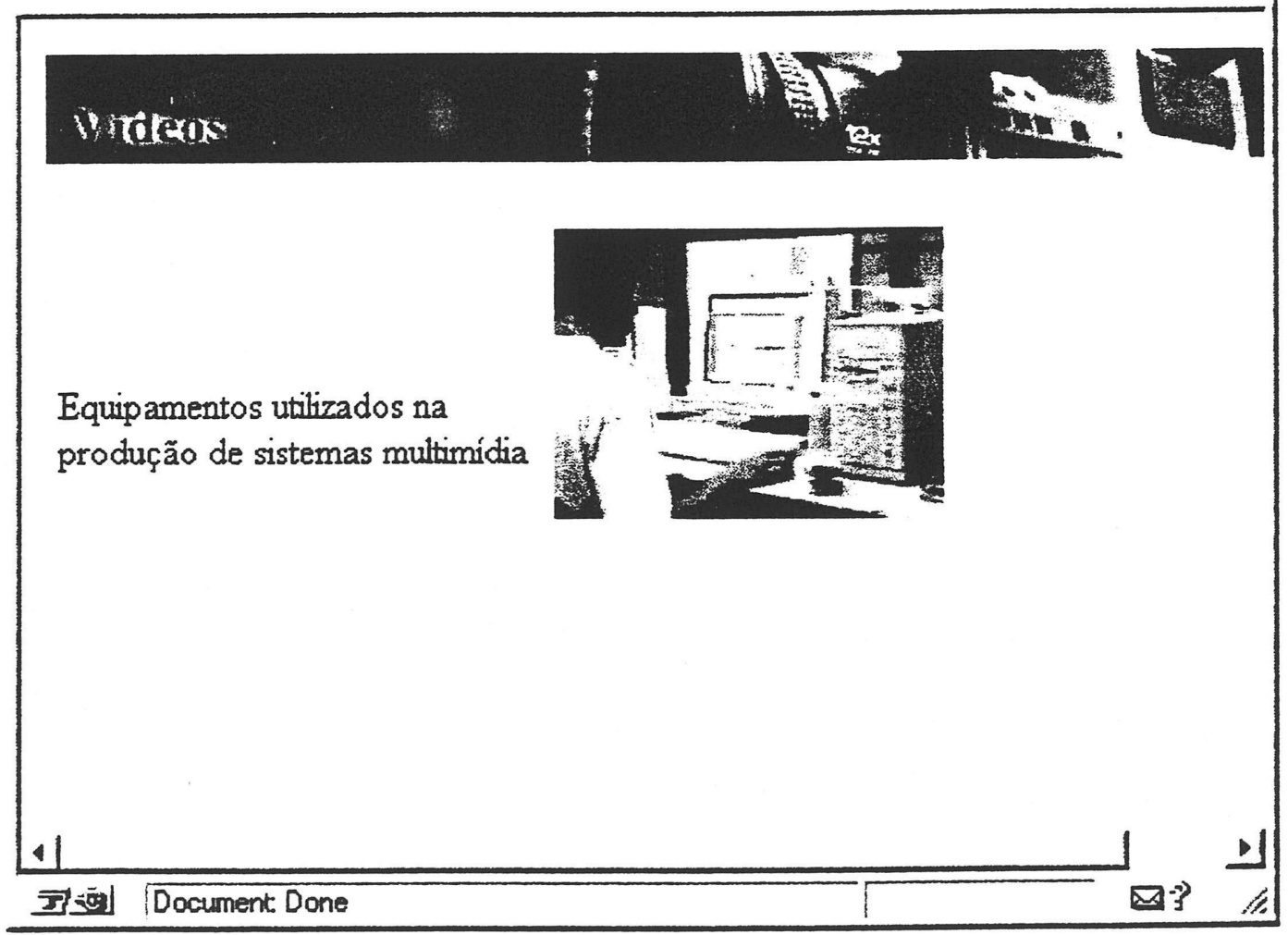

Figura 19: Hiperdocumento com inserção de video

Para realizar tal mecanismo, foi implementada uma base de metadados (Goularte, 1998) com os atributos referentes aos vídeos armazenados no servidor. Os atributos para acesso aos vídeos 
foram mapeados em indices: dados bibliográficos, estruturais e de conteúdo. O conjunto desses indices forma a base de metadados.

A utilização desses índices traz a vantagem adicional de prover suporte ao compartilhamento dos objetos multimídia armazenados no servidor. Por exemplo, pode-se ter um documento no qual um dos componentes é um vídeo, e um outro documento onde se deseja apenas uma seqüência do mesmo vídeo. Esse segundo documento pode ser criado apenas pelo acesso aos índices dessa seqüência específica, no arquivo de vídeo original, em lugar de extrair a seqüência do vídeo e criar um novo arquivo.

O servidor de metadados foi implementado na linguagem de programação JAVA, devido às suas facilidades: é multiplataforma, tem uma vasta biblioteca de funções e é orientada a objetos. A abordagem de orientação a objetos apresenta as vantagens de facilitar a inserção e a remoção de componentes e de facilitar a interoperabilidade entre os componentes, uma vez que cada objeto possui um comportamento bem definido permitindo que os mesmos se comuniquem e interajam de forma bastante simplificada (para maiores detalhes sobre o servidor de metadados, consultar Goularte, 1998) (Figura 20).

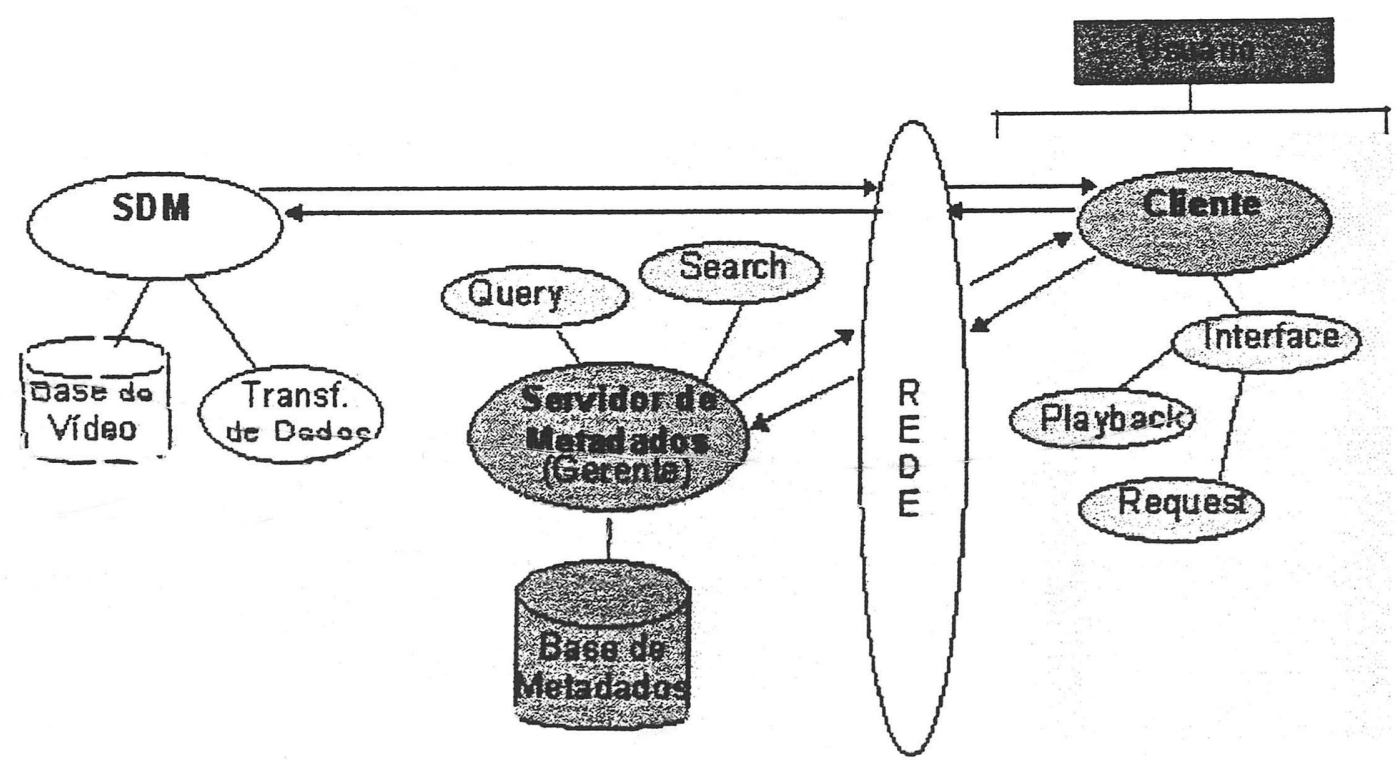

Figura 20: Servidor de metadados integrado ao servidor de vídeo (Goularte, 1998)

O acesso dos usuários ao sistema é realizado por clientes que operam em ambiente WWWW. 


\subsection{Conclusões do capítulo}

O sistema Interland implementa um ambiente completo de treinamento e aprendizado, fazendo uso das diversas mídias e recursos computacionais disponiveis. Com relação aos conceitos apresentados no Capítulo 1, e aos sistemas analisados no Capítulo 2, o Interland se apresenta como uma aplicação didática distribuída, totalmente inserida no ambiente World-Wide W'eb, que agrega elementos de sistemas tutores.

Uma das preocupações na implementação do Interland é oferecer um ambiente personalizado de estudo e desenvolvimento de atividades. Para isso, são utilizados diversos recursos complementares para manter dados relacionados aos alunos - lições estudadas, atividades desenvolvidas, desempenho. São previstos diversos módulos e servidores auxiliares para o sistema, que visam em especial dar acesso facilitado a recursos de multimídia e interação que liberem os usuários dos detalhes do sistema; também incorporam ferramentas que eliminam a necessidade de se trabalhar com diversos programas diferentes para a produção de material didático com hipermídia. O servidor de vídeo, em conjunto com o servidor de metadados, proporciona facilidades para inserção de vídeo em hiperdocumentos.

Um dos módulos do sistema Interland, em desenvolvimento, implementa a interface do professor com recursos de autoria: o sistema T.A., objeto deste trabalho, descrito no capítulo seguinte. 


\section{O Sistema T.A.}

O Sistema T.A. ("Teaching Assistant') se propõe a auxiliar o professor na tarefa de preparação do material didático dentro do sistema Interland. Suas funções principais são:

- oferecer modelos de hiperdocumentos e conjuntos de hiperdocumentos ("Webs") que visem uma estrutura simples e eficiente para a implementação do material didático;

- prover ferramentas de desenvolvimento e scripts para uso de recursos interativos e de multimídia no material;

- dar acesso a aplicativos para a montagem de sessões;

- apresentar informações relacionadas a alunos e grupos de alunos, para fins de avaliação e acompanhamento de desempenho.

Dessa forma, pretende-se evitar que o professor se preocupe com estilo de documentos, gerenciamento de hipertexto, e detalhes do próprio sistema Interland.

Neste capítulo, mostramos as características pretendidas para esse sistema.

\subsection{Webs de disciplinas}

Em termos de gerenciamento, sites $W e b$ são conjuntos de hiperdocumentos com determinadas características de navegação e apresentação. A nomenclatura "Web" ou "miniWeb" está presente em alguns editores que atuam no gerenciamento da navegação dos sites (por exemplo, o MS FrontPage e o AOLPress). No contexto do sistema T.A., os conjuntos de hiperdocumentos estão associados às diversas matérias; portanto, consideramos que os professores estarão trabalhando com "Webs de disciplinas".

Essas Webs são geradas e gerenciadas pelo T.A.; também poderão ser criadas a partir de documentos previamente existentes. Ao entrar no sistema T.A., o professor terá opção de editar uma Web existente, gerar uma nova Web a partir de documentos já prontos, ou criar uma nova Web dentro do sistema. Um exemplo dessa abordagem é implementado pelo software $M S$ FrontPage. 
O professor tem a liberdade de carregar no sistema T.A. documentos já tenham sido desenvolvidos por ele; porém, o T.A. sempre conhece a estrutura de navegação implementada - essa estrutura de navegação está diretamente relacionada ao modelo escolhido para a apresentação do material. Os modelos definem seminários, aulas automáticas, e outros tipos de apresentação.

\section{t.1.1 Edição de documentos}

O sistema T.A. apresenta diversas ferramentas para a composição do material das aulas ou exposições. O professor tem várias opções para editar as aulas: submeter um arquivo texto para formatação, submeter um arquivo MS Word para transformação, submeter um documento HTML pronto, inserir objetos de áudio e vídeo, ou editar um documento através do próprio sistema T.A.

Os modelos de aulas ficam disponíveis para os professores dentro do sistema Interland. O T.A. apresenta os modelos, e o professor tem acesso a exemplos e templates (esqueletos de documentos) à semelhança dos modelos e templates do MS Word, MS PowerPoint, e editores específicos de HTML.

A experiência dos professores na produção de documentos é considerada. Uma opção simples para usuários que dominam as formatações de HTML é implementar um editor remoto de modo texto; uma opção mais atraente para grande maioria dos usuários é adotar um editor WYSIWYG para uso integrado com o sistema T.A.

A abordagem do editor remoto inserido no sistema, entretanto, pode ser aplicada a outras atividades do professor.

\subsubsection{Aplicativos auxiliares}

Alguns recursos especiais, como animações e scripts para formulários, são implementados através da ativação de aplicativos auxiliares pelo T.A. Um exemplo é a manutenção de uma agenda do professor, que pode ser utilizada para o gerenciamento das atividades de uma disciplina.

\subsubsection{Acesso a objetos multimidia}

O sistema T.A. tem um módulo especial (um cliente) para comunicação com o SDM. A interface desse cliente possibilita o acesso aos objetos multimídia de maneira simples: através dela, o professor busca arquivos de mídias em um banco de dados, conforme um assunto desejado, e tem a possibilidade de selecionar trechos de interesse para inseri-los no material didático (ver seção 3.3). 


\subsection{Planejamento de Sessões}

Como visto no Capítulo 3, as sessões consistem de conjuntos de recursos educacionais, restrições de acesso, ferramentas de comunicação e possíveis avaliações, entre outros objetos.

Um template de sessão terá atributos relacionados - por exemplo, recursos utilizados na sessão, documentos que a compõem, e aplicativos. Cada aluno ou grupo de alunos terá instâncias de sessão associadas; os atributos de instância estarão refletindo o ambiente de trabalho de um contexto de estudo (Figura 21).

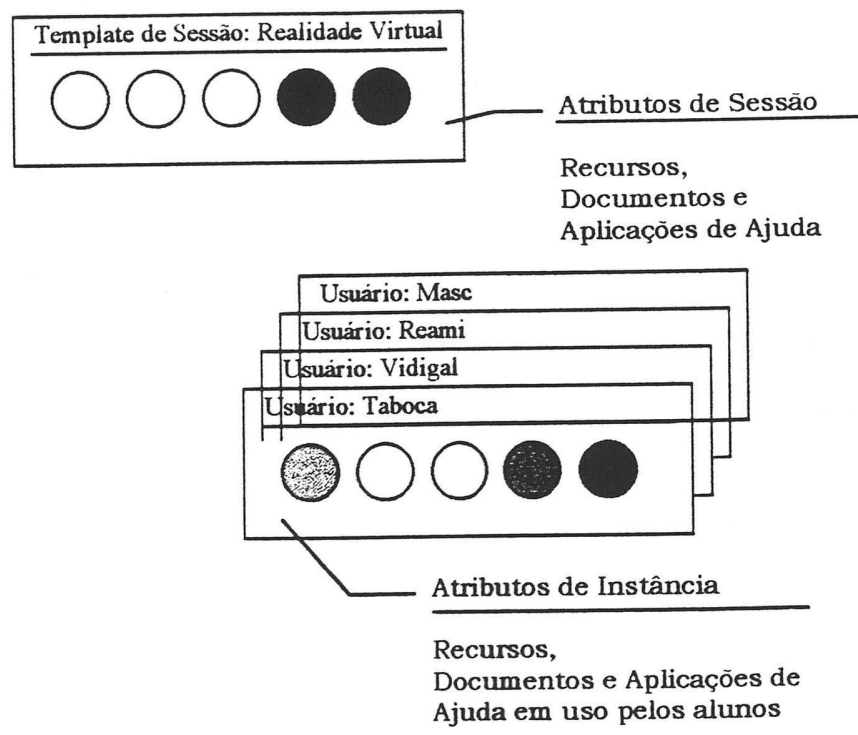

Figura 21: Templates e instâncias de sessão (adaptado de (Galli \& Moreira, 1997))

\subsection{Ajuda}

O sistema de ajuda no T.A. é implementado em um módulo especial, satisfazendo tanto as necessidades dos usuários já acostumados ao sistema como aqueles que o utilizem pela primeira vez. Os recursos do sistema de ajuda estão sempre disponíveis, devendo acompanhar as atividades do usuário para sugerir modificações e realizar algumas correções automáticas. Diversas informações operacionais sobre o sistema Interland e T.A. são encontradas através deste sistema de ajuda, na 
nterface do professor.

\subsection{Conclusões do capítulo}

O sistema T.A. é ativado quando um professor entra seu login e senha no sistema Interland.

Os vários módulos do T.A. permitem a criação e manutenção de Webs de disciplinas, documentos, objetos multimídia, gerenciamento de informações sobre alunos e disciplinas, e acesso a informações sobre o próprio sistema utilizado.

Sua integração ao sistema Interland ocorre de maneira natural pela exploração de recursos da plataforma World-Wide Web: scripts CGI, roteiros em JavaScript, applets Java e plug-ins oferecem a integração de várias ferramentas, de modo que o usuário tem uma interface consistente - um browser - para a execução das diversas atividades.

Um dos pontos principais do sistema TA. é permitir facilmente a introdução de interações e objetos multimídia no material didático. A complexidade das operações é ocultada do usuário, que pode se concentrar apenas na editoração de mais alto nível.

O planejamento e implementação de protótipos do T.A. são apresentados no Capítulo 5. 


\section{Implementação do Sistema T.A.}

Os protótipos do sistema T.A. foram implementados seguindo diversos passos:

1. Projeto inicial de interface; implementações com refinamentos sucessivos.

2. Aquisição de conhecimento: estudo aprofundado dos scripts e tecnologias iá presentes no sistema Interland.

3. Montagem de Webs: estudo de modelos de Webs (associadas aos tipos de apresentação do material), modelos de documentos, análise de wizards de diversos editores e programas, em especial dos editores HTML.

4. Produção de um manual do usuário com informações sobre o uso do sistema e criação de páginas Web (implementado no sistema de ajuda do T.A., em formato simples de páginas HTML).

5. Integração com o servidor de multimídia: projeto e implementação de protótipo para o cliente do servidor de metadados.

Neste capítulo apresentamos o desenvolvimento e implementação dos primeiros protótipos.

\subsection{Decisões de projeto}

Ao examinar vários sistemas de autoria on-line, uma característica da interface não passa desapercebida: a abundância de menus e atalhos para os diversos recursos da ferramenta, que ocupam boa parte da janela do browser. Alguns sistemas pecam por excesso de botões e itens, esquecendo-se de que o constante acionar de links prejudica a concentração do usuário. Além disso, o sistema é, às vezes, baseado em conceitos que exigem um aprendizado anterior para que as edições possam ser realizadas com sucesso.

Thimbleby (1990) lembra que apresentar menos informações pode tomar a interface mais informativa, e que o uso de interfaces já familiares pode facilitar a interação do usuário. Assim, foram consolidadas duas pretensões do sistema TA. para os primeiros protótipos: ter uma interface enxuta e aproveitar ao máximo os ambientes conhecidos dos professores (browsers, editores, ferramentas de apresentação), ocultando detalhes "não vitais" ao trabalho, que podem ser 
aprendidos com a prática, mais tarde.

Para orientar os passos de implementação do sistema, seguimos as orientações propostas por Horton (1994), organizando o trabalho em iterações de Análise, Projeto e Implementação.

\subsection{Análise}

$\mathrm{Na}$ fase de Análise, foram identificados os usuários, suas necessidades e tarefas a serem desenvolvidas, estabelecendo-se alguns objetivos para esta primeira fase de implementação.

Os usuários do TA. são, principalmente, professores universitários com intimidade no uso do computador, mas sem muitos conhecimentos sobre o sistema World-Wide Web (como foi constatado em entrevistas com professores do ICMSC-USP). Testes realizados com alguns editores WYSIWYG não ofereceram bons resultados, pois os usuários não conheciam a ferramenta subjacente (HTML); nesses casos, funcionou muito bem a aplicação de filtros embutidos em programas já familiares.

As necessidades desses usuários, para que possam se utilizar do sistema Interland, são: editar material didático para uso on-line (a maioria passa tal responsabilidade para seus monitores ou bolsistas), com uso de multimídia e equações matemáticas. O aproveitamento de material préexistente também é de grande importância.

Algumas tarefas principais são a edição de hiperdocumentos com uso de multimídia e recursos interativos. A experiência do segundo semestre de 1997 (quando vários monitores do Programa de Aperfeiçoamento de Ensino mantiveram "sites" sobre as respectivas matérias), reforçou a idéia de manutenção de informações relacionadas a um curso e aos alunos, em grupos ou individualmente.

Depois de algumas entrevistas e pesquisas sobre sistemas existentes (vistos no Capitulo 2), os objetivos iniciais puderam ser traçados:

- Em um primeiro momento, oferecer um conjunto de modelos para criação de hiperdocumentos.

Uma vez que os browsers mais utilizados pelos professores são o Netscape Gold ou o Communicator (que incluem editores WYSTWYG), a adoção de modelos é simples e útil. Os modelos embutem características que permitem um bom resultado final, através da proposta de tamanhos e tipos de fontes, distribuição do texto na tela, entre outros 
detalhes.

- Adicionar na interface alguns recursos pré-desenvolvidos para a organização e apresentação de documentos (por exemplo, apresentação de uma seqüência de slides ou um vídeo).

- Tomar disponiveis algumas ferramentas simples que auxiliem o acompanhamento do curso (por exemplo, um quadro de avisos).

Além disso, foi considerada a integração posterior com as outras ferramentas propostas no projeto do sistema Interland (visto no Capítulo 3).

\subsection{Projeto}

O TA. ganhou cinco (5) itens principais, indicando acesso a diferentes conjuntos de ferramentas:

1. Edição de material didático;

2. Acompanhamento de alunos;

3. Controle de apresentação;

4. Agenda do professor;

5. Ajuda.

Estes itens consideram a implementação futura dos vários componentes do sistema Interland. Neste trabalho, foram implementados protótipos dos módulos de edição, da agenda do professor e do módulo de ajuda.

\subsubsection{Módulo de edição}

O módulo de edição oferece os modelos de páginas e as "Webs de disciplinas".

As "Webs" são um conjunto de arquivos básicos: cronograma, glossário, avisos do professor, FAQ. Cada "Web" inclui todo material produzido para a disciplina (slides, apostila, material de apoio).

Os modelos básicos de páginas incluem Material de Apoio (páginas comuns ou com recursos multimídia), Slides (páginas feitas para apresentação por datashow ou canhão), e Apostila.

A Apostila nada mais é do que a transposição de um texto básico para HTML e imagens; a idéia de oferecer este modelo é tomar disponíveis os textos que os alunos antes copiavam, ou aqueles textos cuja informação não se mostra apropriada para apresentação através de hipertexto. Lembrando 
Horton (1994): "coloque um documento on-line se os leitores passam mais tempo procurando informações do que lendo, ou se o documento precisa de mídias como janelas, som, música, animação, ou interatividade" (op. cit., pág. 24). Uma vez que as apostilas são de fato textos de referência, precisando ser lidos em sua totalidade, o modelo Apostila cumpre a simples função de tornar um texto (geralmente longo) disponivel on-line.

\subsubsection{Agenda do professor}

Inicialmente, oferece acesso ao recurso de "avisos do professor", inseridos por CGI script na página principal da "Web de disciplina" correspondente.

\subsubsection{Ajuda}

Conjunto de arquivos HTML com informações e orientações sobre como utilizar o sistema TA., com links para o "Tutorial HTML do ICMSC-USP"15, para sanar eventuais dúvidas sobre a linguagem e o uso de scripts. Atualmente o acesso à ajuda está confinado ao seu módulo específico, mas serão implantados atalhos, especialmente dentro do módulo de edição.

\subsection{Implementação}

O TA. está implementado atualmente por CGI scripts, roteiros JavaScript e conjuntos de documentos HTML. O protótipo atual apresenta as características planejadas de simplicidade e fácil acesso às ferramentas disponíveis.

\subsubsection{Interface básica}

Os recursos do TA. foram organizados através de frames, permitindo que o usuário se localize facilmente em dois modos principais: "trabalho" ou "consulta ao módulo de ajuda".

No modo "trabalho", o menu à esquerda oferece as opções de acesso aos quatro módulos citados anteriormente, através dos itens (Figura 22):

- Como usar o T.A. (módulo de ajuda);

- Edição de material didático (acesso a ferramentas de editoração);

- Acompanhamento de alunos (não implementado);

- Controle de apresentação (não implementado);

15 http://www.icmsc.sc.usp.br/manuals/HTML/ 
- Agenda do professor (acesso a ferramentas interativas).

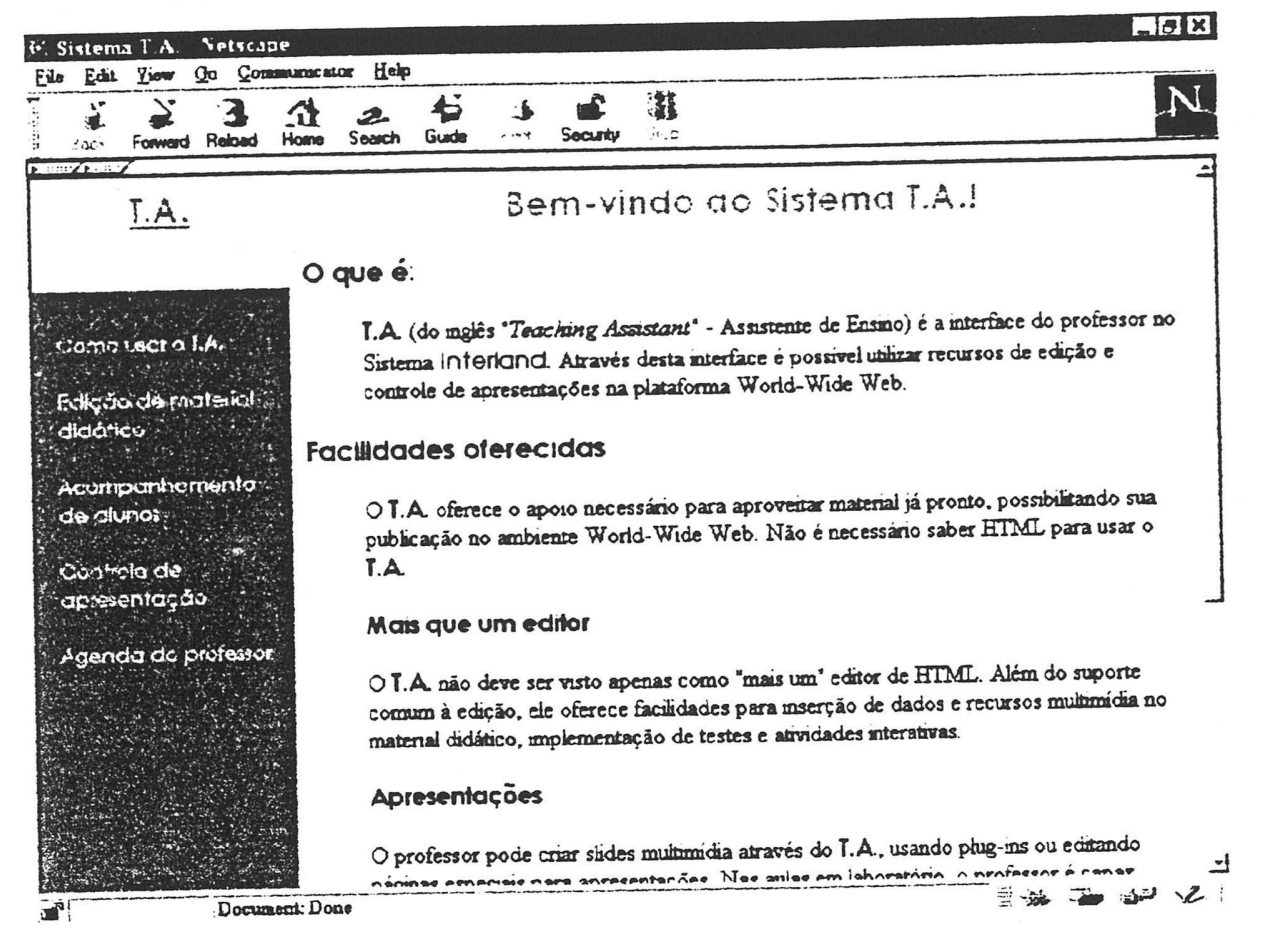

Figura 22: Página principal do T.A.

Ao selecionar o item de ajuda, o menu oferece acesso a itens sobre os recursos do T.A., sendo mantido um link fixo para a página principal do sistema (Figura 23).

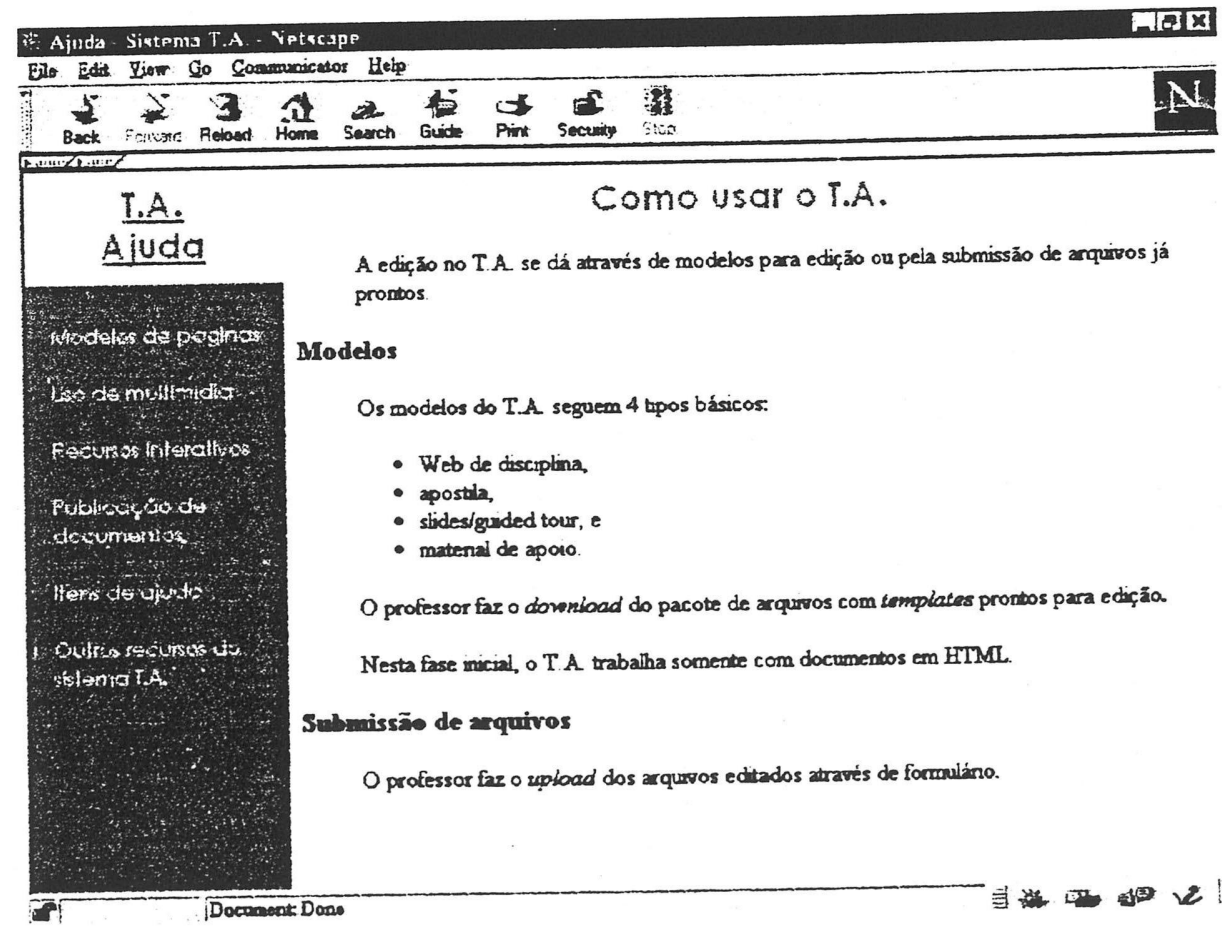

Figura 23: Módulo de ajuda do T.A. 


\section{5.t.2 Interface de edição}

Os modelos de edição estão disponíveis em arquivos compactados contendo os arquivos HTML. Os modelos são copiados para uso local, em um diretório específico: o professor é orientado a escolher um diretório com a sigla do curso respectivo à "Web" editada. No protótipo atual (Figura 24), sugere-se que a edição seja feita utilizando-se um editor WYSIWYG (ver seção 4.7).

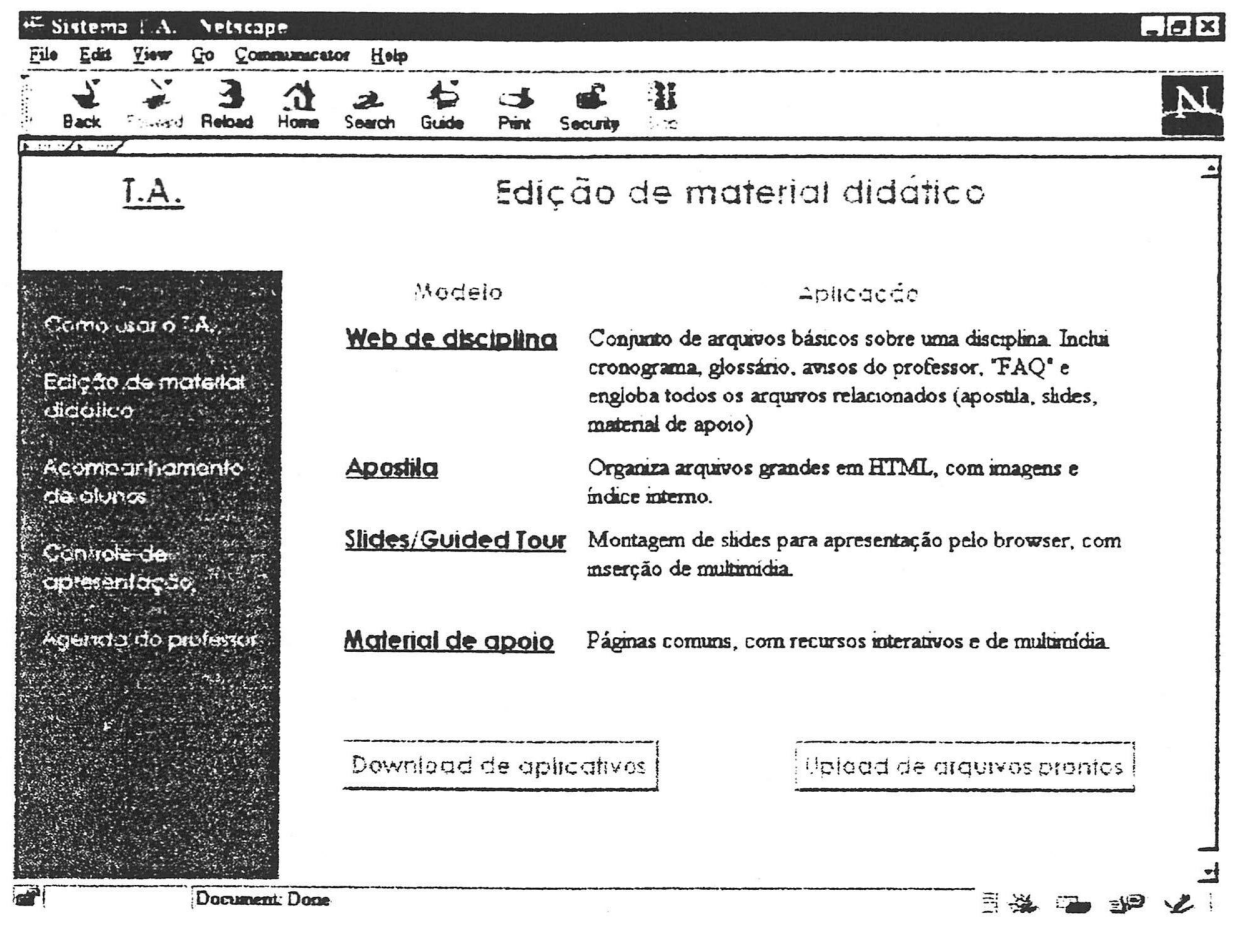

Figura 24: Módulo de edição do T.A.

$\mathrm{Na}$ criação de uma "Web de disciplina", por exemplo, o professor irá fazer o download de um arquivo web.zip, contendo modelos para páginas básicas em arquivos respectivos (Figura 25): bibliografia da disciplina (biblio.html), cronograma (crono.html), glossário (glos.html), "FAQ" ou seção de dúvidas (faq.html), trabalhos propostos e desenvolvidos (trabs.html), e "bookmarks" ou sugestões de sites com informações relacionadas à matéria (books.html).

Esses arquivos podem ser descompactados para um diretório especial de nome "modelos". 


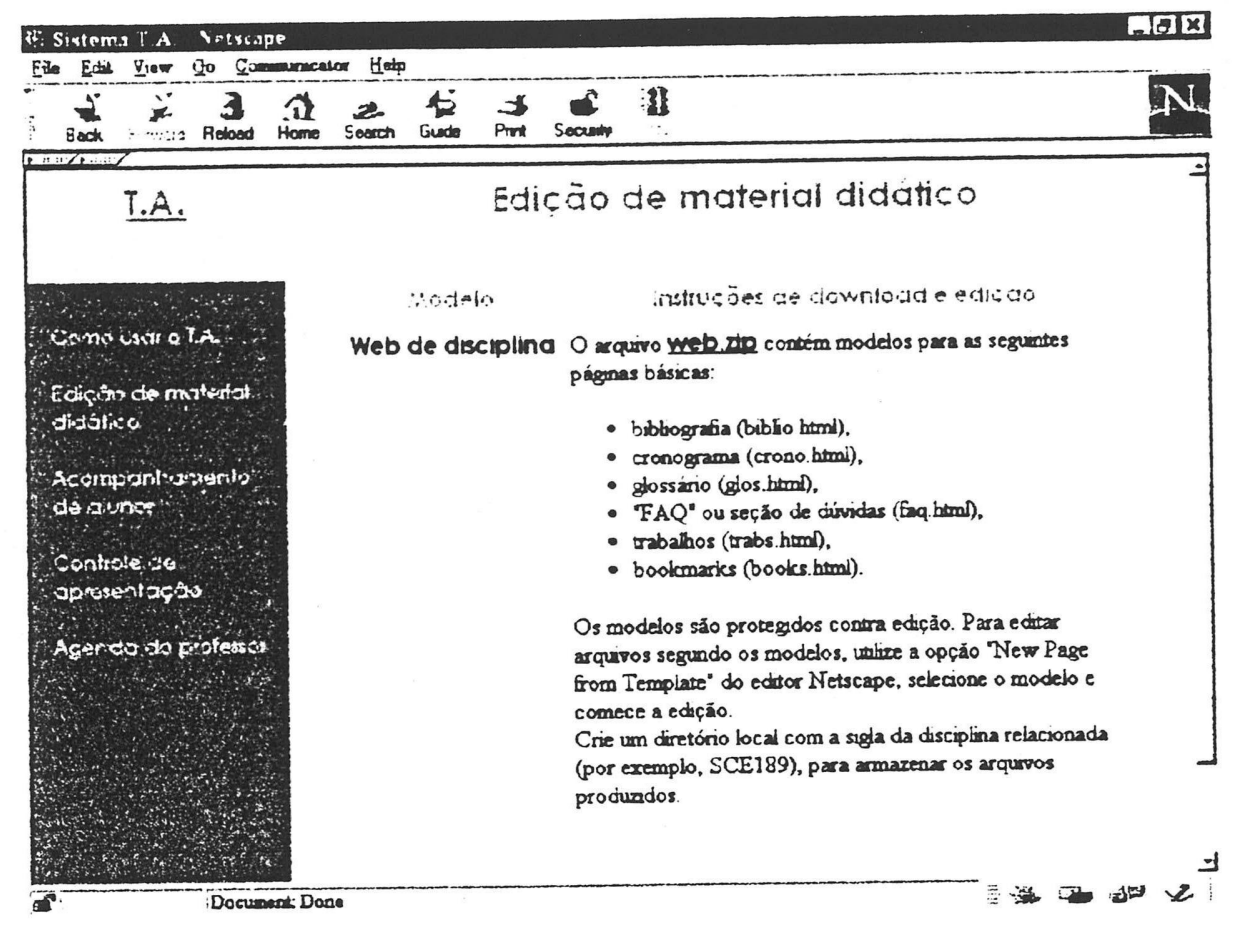

Figura 25: Download de modelos para criação de "Web de disciplina"

Para editar seguindo um modelo, cria-se um documento através da opção "New Page From Template", dos editores Netscape (Figura 26). Abrir um arquivo como template permite a edição de um novo arquivo com as mesmas características do original, sem, no entanto, editar o próprio arquivo original. Mesmo assim, todos os arquivos de modelos são protegidos contra alteração involuntária.

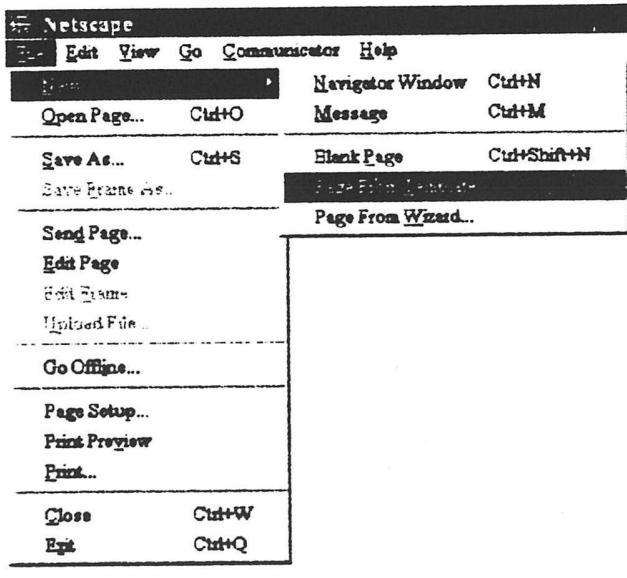

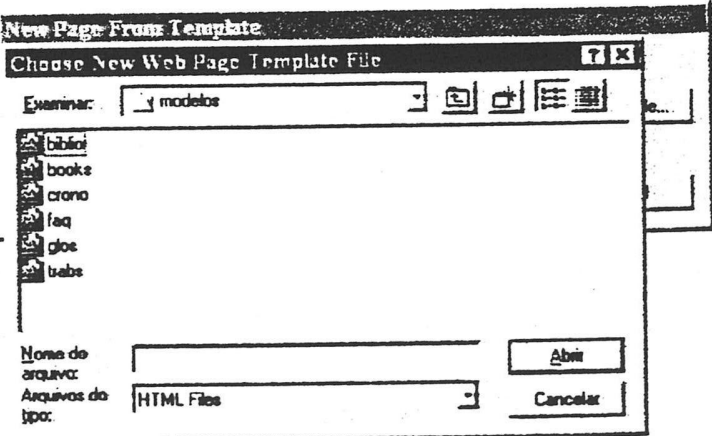

Figura 26: Criação de documento segundo um modelo pronto 


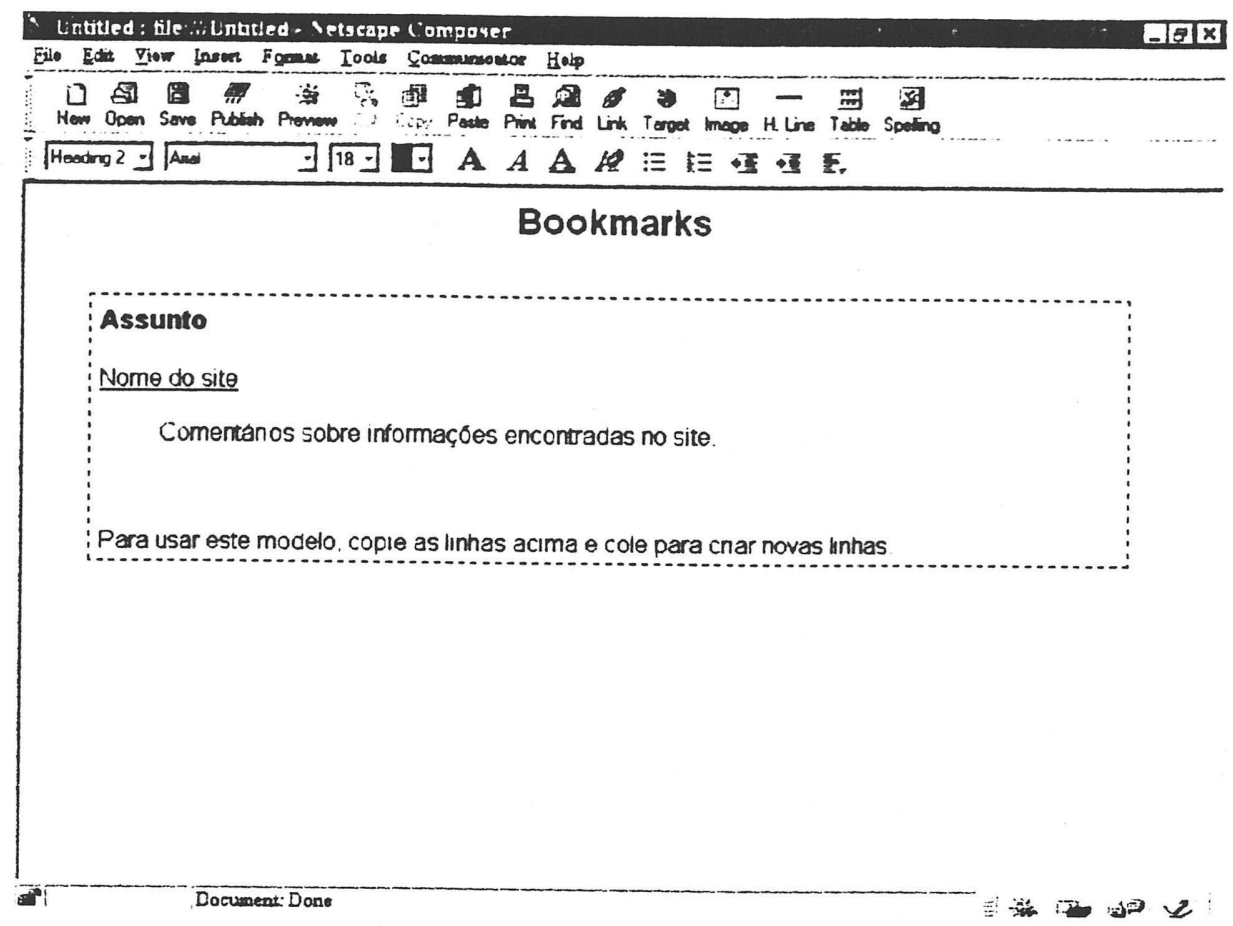

Figura 27: Modelo de arquivo com bookmarks

Terminada a edição através do Netscape, o usuário atualiza seus documentos através do sistema TA.: os arquivos são enviados para a área reservada para sua disciplina no sistema Interland, através da função de upload disponível pelo módulo de edição. Esse envio de arquivos locais para o servidor remoto (que mantém o Interland) é realizado através de formulários e CGI scripts. Ao ser gerada uma nova "Web", um script específico para "Webs" cria um conjunto de frames que reúne seus itens básicos em uma organização semelhante ao do próprio TA.: um frame índice e outro para textos, que apresenta o conteúdo dos diversos arquivos. Todas as "Webs" geradas nesta fase de implementação têm essa estrutura.

Os itens de segurança e gerenciamento de "Webs" ainda não foram implementados, dependendo do desenvolvimento de outros trabalhos.

A edição do material de apoio inclui um cliente do servidor de metadados (Goularte, 1998) para seleção de trechos de vídeo. Através desse cliente (implementado em Java), o professor busca arquivos de vídeo de acordo com um assunto desejado, e tem a possibilidade de selecionar trechos inicial e final da seção do vídeo (ver seção 3.3). As informações de tempo para reprodução desses trechos são capturadas e inseridas no documento que estiver em edição no momento. Essa inserção 
é feita através de Java e JavaScript, e produz as linhas de HTML que chamam o cliente com os parâmetros do trecho de vídeo selecionado.

Os aplicativos de edição disponíveis pelo TA. são plug-ins e filtros que transformam documentos produzidos por editores comumente utilizados por professores (MS Word e MS PowerPoint). Os documentos assim produzidos serão transformados para modelos do TA. (ver "Conclusões e Trabalhos Futuros", Capítulo 6).

\subsubsection{Interface da agenda}

A agenda é um item do sistema TA. que oferece ao professor a possibilidade de personalizar sua interface no sistema e selecionar algumas facilidades para o gerenciamento de cursos. Através de formulários, o professor pode solicitar o envio automático de mensagens de e-mail que lembrem determinados eventos ou insiram avisos na página principal de uma "Web de disciplina".

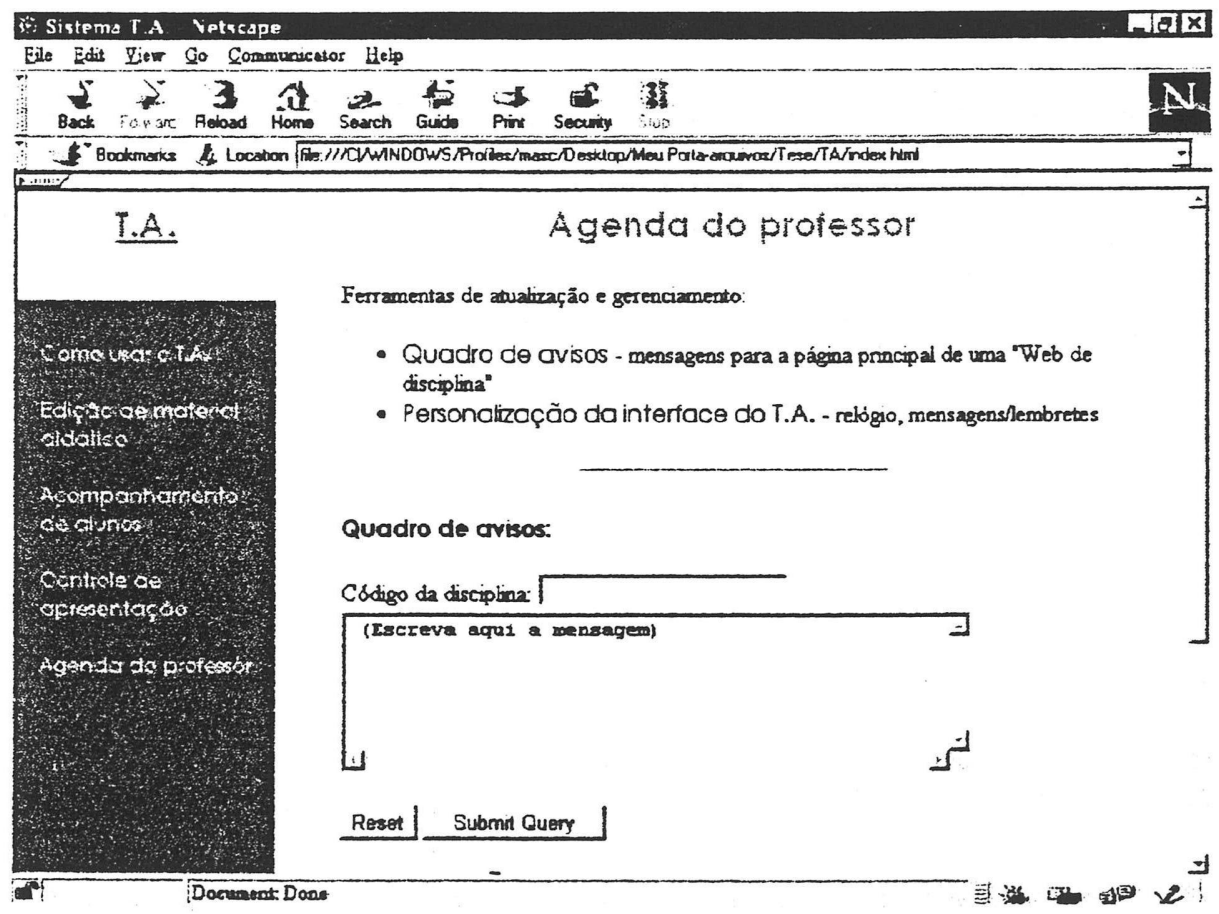

Figura 28: Interface da agenda do professor

Algumas características da agenda ainda estão em fase de testes, e vários itens farão parte de trabalhos futuros (ver Capítulo 6). 


\section{Conclusões e trabalhos futuros}

O sistema TA., interface do professor no sistema Interland, atualmente não implementa um editor, mas oferece ferramentas para edição e montagem de conjuntos de material didático. Através de ferramentas auxiliares e modelos de documentos, o TA. se propõe a evitar problemas na autoria de hipermídia (Seção 1.3.2): linkes e estruturas de navegação são manipuladas pelo sistema e não pelo autor.

A proposta de uma estrutura básica de "Web de disciplina" (Seção 4.1) tem por objetivo afastar os indesejáveis problemas do "material didático na Web" (Seção 2.1.2). Essa abordagem leva o autor a escolher os modelos já prontos como ponto de partida na produção de seus documentos, oferecendo parâmetros de edição para autores sem experiência. Uma desvantagem é que, ao forçar a adoção de uma apresentação uniforme das disciplinas, tal abordagem limita a criatividade dos autores experientes.

É preciso salientar, porém, que a característica de apresentação uniforme é bem-vinda para o aluno, usuário final das "Webs", por facilitar sua localização no material didático (Anexo 2 e Seção 2.1.5). Ao manter determinadas funções de navegação fixas, as "Webs" oferecem ao aluno a facilidade de já saber onde encontrar informações específicas. Em uma situação na qual há várias "Webs de disciplina" que precisam ser consultadas, tal facilidade de localização é desejável.

Alguns problemas encontrados foram devidos ao estágio de evolução dos programas que suportam a edição de documentos para a Wrold-Wide Web. Além dos modelos em arquivos HTML, foram gerados e testados alguns modelos MS Word, visando a edição dos documentos no próprio Word, com posterior transformação desses documentos para HTML (através do WordIA, assistente para Word 7.0, ou usando o Word 97). Esses modelos passariam posteriormente por um parser do lado do servidor para a aplicação de modelos escolhidos pelo professor. Porém, muitos problemas na transformação gerada pelas ferramentas do Word inviabilizaram tal implementação neste atual estágio de desenvolvimento.

Em comparação com os sistemas on-line de apoio à autoria analisados (Seção 2.2), o TA. se destaca por permitir a introdução de recursos multimídia (no estágio atual, vídeo) disponíveis em uma base de dados. Para isso concorrem as facilidades da plataforma World-Wide Web, em especial através da 
utilização de recursos do lado do cliente (roteiros e programas executados pelo browser). As interações complexas ficam ocultas, deixando que o usuário se concentre nas atividades de mais alto nível na-editoração dos documentos e gerenciamento de disciplinas. Com isso, o autor não precisa aprender a utilizar outros programas ou ambientes: apenas com o browser, ele tem acesso a modelos de páginas, recursos de edição de documentos, manipulação de vídeo, e recursos interativos através de scripts.

Os protótipos não podem ser considerados independentes de plataforma, uma vez que implementam os modelos e algumas funções com base em características dos browsers Netscape (versões 3.0 em diante), por exemplo o script de upload de arquivos e algumas funções com roteiros JavaScript. Isso não foi considerado problemático devido à utilização desse browser pelos usuáriosalvo do sistema.

Considerando a proposta de se explorar o ambiente eletrônico no apoio aos processos de ensinoaprendizagem, o sistema TA. se vale das vantagens do ambiente World-Wide Web para aglomerar ferramentas desenvolvidas para esse ambiente. Com isso, o TA. se apresenta como um sistema que pode crescer de maneira progressiva sem necessidade de manutenções complexas.

Os protótipos iniciais do TA. implementaram um pequeno esboço do que o sistema pode oferecer.

Para trabalhos futuros, a médio prazo, podemos citar os seguintes:

- Adoção de modelos para MS Word, visando a aplicação automática de modelos em documentos HTML gerados por plug-ins e extensões.

- Inserção de temas (conjuntos de ícones) associados aos modelos, enriquecendo a apresentação mas mantendo a estrutura básica atual dạ "Webs".

- Ampliação das tarefas possíveis através da agenda do professor, para permitir atualização de informações nas "Webs" - por exemplo, mudanças no cronograma.

- Melhoria do sistema de upload e manutenção de arquivos, com a maior integração entre o sistema Interland e o sistema TA.

- Ampliação do número de modelos para material de apoio.

- Implementação de uma versão do TA. para a interface do aluno. 
- Desenvolvimento de mecanismos para a comunicação entre as "Webs", com reaproveitamento de documentos. 


\section{ANEXO 1: Características do aprendizado}

Edwards e Holland (1994) nos lembram que o uso de novas tecnologias no ensino não deve ocorrer simplesmente porque essas tecnologias existem. Por experiência, sabemos que o uso inadequado de bons recursos didáticos leva professores e alunos à falta de incentivo para explorá-los de maneira mais produtiva.

Para saber qual a utilidade de cada novo recurso, e como empregá-lo da forma mais correta possível, é necessário ter noções sobre os elementos envolvidos nas atividades que levam ao aprendizado. Para Bordenave e Pereira (1988), compreender o processo da aprendizagem é vital para o professor, assim como entender a fisiologia do corpo humano o é para o médico. ${ }^{16}$

\section{O Processo de Ensino-Aprendizagem}

Não sabemos com precisão como se dá o aprendizado, ou como funcionam nossos mecanismos de memória e o próprio cérebro humano. Através de pesquisas e experiências vem sendo possível a elaboração de teorias e a determinação de fatores que ajudam (ou prejudicam) uma pessoa a aprender.

Ao aprender algo, aprendemos não somente essa única coisa, pois interagimos com um conjunto de elementos importantes que modificam nossa maneira de pensar e reagir (de acordo com as características do que é aprendido). Sentimentos de curiosidade, tensão, ansiedade, angústia, entusiasmo, frustração, alegria e impaciência, entre outros, podem ser facilmente detectados no decorrer de um semestre de estudos: os processos emocionais que acompanham o aprendizado influem no desempenho em aprender um assunto, determinando também a motivação para o aprendizado de novas matérias. (Bordenave \& Pereira, 1988).

Podemos destacar vários fatores importantes que concorrem durante o processo de ensinoaprendizagem (Bordenave \& Pereira, 1988; ver também Magro, 1979):

\footnotetext{
16 Neste texto, não estaremos nos aprofundando em teorias cognitivas e pedagógicas, apresentação somente os principais pontos que nortearam o desenvolvimento do presente trabalho.
} 
- Por parte do aluno:

Motivações para aprender a matéria; conhecimentos anteriores do aluno que, por serem relacionados a um novo assunto, auxiliam em seu aprendizado; atitude com relação ao professor (empatia); atitude com relação à matéria.

- Por parte do assunto a ser aprendido:

Estrutura; tipos de aprendizagem necessários para seu aprendizado; ordem de apresentação dos itens que o compõem; relacionamento do assunto com outros, que o completem ou facilitem seu entendimento.

- Por parte do professor:

Exposição oral; escolha de formas adequadas para a apresentação do assunto ensinado; orientações sobre o desempenho dos alunos; relacionamento com os alunos (empatia); atitude com relação à matéria ensinada.

- Outros fatores:

Ambiente da aprendizagem: horário, acomodações, $\mathrm{n}^{\circ}$. de estudantes na sala de aula, recursos didáticos.

\section{Identificação de problemas de aprendizagem}

Dado o número e a complexidade dos fatores que concorrem para que um assunto ensinado seja realmente aprendido, Bordenave e Pereira (1988) enfatizam a importância da motivação. Afinal, se os estudantes não aprenderem, as horas gastas na exposição de matérias apenas resvalam pela epiderme dos alunos, sem atingi-los (op. cit., pág. 39).

Magro (1979) apresenta um resumo interessante dos tipos de estudo que resultam ou não em aprendizado:

- Estudo receptivo é a aceitação passiva do que é ensinado, sem crítica. O aluno apenas realiza cópia ou audição mecânicas; não participa da aula, pois lhe falta motivação. A aula é vista como um perído em que só se recebe informações; o estudante é um mero "consumidor" do ensino. $O$ esforço de analisar é sempre adiado: durante a aula o aluno somente anota, deixando para estudar e pensar sobre o assunto em casa. Conforme a natureza da matéria 
ensinada, o aluno poderá aprender com esse estudo individual; porém, se não conseguir determinar o contexto do assunto, identificar seus pontos principais e dificuldades, continuará passivo e desmotivado.

Esta modalidade de estudo também surge quando o tipo de explanação da matéria (ou o relacionamento professor-aluno) não desenvolve ou não permite o estabelecimento da motivação e da participação dos alunos.

Também aqui se refugia o aluno com o "trauma do fracasso": ele não se expõe ao risco de fazer perguntas temendo críticas por parte dos colegas ou mesmo do professor, que pode não querer ser interrompido em sua explanação.

- Estudo ativo implica na participação consciente nas aulas: o aluno está motivado, atendo à aula, e acompanha a exposição fazendo perguntas e anotações.

- Estudo antecipado é um passo à frente do estudo ativo. $O$ aluno estuda além do que é visto em aula, busca outras fontes sobre o assunto ensinado. Assim, consegue distinguir os pontos principais dos derivados, dirigindo seus esforços para as dificuldades da matéria e seus itens essenciais. Este estudo facilita também a retenção, pois o mesmo assunto é visto de formas diferentes e várias vezes.

Enquanto o estudo passivo dificilmente leve ao aprendizado (a não ser a duras penas), o estudo ativo e antecipado são atitudes que tendem ao sucesso: mantém-se um ritmo regular de estudo no decorrer do curso, não apenas às vésperas das provas. $O$ aluno consegue localizar o assunto estudado em um contexto que facilita sua compreensão, e toma-se capaz de transferir seu conhecimento para resolver exercícios.

Ao avaliar o desempenho dos alunos, por exames e participação em aula, o professor pode detectar problemas e reprogramar suas estratégias de ensino, estimulando os alunos a responder com o ritmo de estudo necessário.

\section{Psicologia Cognitiva}

Dado o objetivo de estimular os estudantes, é necessário considerar vários aspectos subjacentes, em nível mental e psicológico, que podem ser explorados para ajudá-los nesse caminho. 


\section{Modelos Mentais}

Há diversas teorias sobre o modo segundo o qual o conhecimento é representado em nossa memória. De todos os conceitos teóricos sobre a organização do conhecimento, a noção de modelos mentais é a que tem sido mais explorada e desenvolvida. Modelo mental é o modelo que as pessoas têm de si mesmas, das outras pessoas, de seu ambiente, e das coisas com as quais interagem. Esses modelos são formados através de experiências, treinamento, e instrução (Norman, 1988).

O ser humano tem uma propensão natural a entender e modelar seu ambiente, para controlá-lo e para ser capaz de pensar sobre ele, "controlá-lo" em sua imaginação (Thimbleby, 1990); um exemplo é a nossa capacidade de localização em uma cidade, depois de conhecermos algumas vias principais.

Thimbleby (1990) acrescenta: a dificuldade que a maioria das pessoas têm para ensinar outras provém do fato de que a prática acaba dispensando o uso das abstrações (ou modelos) adotadas na fase de aprendizado - abstrações que fariam sentido para quem ainda está aprendendo. Em outras palavras, esquecemos nossa antiga maneira de pensar sobre o assunto, quando ele nos era ainda pouco familiar. Para compensar a distância entre esses modelos (do professor e dos alunos), são necessárias estratégias que ajudem os alunos a desbravar novos caminhos de pensamento até chegar (ou se aproximar) ao nível de abstração familiar ao professor.

\section{Atenção}

A atenção é o processo de filtrarmos os estímulos do ambiente para podermos nos concentrar em um único estímulo. Quando se tenta atender a mais de um evento ao mesmo tempo, se dá a atenção dividida; neste caso não há respostas eficientes para todos os eventos concorrentes, pois não há concentração suficiente para todos. (Preece et al., 1994)

Um aluno desatento é aquele que focaliza sua concentração em estímulos localizados fora do ambiente da aula; falta de motivação e problemas pessoais são fatores que geralmente produzem esse comportamento.

A organização do assunto apresentado ajuda a focalizar a atenção; recursos mnemônicos também são bons recursos, e são fartamente usados em cursos pré-vestibulares (geralmente, sob a forma de músicas e poemas com conceitos importantes). O mesmo se dá com o emprego de cores e a 
combinação de mídias. O excesso de estímulos auxiliares, entretanto, também pode levar à atenção dividida.

\section{Memória}

Pesquisas e experiências mostram a memória humana como um sistema bastante versátil. A memória armazena "imagens" que nos permitem identificar e classificar sinais, sons, gostos, cheiros e sentimentos; registra fatos mundiais e detalhes sobre experiências e desempenho de tarefas. Entretanto, uma pessoa consegue se lembrar de determinadas coisas mais facilmente do que de outras.

Preece et al. (1994) destaca a "Teoria dos níveis de processamento", apresentada por Craik e Leckhart em 1972: segundo essa teoria, a facilidade com que um novo material é lembrado depende do quanto ele é significativo; as informações podem ser processadas em diferentes níveis, cuja profundidade determina a facilidade com que um estímulo pode ser lembrado ao longo do tempo - quanto mais significativo o estímulo, maior a profundidade em que será processado.

Fatores que contribuem para o significado de uma informação incluem atributos como familiaridade e sua imagem associada: a familiaridade se refere à freqüência com que a informação ocorre no dia-a-dia (daí a importância do estudo contínuo); sua imagem associada é a imagem que vem à mente de uma pessoa, relacionada a tal informação (por exemplo, a imagem que temos associada à palavra "bandeira", o gráfico de que nos lembramos ao ver a equação de uma função).

Ao longo do tempo, lembranças sobre determinado assunto sofrem interferências de lembranças de assuntos relacionados. A interferência retroativa inibe as lembranças anteriores com lembranças mais recentes; essa interferência faz com que sejam confundidas informações com estrutura muito parecida, tais como línguas estrangeiras, comandos de linguagens de programação, ou fórmulas matemáticas e fisicas. A interferência proativa causa o inverso: as lembranças anteriores interferem nas lembranças mais recentes (Magro, 1979; ver também Thimbleby, 1990).

\section{Cognição e Multimídia}

Greenfield (1987) comenta que cada meio de comunicação transmite certos tipos de informação com melhor desempenho, enquanto outros meios apresentam deficiências e falta de recursos. As características de uma mídia levam-na a ser particularmente adequada para apresentar determinados 
assuntos no processo educacional. Essas características influem também no processo cognitivo: cada meio atinge e desenvolve um conjunto particular de habilidades para o processamento e produção de informações. Como conseqüência, as mídias têm papéis complementares na educação e no desenvolvimento cognitivo, o que nos leva a uma estratégia de educação multimídia.

Segundo Lindstron (1995), usando multimídia podemos trabalhar com associação multissensorial, informação dinâmica e baseada no tempo, feedback (resposta do usuário) e interação, personalização e definição de objetivos, flexibilidade e capacidade de alterações, criatividade e experimentação.

Por suas características naturais, o uso de multimídia (recursos audiovisuais, por exemplo) produz um impacto emocional nos alunos, além do efeito cognitivo ou intelectual: dado que as pessoas não se utilizam igualmente dos canais sensoriais, o uso de várias mídias de maneira adequada proporciona maiores chances de sucesso na transmissão de uma mensagem e, conseqüentemente, oferece grande possibilidade de atingirmos as condições de aprendizado para cada aluno em particular.

Destacamos a importância de selecionar e utilizar os meios mais adequados para cada etapa do processo de ensino. $\mathrm{O}$ uso de mídias, em resumo, precisa ser planejado de acordo com uma base pedagógica (Bordenave \& Pereira, 1988):

- possibilidade de envolvimento dos alunos com o material apresentado (Thimbleby (1990) cita o Efeito Hawthome: as pessoas tendem a se esforçar mais quando sentem que participam em alguma coisa nova, ou lidam com alguma coisa sobre a qual têm controle);

- aproveitamento das funções próprias da mídia no processo de aprendizagem e preocupação com a qualidade da mídia produzida. O professor não precisa ser um especialista, porém deve estar ciente das noções básicas para desenvolver um material adequado.

- adequação do ambiente ao tipo de apresentação. Este é um fator que nem sempre pode ser controlado pelo professor;

- comportamento e estratégia didática do professor;

- análise do tempo disponível. 


\section{Planejamento pedagógico}

Várias abordagens do processo de ensino propõem o planejamento de etapas que acompanham o aluno desde a apresentação de estímulos para o aprendizado da matéria (pela definição de objetivos e apresentação dos itens principais), aplicando recursos que facilitam o envolvimento do aluno, a retenção dos conceitos e, finalmente, proporcionando a transferência do conhecimento adquirido, acompanhando o progresso do aluno para confirmar seu aprendizado. 


\section{ANEXO 2: Autoria de hipermídia para a World-Wide Web}

O sistema World-Wide Web (também chamado WWW ou simplesmente Web) (Berners-Lee et al., 1994) originou-se de um pequeno sistema em hipertexto usado para manter informações em um projeto distribuído, do qual participavam diversas equipes geograficamente separadas. A Web foi projetada de modo que nenhuma grande mudança centralizada teria de ser feita para a introdução de novos relacionamentos entre diversos sistemas de informação. Essa propriedade permitiu que a WWWW se expandisse rapidamente de suas origens no $\mathrm{CERN}^{17}$ através da Internet.

A idéia básica do sistema é oferecer "um mundo de informações sem fronteiras", com uma interface consistente e a incorporação de um vasto conjunto de tecnologias e tipos de documentos, dando suporte a uma "leitura universal" (acesso a todo tipo de informação disponível no sistema de maneira uniforme, independentemente de plataforma de hardware ou software). Considerando estes propósitos de maneira rígida, a Web não atingiu o estágio de "leitura universal".

O sistema Web está baseado nos seguintes fundamentos:

- um sistema de endereços (URI - Universal Resource Identifier) que visa tornar o "mundo de informações sem fronteiras" possível, apesar dos muitos protocolos diferentes;

- um protocolo de rede (HTTP - HyperText Transfer Protocol);

- uma linguagem de formatação (HTML - HyperText Markup Language) que todo cliente WWW entende, e que é usada para a transmissão de coisas básicas como texto, menus e informações através da rede.

A Web é um sistema distribuído sobre o "modelo cliente-servidor". Os clientes WWW são chamados browsers (na literatura, também chamados de "paginadores", "folheadores", ou "navegadores", dispositivos de apresentação); os browsers são os programas responsáveis pela requisição de arquivos aos servidores sempre que uma ligação de hipertexto (link) é acionada por um usuário, e pela apresentação do conteúdo recebido. Os servidores WWWW (ou servidores HTTP)

${ }_{17}$ Centre d'Etudes et Recherches Nucleaires, em Genebra, Suiça. 
recebem as requisições dos clientes, enviando os arquivos solicitados ou ativando programas (chamados scripts) que desempenham funções complementares.

\section{Autoria na Web}

Quando um browser recebe um documento para apresentação, ele verifica "o que" está recebendo: pela extensão do arquivo e/ou pelo cabeçalho HTTP do pacote que traz o arquivo, o browser descobre se o conteúdo é uma imagem, texto, ou outro tipo de informação. Ao verificar que é um documento HTML, ele faz uma análise sintática do texto, de acordo com a versão de HTML que ele entende; encontrando um elemento conhecido, apresenta a formatação de acordo com sua folha de estilo intema. Por exemplo: para um browser $\mathrm{X}$, um cabeçalho de nível 1 é definido com uma fonte Times Roman de 16 pontos; em um browser $\mathrm{Y}$, o mesmo cabeçalho de nível 1 pode estar definido com fonte Arial de 13 pontos. Os usuários dos browsers também têm a liberdade de modificar alguns itens: fonte e tamanho da letra, apresentação de imagens ou não, cores padrão ou personalizadas. Essa característica permite a convivência de diversas versões particulares de browsers e versões de HTML, pois ao encontrar um elemento HTML que não compreende (isto é, que não esteja presente em sua folha de estilo para apresentação), o browser simplesmente o ignora (Sams.net, 1996).

Assim, a edição de documentos para a World-Wide Web é uma atividade que não oferece uma "certeza absoluta" quanto aos resultados obtidos pelos leitores. Diferentes browsers podem oferecer diferentes resultados.

Além disso, é preciso lembrar que o hipertexto em sistemas de ajuda locais ou em CD-ROM é diferente do hipertexto na Web; a recuperação dos documentos no sistema Web implica normalmente na transmissão de dados em redes distintas e distantes - transmissão muitas vezes prejudicada pela estrutura das redes intermediárias. A navegação on-line pesa ainda mais na eficiência das apresentações, em especial nas apresentações didáticas, pois a demora em recuperar informações pode quebrar o "fio de pensamento" do leitor.

Um dos problemas relacionados ao hipertexto na Web é sua estrutura; enquanto padrões como HyTime (Hypermedia Time-based Document Structuring Language) e ODA (Office Document Arcbitecture) têm conjuntos de regras, módulos e arquiteturas, HTML trata apenas da apresentação do documento. Vários sistemas e modelos vêm sendo propostos para facilitar e aprimorar tanto a apresentação de 
informações como a navegação em hipermídia - em especial, HDM (Hypertext Design Moded), AHM (Amsterdam Hypermedia Moded) e RMM (Relationship Management Methodology). Para documentos na World-Wide Web, o modelo proposto é o recente OOHDM (Object-Oriented Hypermedia Design Model). O sistema LiOS (Link-Oriented System), por sua vez, avalia automaticamente os hiperdocumentos com base em sua estruturação, classificando ligações quanto ao reuso e consistência; seu objetivo é auxiliar os autores a implementar melhorias na qualidade da organização desses links (Fortes, 1996).

Todos esses modelos e sistemas são ferramentas úteis para o autor de hipermídia e devem ser considerados, evitando os problemas presentes nas estruturas de hiperdocumentos construídas de forma meramente empírica.

\section{Interação na Web}

Usando apenas HTML, o único tipo de interação que conseguimos colocar em páginas (documentos) Web é o acionamento de ligações, o que produz a navegação. A idéia das páginas dinâmicas é permitir que o usuário participe ativamente da geração dos documentos recuperados (solicitados e recebidos) por ele. As páginas dinâmicas podem ser implementadas em uma destas duas formas:

1. um programa do lado do servidor processa a requisição do cliente e retorna uma resposta;

2. o servidor envia para o cliente um documento juntamente com um programa ou roteiro.

No primeiro caso, o processamento é realizado do lado do servidor. Funciona desta maneira a maioria dos programas acionados por formulários (para tratamento dos dados), bem como os SSIs (Server-Side Includes). No segundo caso o processamento é local, disparado pelo cliente. Em particular, funcionam desta forma os applets $\mathrm{Java}^{18}$ e os roteiros JavaScript ${ }^{19}$. Conforme a aplicação, a vantagem é de uma ou outra implementação. Algumas aplicações interessantes são possíveis com JavaScript, tais como a manipulação dos chamados cookies (Netscape, 1996): cookies são um mecanismo geral que pode ser usado por scripts para armazenar e recuperar informações do lado do

18 Java é uma linguagem orientada a objetos projetada pela Sun Microsystems. É uma linguagem interpretada, de grande portabilidade. Os programas (applets) Java são compilados em bytecodes e executados por uma máquina virtual Java Virtual Machine).

19 JavaScript é uma linguagem para scripts (roteiros), baseada na sintaxe de Java. Roteiros em JavaScript são interpretados e executados diretamente pelos browsers. 
cliente. Um exemplo da aplicação de cookies é a criação de uma página que ofereça ao usuário os recursos selecionados por ele em um acesso anterior.

\section{Estudo da Interação Usuário-Computador}

Interação é uma ação que se exerce mutuamente entre duas ou mais coisas ou duas ou mais pessoas (Ferreira, 1988). Quando um usuário está interagindo com um sistema computacional, dois complexos processadores de informação estão efetivamente conduzindo um diálogo. Um deles, o usuário, estará empenhado em alguma atividade direcionada para um objetivo. O outro, o sistema computacional, é a ferramenta mediadora da conquista desse objetivo (Bamar, 1991). Ainda segundo Bamar, o estudo da interação entre usuário e computador procura compreender os fatores humanos envolvidos nessa comunicação, e verificar quais deles levam a um uso eficiente e produtivo das ferramentas computacionais.

A área de atuação da Interação Usuário-Computador (Human-Computer Interface ou HCI) abrange estudos em diversas áreas (Baeker, 1995; veja também Preece, 1993): aspectos de computadores em ambientes de trabalho e lazer, tipos de aplicação, suporte ao usuário, psicologia cognitiva, ergonomia, teorias de comunicaçăo e linguagem, projeto de interfaces, arquitetura de sistemas, entre outros. Desenvolver sistemas utilizáveis é a maior contribuição de HCI para o projeto de sistemas computacionais.

\section{Estilos de interação}

Há muitas formas de se interagir com um computador. Essas formas variam de acordo com as diferentes tarefas, conceitos computacionais e dispositivos de interface. Ben Shneiderman, em (Schneiderman, 1991), faz uma análise detalhada das características de cada estilo de interação, abordando a seleção por menus, o preenchimento de formulários, o uso de linguagens de comando, linguagem natural, e a manipulação direta.

\section{Interfaces}

As interfaces de usuário são os elementos dos sistemas computacionais que permitem à pessoa que usa o computador ter acesso às facilidades oferecidas por ele. Essas interfaces, freqüentemente, não são tão boas como deveriam ser; em geral, são dificeis de compreender, levando o usuário a cometer erros desnecessários em sua interação com o sistema. A interface com o usuário parece 
não preocupar boa parte dos projetistas, em geral porque os usuários se adaptam, investindo muito de si mesmos aprendendo a lidar com sistemas ruins ${ }^{20}$ (Thimbleby, 1990).

Chamam-se "ruídos" os elementos que perturbam a comunicação. No ambiente computacional, tais ruídos são decorrentes de problemas no projeto da interface e características do equipamento e do contexto dos usuários (monitor com baixa resolução gráfica, softwares antigos, limite de tempo para cumprir uma tarefa, experiência anterior, entre outros).

Em especial nos ambientes de suporte ao aprendizado, o sistema como um todo deve ser útil para estender o conhecimento e a compreensão do estudante: o esforço mental dos usuários deve ser direcionado para pensar no que estão produzindo (Allinson \& Hammond, 1989). Em outras palavras, o sistema deve ser fácil de usar para que os usuários não precisem se esforçar muito para "dirigir" o ambiente que estão usando (Allinson \& Hammond, 1989).

\section{Noções de Interação Usuário-Computador aplicadas a Hipermídia}

Com a popularização da World-Wide Web, qualquer pessoa tomou-se capaz de montar um conjunto de hiperdocumentos interativos; porém, o conhecimento formal, e a aplicação de conceitos relacionados a Engenharia de Software e Interação Usuário-Computador, podem elevar a qualidade desses hiperdocumentos em termos de autoria. A falta desses conhecimentos, embora não seja sentida pelos projetistas, atinge diretamente os usuários do sistema.

Uma coleção de diretivas para o projeto de interfaces hipermídia pode ser formada pela consulta a diversos documentos (em especial, (Apple, 1994), (Marcus, 1992), (Nielsen, 1996a,b,c) (Preece et al., 1994), (Schuler, Hannemann \& Streitz, 1994) e (Thimbleby, 1990)). Um resumo dos pontos principais é apresentado a seguir.

\section{A aplicação hipermidia sob várias perspectivas}

Uma aplicação hipermídia estruturada pode ser considerada sob várias perspectivas (Schuler, Hannemann \& Streitz, 1994):

1. Em termos das estruturas de representação que descrevem as informações;

${ }^{20}$ Casos de estudo interessantes são discutidos por Thimbleby (1990), incluindo as interfaces dos sistemas UNIX e DOS. 
2. segundo a maneira com que os usuários interagem com a aplicação (navegação), e segundo o comportamento dessas informações (mudança de estado ao longo do tempo), de maneira independente ou como resposta a ações do usuário.

3. pela apresentaçäo de informações na tela;

4. segundo as funcionalidades da aplicação, além da navegação (por exemplo, oferecer versões das informações em um arquivo para cópia e/ou impressão) .

\section{O usuário como centro do projeto}

A autoria de sistemas hipermídia pode ser comparada com outros processos criativos - escrever um livro, organizar uma exibição, produzir um filme (Schuler, Hannemann \& Streitz, 1994). O primeiro passo é definir o público (leitores/usuários) (Apple, 1994): entrevistas e levantamento de requisitos fazem parte do planejamento do sistema. Os autores precisam ter em mente as idéias a serem desenvolvidas, como elas serão estruturadas, a melhor mídia para expressar cada idéia, como elas serão montadas, e as rotas de navegação através do material (Schuler, Hannemann \& Streitz, 1994). A interface dos autores deve facilitar seu trabalho.

\section{Estrutura das apresentações}

É necessário um suporte para a navegação, que dê sentido de estrutura e lugar ao conjunto de hiperdocumentos. Mapas do conjunto de documentos e ferramentas de busca são características desejáveis (Nielsen, 1996c). Um bom sistema de navegação responde a cinco questões básicas do usuário (Apple, 1994):

- o que há nesta apresentação?

- onde estou agora?

- para onde posso ir?

- como chego lá?

- onde já estive?

O sistema de navegação escolhido depende dos usuários, do assunto, e do estilo de apresentação em geral. A estrutura linear encoraja (e força) o usuário a seguir um caminho lógico simples através das informações (Apple, 1994). A estrutura hierárquica é baseada em conteúdo, pois une partes do material em grupos significativos de assuntos relacionados; o índice é uma estrutura que oferece 
acesso às informações sem implicar em uma relação entre a fonte e o destino do link (Schuler, Hannemann \& Streitz, 1994).

\section{Metúforas e Modelos Mentais}

As metáforas são usadas em interfaces para assegurar que o usuário possa adotar rapidamente um modelo mental correto do sistema. A hipermidia requer metáforas estruturais devido ao problema inerente às hiperestruturas, que é "perder-se no hiperespaço" (Schuler, Hannemann \& Streitz, 1994; veja também Preece et al., 1994).

\section{Ícones e Cores}

Segundo Marcus (1992), um ícone é uma coisa que se parece com o que significa: deve ser significativo e reconhecido intuitivamente dentro de um contexto (Preece et al., 1994; veja também Nielsen, 1996a).

A cor é um dos elementos mais subjetivos da apresentação (Lindstron, 1995), e seu uso exige cuidados especiais. As principais aplicações de cores buscam atender os seguintes itens (Marcus, 1992):

- chamar a atenção para dados ou informações específicas;

- identificar elementos de estruturas e processos;

- melhorar o aspecto, a confiabilidade das informações, facilitar a lembrança e a compreensão, reduzindo erros de leitura ou compreensão.

\section{Grades}

Uma grade de layout é um conjunto de linhas horizontais e verticais que divide o campo visual em pedaços que apresentam integridade conceitual (informações referentes a um mesmo assunto) e visual (informações representadas/apresentadas de forma semelhante) (Marcus, 1992). Essa divisão oferece variedade, uso adequado do espaço e também consistência na apresentação de ilustrações e texto. A organização guia os olhos dos leitores, oferecendo um rápido reconhecimento e possibilitando sua localização no contexto da apresentação (Lindstron, 1995; veja também Marcus, 1992). 


\section{Projeto de páginas $W e b$}

Além de seguir o projeto de hiperdocumentos em geral, as páginas do sistema World-Wide Web precisam de certos cuidados especiais, tanto com relação à navegação como aos recursos de formatação oferecidos pelas versões de HTML.

Um dos debates sobre implementação de sites é o uso de frames" ${ }^{21}$, apontado como um "grande erro" de design por Jakob Nielsen (Nielsen, 1996c). Na prática, os usuários demonstram certa irritação pela diminuição do espaço para o texto, devido às bordas; mas as novas formatações já introduziram frames sem bordas, oferecendo um efeito final limpo e mais agradável. Usuários inexperientes se saem muito bem com a interface de frames. Portanto, consultar os usuários, ou realizar uma experiência em laboratório, poderá identificar preferências de apresentação. Caso a implementação o exija, os frames podem ser substituídos por tabelas.

Animações, mensagens que piscam (blink) ou deslizam (marquee), e outros efeitos contínuos, devem ser evitados. Nenhum recurso especial deve ser usado gratuitamente, todos os componentes da página devem ser necessários e funcionais (Nielsen, 1996c).

Diversos itens de projeto para autoria na Web são encontrados em referências on-line, livros e apostilas (em especial (Apple, 1994), (Nielsen, 1990), (Sun, 1995)), focalizando desde a importância da identificação de autores até o uso de ícones para a identificação do site e carregamento mais rápido das páginas. Principalmente, é destacado o comportamento dos usuários da Web: eles não "lêem" sites mas, sim, "navegam" por eles.

$21 \mathrm{Ou}$ "quadros", de acordo com algumas traduções. 


\section{REFERÊNCIAS}

Allinson, L., \& Hammond, N. (1989). A leaming support environment - The Hitch-hiker's guide. In R. McAleese (Ed.), Hypertext: Theory into practice. (pp. 62-74). Norwood, NJ: Ablex Publishing Corporation.

Apple Computer, Inc. (1994). Hypercard - Stack design guidelines. ( $7^{2}$. edição) Addison-Wesley.

Baeker, R. M. et al. (1995). Readings in HCI Toward the year 2000. (2ª edição). Morgan Kaufmann Pub.

Barker, P., \& Manji, K. (1992). Computer-based training: An institutional approach. Education \& Computing, 8, 229-237.

Bamar, P. (1991). The contributions of applied cognitive psychology to the study of humancomputer interaction. In B. Schackel, S. Richardson (Eds.), Human Factors for Informatics Usability. Cambridge University Press.

Barreira, W. (1994). Tudo ao mesmo tempo agora. In Superinteressante, 9, 18-21 (Ano 8). São Paulo: Editora Abril.

Bemers-Lee, T., Cailliau, R., Luotonen, A., Nielsen, H. F., \& Secret, A. (1994). The WorldWide Web. Communications of the ACM, 37 (8), 76-82.

Bizzo, N. (2. semestre de 1996). Qualidade na educação. In Boletim on-line da Escola do Futuro, [Online]. Available: http://www.futuro.usp.br/ [17 de março de 1997].

Bordenave, J. D., \& Pereira, A. M. (1988). Estratégias de Ensino-Aprendizagem (10². edição). Petrópolis, RJ: Editora Vozes.

Brusilovsky, P., Schwarz, E., \& Weber, G. (1996) A tool for developing adaptive electronic textbooks on WWW. Proceedings of WebNet'96 (World Conference of the Web Society) pp. 64-69. [On-line] Available: http://www.contrib.andrew.cmu.edu/ plb/WebNet96.html [12 de outubro de 1997 ]

Buford, J. F. K. (1994). Uses of multimedia information. In J. F. K. Buford (Ed.) Multimedia Systems. (pp.1-25) New York, NY: Addison-Wesley.

Castro, M. A. S. (1996). Pesquisa científica e os novos ambientes eletrônicos. In Catálogo eletrônico da 48.reunião anual da SBPC (PUC-SP, julho, 1996). [CD-ROM]. Available: Infoco Consultoria de Sistemas/Mesa Redonda.

Castro, M. A. S., Goularte, R., Reami, E. R., \& Moreira, E. S. (1997). Infra-estrutura de suporte à editoração de material didático utilizando multimídia. Revista Brasileira de Informática na Educação, 1, 61-70.

Crespo, A., Chang, Bay-Wei, \& Bier, E. A. (1997). Responsive interaction for a large Web application: The Meteor Shower architecture in the WebWriter II Editor. In WWW6 Hyperproceedings. [On-line] Available: http://www6.nttlabs.com/HyperNews/get/ PAPER86.html [15 de novembro de 1996] 
DeSieno, R. (julho/agosto de 1995). Netlaw: The faculty and digital technology. Educom Review, 30 (t). [Online]. Available: http://www.educom.edu/web/pubs/review/reviewArticles/ 30446.html [11 de fevereiro de 1997].

Duncan, E. B. (1989). A faceted approach to hypertext?. In R. McAleese (Ed.) Hypertext: Theory into practice. (pp. 157-163). Norwood, NJ: Ablex Publishing Corporation.

Edwards, A. D. N. \& Holland, S. (1994). Editor's Preface. In A. D. N. Edwards \& S. Holland (Eds.), Multimedia interface design in education. (NATO ASI Series, $1^{2}$. reimpressão corrigida). Berlim: Springer-Verlag.

Ferreira, A. B. H. (1988). Dicionário Aurélio básico da Lingua Portuguesa. São Paulo: Editora Nova Fronteira S/A.

Fortes, R. P. M. (1996). Análise e avaliação de hiperdocumentos: Uma abordagem baseada na representação estrutural. Tese de Doutorado. São Carlos: IFSC-LSP.

Galli, M. S., \& Moreira, E. S. (1997). Desenvolvimento de estratégias de serviço de provimento de vídeo para biperdocumentos educativos. Relatório de Iniciação Científica (PIBIC/CNPq). São Carlos: ICMSC-USP.

Gibbs, S. J. \& Tsichritzis, D. C. (1995). Multimedia programming - Objects, enrironments and frameworks. Wokinghan, Inglaterra: Addison-Wesley.

Goodyear, P., Njoo, M., Hijne, H., \& van Berkum, J. J. A. (1991). Learning processes, learner attributes and simulations. Education e'r Computing, 6, 263-304.

Goularte, R. (1998). Utilização de metadados no gerenciamento de acesso a servidores de vídeo. Dissertação de Mestrado. São Carlos: ICMSC-USP.

Greenfield, P. M. (1987). Electronic technologies, education, and cognitive development. In D. E. Berger, K. Pezdek, \& W. P. Banks (Eds.), Applications of cognitive psychology: Problem solving, education and computing (pp. 17-32). Hillsdale, NJ: Lawrence Erlbaum Associates.

Guimarães, C. V. (1997). Controle de tarefas em ambientes multimidia de ensino. Relatório de Iniciação Científica (PIBIC/CNPq). São Carlos: ICMSC-USP.

Hachisuca, A. M. M. (1997). Desenvolvimento de um sistema servidor para aplicações multimídia. Anais do II Workshop de Teses e Dissertaçoes em Andamento - ICMSC-USP. São Carlos: ICMSC-USP.

Harmon, P. (1987). Intelligent job aids: How AI will change training in the next five years. In G. P. Kearsley (Ed.) Artificial Intelligence and Instruction - Applications and Methods. Addison-Wesley.

Heterick Jr., R. C. (novembro/dezembro de 1994). A stone soup. Educom Review, 29 (6). [Online]. Available: http://www.educom.edu/web/pubs/review/reviewArticles/29664.html [10 de janeiro de 1998].

Horton, W. (1994). Designing and writing online documentation: Hypermedia for self-supporting products. ( ${ }^{a}$. edição). New York: John Wiley and Sons, Inc.

Hubler, A. W., \& Assad, A. M. (1996). CyberProf: An intelligent human-computer interface for asynchronous wide area training and teaching. World Wide Web Journal, 1 (1) (Proceedings of the Fourth International World Wide Web Conference) [On-line] Available: http://www.w3j.com/1/247.html [23 de outubro de 1997]

Lindstron, R. L. (1995). Guia business week para apresentações em multimidia. São Paulo: Makron Books. 
Linn, M. C. (1996). Key to the information highway. Communications of the ACM, 39 (4), 34-35.

Litto, F. M. (fevereiro/março/abril/maio de 1996). A Escola do Futuro da USP - Um laboratório de ponta em prol da educação brasileira. In Jornai da APASE, 31, 8-11 (Ano 3).

Magro, M. C. (1979). Estudar também se aprende. São Paulo: E.P.U - Editora Pedagógica e Lniversitária Ltda.

Marcus, A. (1992). Graphic design for electronic documents and user interfaces. New York: ACM Press.

Mc.lleese, R. (1989). Navigation and browsing in hypertext. In R. Mc.tleese (Ed.) Hypertext: Theory into practice. (pp. 6-44). Norwood, NJ: Ablex Publishing Corporation.

McKnight, C., Richardson, J., \& Dillon, A. (1989). The authoring of hypertext documents. In McAleese, R. (Ed.), Hypertext: theory into practice. (pp. 138-147). Norwood, NJ: Ablex Publishing Corporation.

Moreira, E. S., Nunes, M. G. V., \& Pimentel, M. G. C. (dezembro de 1995). Design Issues for a distributed hypermedia-based tutoring system (HyDTS). Proc. of International Conference on Computer Application in Industry, 108-113.

Netscape Communications Corporation (1996). Persistent client state HTTP cookies. [On-line] Available: http://home.netscape.com / Cookies [12 de fevereiro de 1997]

Nielsen, J. (1990). Hypertext é hypermedia. Boston: Academic Press.

Nielsen, J. (1996a). Icon usability. [On-line] Available: http://www.sun.com/sun-onnet/uidesign/icons.html [10 de outubro de 1996].

Nielsen, J. (1996b). Interface design for Sun's WWW site. [On-line] Available: http://www.sun.com/sun-on-net/uidesign/ [10 de outubro de 1996].

Nielsen, J. (1996c). Top tem mistakes in Web design. [On-line] Available: http://www.sun.com/960416/columns/alertbox/ [10 de outubro de 1996].

Norman, A. D., \& Spohrer, J. C (1996). Leamer-Centred Education. Communications of the ACM, 39 (4), 24-27.

Norman, K. L. (1996). Teaching in the surtched on classroom: An introduction to electronic education and bypercourseware. [Online]. Available: http://www.lap.umd.edu/SOC/sochome.html [20 de janeiro de 1997].

Park, O.-C., Perez, R. S., \& Seidel, R. J. Intelligent CAI: old wine on new bottles, or a new vintage? In G. P. Kearsley (ed.), Artificial intelligence and instruction - Applications and methods. Wokinghan: Addison-Wesley.

Pozzembom, W. (10 de setembro de 1996). Uso da informática ainda está em desenvolvimento. In LER, pp. 4-5.

Preece, J. (1993). Human-computer interaction in the informatics curriculum. Education do Computing, 8, 295-301.

Preece, J., Rogers, Y., Sharp, H., Benyon, D., Holland, S., \& Carey, T. (1994). Human-Computer Interaction. Wokinghan: Addison-Wesley.

Ringsted, M. (1994). On-site distance learning: A multimedia full-scale experiment in Denmark. In A. D. N. Edwards, \& S. Holland (Eds.) Multimedia interface design in education (NATO ASI Series, $1^{2}$. reimpressão corrigida) (pp. 45-56). Berlim: Springer-Verlag. 
Romanatto, M. J., Torres-Alamilla, S., \& Monard, M. C. (1996). Descrição de cursos sobre inteligência artificial na Internet. Relatório Técnico do ICMSC nº. 49. São Carlos: ICMSC-LSP

Ruth, S. (setembro/outubro de 1997). Getting real about technology-based learning. The medium is not the message. Educom Review, 32 (5). [Online]. Available: http://www.educom.edu/web/pubs/review/reviewArticles/32532.html [10 de janeiro de 1998].

Sams.net Publishing (1996). Discover the W'orld-Wide Web with your Sportster. (2ª . edição)

Schuler, W; Hannemann, J., \& Streitz, N. (1994). Designing user interfaces for bypermedia. ESPRIT Research Reports. Berlim:Springer.

Shneiderman, B. (1991). A taxonomy and rule base for the selection of interaction styles. In B. Shackel, \& S. Richardson (Eds.), Human Factors for Informatics Usability. Cambridge University Press.

Skillicom, D. B. (1996). Using distributed hypermedia for collaborative leaming in universities. The Computer Journal, 39, 471-482.

Streitz, N. A. (1988). Foundations of hypermedia design. In W. Schuler, J. Hannemann, \& N. A. Streitz (Eds.), Designing user interfaces for bypermedia (ESPRIT Research Reports, Project 6532, volume 1) (pp. 1-3). Berlim: Springer-Verlag.

Sun Microsystems, Inc. (1995). Guide to Web style.[On-line] Available: http://www.sun.com

Tedesco, P. A., Barros, F. A., \& Souza F. F. (1997). SEI - Sistema de Ensino Inteligente. Anais do VTII Simpósio Brasileiro de Informática na Educação (volume 1) 49-59.

Thimbleby, H. (1990). User interface design. ACM Press.

Valente, J. A.; \& Almeida, F. J. (1997). Visão analítica da informática na educação no Brasil: a questão da formação do professor. Revista Brasileira de Informática na Educação, 1, 45-60. 


\section{GLOSSÁRIO}

C. II - Computer-Aided Instruction: Instrução assistida por computador.

CBT - Computer-Based Training: Treinamento baseado no uso de computador.

Conhecimento - conjunto de relacionamentos entre informações, que capacita uma pessoa a desempenhar funções, compreender situações, responder a estímulos.

Documento - ver hiperdocumento.

Download - "fazer download": copiar arquivo(s) de um computador remoto para um computador local.

Hiperdocumento - documento que apresenta características de hipertexto ou hipermídia. Neste texto, também chamado "documento" ou "página"

Hipertexto - conjunto de texto que apresenta ligações associativas (links) entre informações, ou assuntos relacionados.

Hiperlink — ligação entre dois elementos de informação em um hipertexto.

Hipermídia - conjunto de várias mídias (multimídia) interligadas; neste texto, um superconjunto de hipertexto.

ICAI — Intelligent Computer-Aided Instruction.

Informação — dado referente a objetos, situações, seres, procedimentos.

Internet - conjunto mundial de redes de computadores, interligadas através dos protocolos de comunicação TCP/IP, independentes de plataforma.

Link - o mesmo que hiperlink. 
Lixo cibemético - informações variadas sobre produtos e empresas, dados que pouca ligação têm com um assunto sendo pesquisado e que, mesmo assim, são recuperados nas buscas através de catálogos na Intemet.

Multimídia - uso simultâneo de diversas mídias (texto, imagem, áudio, entre outras)

Página - ver hiperdocumento.

Script - programa simples, utilizado para complementar as funções de servidores HTTP. Um script pode gerar documentos HTML, enviar e-mails, consultar bases de dados, entre outras aplicações.

Sistema Interland - sistema de apoio ao ensino e ao aprendizado, implementado na plataforma World-Wide Web.

Site (ou site Web) - conjunto de hiperdocumentos no sistema World-Wide Web, com determinadas características de conteúdo, navegação e apresentação

STI — Sistema Tutor Inteligente.

T.A. - Teaching Assistant. Interface do professor no sistema Interland.

Template - modelo com campos para inserção de informações, que auxilia na produção de documentos, programas ou conjuntos de dados.

Upload - "fazer upload": copiar arquivo(s) de um computador local para um computador remoto.

Web de disciplina — conjunto de hiperdocumentos associados a uma matéria.

World-Wide Web — sistema hipermídia implementado na Internet. 


\section{APÊNDICE}

Este apêndice contém dois artigos publicados durante o desenvolvimento deste trabalho de mestrado:

- "Infra-estrutura de Suporte à Editoração de Material Didático Utilizando Multimídia". Artigo publicado na Revista Brasileira de Informática na Educação, n. 1, pp. 61-70, setembro de 1997.

- "Utilização de Multimídia em Ambientes Educacionais Baseados em WWW". Artigo aceito como resumo no VIII Simpósio Brasileiro de Informática na Educação, novembro de 1997. 


\title{
INFRA-ESTRUTURA de SUPORTE À EDITORAÇÃo de MATERIAL DidÁtico UTilizando Multimídia
}

\author{
Maria Alice Soares de Castro, Rudinei Goularte, Elderclei Regis Reami, Edson dos Santos Moreira \\ Departamento de Ciências de Computação e Estatística - ICMSC - Universidade de São Paulo -
São Carlos

\section{RESUMO} \\ (\{masc,rgoulart,reami,edson\}@icmsc.sc.usp.br)
}

Através da multimídia e da hipermídia, os sistemas didáticos exploram fatores como associação multissensorial, interação e experimentação, trabalhando com diversos recursos para educacional distribuído que visa integrar ferramentas de edição e de aproposta de ambiente didático multimídia no ambiente World-Wide Web. O projeto da infra- e apresentação de material da entrega dos dados multimídia consiste na utilização de servidores destrutura de gerenciamento e em sistemas VOD), utilizados em conjunto com bases de dados de metadados.

\begin{abstract}
Through the use of multimedia and hypermedia, educational systems exploit features, such as multisensorial association, interaction and experimentation, making use of several resources, in order to promote an effective learning experience. This article presents a proposal of a distributed educational environment that aims to integrate WWW-enabled presentation and editing tools for documents containing multimedia objects. The design of the management infrastructure and the multimedia data delivery system consists in the use of VOD-based multimedia data servers and
metadata databases.
\end{abstract}

Palavras-chave: Multimídia, Hipermídia, Informática na Educação, Video-On-Demand.

\section{INTRODUÇÃo}

Os seres humanos se utilizam de multimídia no seu processo de comunicação, e essa comunicação multimídia auxilia no processo cognitivo ao atuar no processamento de informações
(Greenfield, 1987).

Por sua vez, as tecnologias de comunicação exercem a função de disseminadores de conhecimento, liberando estudantes e professores das limitações de tempo e espaço, enriquecendo o ensino com recursos de multimídia, interação, simulações, e permitindo o estudo individualizado. facilidades de aprendiza de implementação de sistemas didáticos, adiciona a faculdade de se levar tais o ciclo de isolamento dos núcl público maior, podendo diminuir diferenças regionais e quebrando

dos nucleos educacionais e científicos.

tudo, é necessário haver mologias no ensino não implica em sucesso no aprendizado. Acima de dando oportunidade ao surgimento de uma nova maneira de experiências com Tecnologia da Informação no ensino obtêm sucesso quando, além da consulta 
apresentação de textos on-line, cada tareta oferece métodos e tecnologias apropriadas, com grande ênfase na comunicação, e recursos para trabalho cooperativo: correio eletrônico, grupos de opinião, conversa on-line e dever eletrônico.

Harrison (1995) propõe doze critérios de avaliação e comparação de sistemas hipermídia, sendo eles definidos em termos do uso de multimídia, objetos, scripts, ambiente multiusuário, links e padrões; das possibilidades de escalabilidade, interoperabilidade e extensibilidade; e da independência de tecnologia, apoio on-line ao usuário e suporte à intemacionalização.

Baseado nesse contexto, um ambiente que provê ferramentas para a utilização de multimídia na editoração e na apresentação de material didático, estabelecendo um sistema distribuído de apoio ao aprendizado (Interland), é proposto.

O Interland se encaixa na definição de sala de aula eletrônica fornecida por Kent L. Norman (Norman, 1997): uma sala de aula que incorpora métodos tradicionais e facilidades tecnológicas para promover o aprendizado. Essa abordagem maximiza o número de canais de comunicação através do uso de recursos computacionais.

Este artigo está dividido da seguinte forma: a seção 2 descreve as motivações para a utilização de multimídia, hipermídia e interação usuário computador em sistemas de apoio ao aprendizado, mostrando as vantagens da utilização conjunta dessas técnicas; a seção 3 mostra uma infra-estrutura de gerenciamento para o fornecimento eficiente dos dados multimídia utilizados na edição de documentos; a seção 4 apresenta uma proposta de ambiente - o Interland - que visa integrar ferramentas que auxiliem na preparação e apresentação de material didático; por fim apresenta-se uma análise das perspectivas do Interland.

\section{MotivaÇões para a UtilizaÇão de MUltimídia e HiPertexto EM SiSTEMAS de APOIO AO APRENDIZAdo}

Os computadores, atualmente, assumem o papel de ferramenta auxiliar no processo de ensino, como ponte de comunicação para fins educacionais (Norman \& Spohrer, 1996). A presença da Internet em instituições de ensino e sua utilização como ferramenta de pesquisa são discutidos em Castro (1996). Entre os diversos fatores positivos, não se espera mais pela importação de livros e pela impressão de periódicos, sendo imediato o acesso a informações atualizadas e recursos prontos para utilização. A interface gráfica amigável, surgida com o sistema World-Wide Web, aproxima da Internet as pessoas que antes não se sentiam à vontade com os diversos protocolos de acesso. Em comparação com outros serviços de pesquisa bibliográfica, o ambiente é muito mais ágil, oferecendo muita informação que não se encontra em mídias convencionais.

Segundo Skillicom (1996), a tecnologia da informação toma possível oferecer aprendizado de melhor qualidade devido a diversos fatores: pode-se oferecer mais riqueza de informações através do material on-line, mostrando os relacionamentos entre os assuntos apresentados; os recursos de multimídia podem tomar disponíveis permanentemente as melhores explicações, apresentações e resoluções de problemas; é possivel oferecer caminhos altemativos, de acordo com estilos e ritmos de aprendizado dos estudantes, avaliando e oferecendo explicações simplificadas para os itens que mais provocarem dúvidas; os cursos on-line podem também ensinar a localizar informações em grandes sistemas, agindo como um filtro de informações na WWW.

Além dessas características, os sistemas de apoio à educação procuram implementar uma organização básica que dê suporte tanto à apresentação do material didático on-line (chamado courseware), como à cooperação entre alunos e professores (Barker \& Manji, 1992; veja também Ringsted, 1994). 


\section{Multimídia}

Greenfield (1987) comenta que cada meio de comunicação apresenta características que o tomam mais adequado do que outros para determinados tipos de informação. Esse fato influi no processo cognitivo ao atuar sobre os sentidos, ativando conjuntos específicos de habilidades responsáveis pelo processamento de informações. Portanto, as mídias desempenham papéis complementares no processo de aprendizado, o que aponta em direção a um sistema de educação multimídia.

Multimídia é o uso simultâneo de dados em diferentes formas de mídia (voz, vídeo, texto, animações e outras) (Buford, 1994). Os seres humanos são comunicadores de multimídia: experimentam o mundo por meio de sentidos, e se expressam através de diversos e elaborados sinais verbais e visuais. Lindstron (1995) comenta que a "comunicação monomídia" limita o processo de comunicação, por não considerar os outros canais através dos quais naturalmente enviamos e adquirimos informações. Ainda segundo Lindstron, usando multimídia podemos trabalhar os seguintes fatores: associação multissensorial, informação dinâmica e baseada no tempo, feedback (resposta do usuário) e interação, personalização e definição de objetivos, flexibilidade e capacidade de alterações, criatividade e experimentação.

De acordo com Gibbs e Tsichritzis (1995), os tipos de mídia são divididos em dois grupos: temporal (mídia dinâmica ou contínua) e não temporal (mídia estática ou discreta). Animações, áudio e vídeo digitais são exemplos de mídias contínuas (variam com o tempo: são produzidas a uma determinada taxa de amostragem e devem ser reproduzidas nessa mesma taxa) enquanto textos e gráficos são exemplos de mídias discretas (Buford, 1994; veja também Gibbs \& T'sichritzis).

\section{Hipertexto e Hipermídia}

Hipertexto é um sistema de representação de conhecimento no qual diversos elementos de conhecimento podem ser montados de maneiras diferentes, de acordo com as diferentes perspectivas dos usuários do sistema. Através de ligações (linkes), o hipertexto oferece mecanismos para se descobrir as ligações conceituais entre seções de assuntos relacionados (Duncan, 1989). Uma de suas vantagens é permitir a exploração através dessas ligações conceituais. Em outras palavras, o hipertexto procura simular o processo de associação realizado pela mente humana, sendo um de seus objetivos melhorar estratégias de aprendizado existentes (McAleese, 1989; ver também Nielsen, 1990).

O funcionamento do hipertexto, como uma aplicação de armazenamento e recuperação de informações, foi previsto por Vannevar Bush em 1945 (Baeker \& Buxton, 1987). Bush descreveu um dispositivo chamado MEMEX, no qual um indivíduo armazenaria todas as informações que possuísse: livros, anotações, registros, comunicações. Através de microfilmes, alavancas, botões e sistemas de índice, seria possível localizar as informações requisitadas, visualizando-as pela projeção em telas e realizando buscas progressivas ou regressivas. A idéia da projeção progressiva, segundo Bush, era oferecer uma facilidade de indexação associativa, segundo a qual cada item poderia sempre selecionar outro. Essa seria a característica essencial de MEMEX.

Nos anos 60, Douglas Engelbart e Ted Nelson elaboraram conceitos do sistema MEMEX de maneiras diferentes. Ted Nelson propôs em 1965 o sistema Xanadu e foi o primeiro a empregar a palavra "hipertexto" para descrever a visão de textos interligados, formando estruturas complexas (as informações eram então digitais, e não armazenadas em microfilmes). Engelbart percebeu a importância de considerar as diversas abordagens para a interação usuário-computador, desenvolvendo várias ferramentas (tais como o mouse) para concretizar seu sistema interativo NLS, apresentado em 1968. A partir de então, várias outras experiências e projetos implementaram estruturas e conceitos relacionados a hipertexto. Finalmente, em 1986 foi apresentado o sistema 
Guide, primeiro sistema de hipertexto amplamente disponível. A seguir, a Apple Computer Inc. lançou o HyperCard, dando grande impulso à utilização e desenvolvimento de sistemas em hipertexto, incorporando também a utilização de multimídia. (Baeker \& Buxton, 1987; ver também Nielsen, 1990).

A associação entre hipertexto e multimídia define a hipermídia: textos, imagens e sons tomam-se disponiveis à medida em que o usuário percorre as ligações existentes entre eles.

A WWWW (Bemers-Lee et al., 1994) é o sistema hipermídia mais conhecido na atualidade. Sua independência de plataforma e a possibilidade de agregar novos recursos e serviços aos documentos apresentados, implicam na facilidade de execução dos vários recursos pedagógicos - incluindo simulações e interações.

Existe uma longa tradição no projeto de documentos em papel, mas há pouca ou nenhuma para o projeto de documentos ou outras aplicações hipermídia (Streitz, 1994). O sucesso ou o fracasso de nossa interação com um hiperdocumento ${ }^{22}$ será determinado pelas decisões feitas pelo autor sobre quais nós (pedaços de informação, documentos hipertexto) devem ser unidos por ligações. O hipertexto é não-linear, assim como as idéias; o problema da autoria de hipertexto é escolher o melhor "caminho de pensamento" para os documentos, através das ligações (McKnight et al., 1989).

Os problemas enfrentados pelos leitores são conhecidos (desorientação ou dificuldades em localizar a informação desejada, sobrecarga cognitiva ${ }^{23}$. $O$ autor, por sua vez, precisa aprender a expressar suas idéias no novo meio - a expressão de idéias não mais se limita às palavras, mas deve incluir as conexões entre os nós. $O$ autor precisa antecipar os usos que o leitor irá fazer da informação apresentada, prevendo as ligações necessárias. De outra forma, o usuário poderá apenas ficar "passeando" pela base de conhecimentos, de maneira desmotivada e ineficiente (McKnight et al., 1989; veja também Allinson \& Hammond, 1989).

\section{INTERAÇÃO USUÁRIO-COMPUTADOR}

O aprendizado envolve diversas habilidades. Entre elas, a capacidade de generalizar, de induzir, de fazer analogias e de receber instrução. Aprendemos por indução quando realizamos grande quantidade de observações sobre o comportamento de um fenômeno para descobrir regras e procedimentos. $O$ aprendizado por generalização acontece quando uma pessoa observa um conjunto de objetos e descobre, entre eles, uma classe cujos membros possuem características em comum (Araribóia, 1989). Aprender por analogia é reconhecer pontos de semelhança entre coisas diferentes (por exemplo, ferramentas diferentes com funções semelhantes) (Ferreira, 1988). Os métodos de ensino, portanto, devem explorar esses métodos de aprendizado. $O$ aluno deve ser encorajado a formar relacionamentos entre o conhecimento que já tem e os novos elementos apresentados, desenvolvendo estruturas para seu conhecimento (Allinson \& Hammond, 1989).

O suporte à navegação, o uso de metáforas e a combinação de ícones e cores, devem oferecer uma interface agradável que livre o usuário de preocupações com o funcionamento do sistema. Os recursos de apresentação devem ser usados de maneira que o leitor possa reconhecer o ambiente, localizando-se com facilidade no contexto dos documentos.

22 Hiperdocumento: documento que possui ligações (linkes) para outros documentos (hipertexto) e ligações para outras mídias como sons e vídeo, podendo essas outras mídias agirem também como ligações, ao invés de apenas o texto desempenhar essa funçăo.

23 A sobrecarga cognitiva acontece quando o usuário precisa saber e se lembrar de muitos detalhes sobre sua navegação - ou sobre o sistema - para conseguir se orientar no conjunto de informaçōes. 
Com a popularização da WWW, qualquer pessoa tomou-se capaz de montar um conjunto de hiperdocumentos interativos; porém, o conhecimento formal, e a aplicação de conceitos relacionados a Engenharia de Software e a Interação Usuário Computador, podem elevar a qualidade desses hiperdocumentos em termos de autoria. A falta desses conhecimentos embora não sèia sentida pelos projetistas, atinge diretamente os usuários.

\section{Infra-estrutura PaRA ARMAzenamento e ENTREga de DAdos MULTIMÍDIA}

Em um ambiente distribuído, como a WWWW, onde uma comunidade de usuários (clientes) deseja obter dados multimídia simultaneamente ou não, é necessário um sistema que administre o fornecimento do material requisitado de forma eficiente. O gerenciamento eficiente é necessário devido ao grande volume dos dados, de mídia contínua em especial, e ao grande número de usuários desejando utilizar esses dados, o que ocasionalmente pode sobrecarregar o sistema tomando o acesso aos dados muito lento ou mesmo impossível.

Um componente desse sistema é um servidor de dados multimídia. Esse servidor realiza o armazenamento de dados como áudio, vídeo e gráficos (entre outros) em algum tipo de dispositivo físico (disco, fita, etc.). O armazenamento pode ser realizado com a ajuda de técnicas como RAID ${ }^{24}$ (Lee et al., 1994), armazenamento hierárquico (Federighi \& Rowe, 1994) ou armazenamento terciário (Lougher \& Shepherd, 1993) para aumentar a eficiência na gravação e na entrega dos dados.

Além do armazenamento, um servidor de dados multimídia deve receber pedidos, simultâneos ou não, de acesso aos dados a partir de um grande número de usuários dispostos em locais geograficamente diferentes. Após receber os pedidos o sistema deve honrá-los, transmitindo (sob demanda) o material solicitado ao usuário.

\section{SISTEMAS VOD}

Sistemas que se enquadram nas características acima descritas para servidores de dados multimídia são os sistemas de vídeo sob demanda, também conhecidos como sistemas VOD (Video-OnDemand) (Berger, 1995; veja também Little \& Venkatesh, 1994). Apesar de sistemas VOD concentrarem suas atenções no fornecimento de vídeo, suas técnicas e conceitos podem ser aplicados a outros tipos de mídia continua (como áudio e animação) ou não-contínua (texto, gráficos, etc.), de forma que sistemas VOD constituem uma boa base para a implementação de servidores de dados multimídia.

Uma característica marcante de sistemas VOD, assim como em sistemas multimídia em geral, é a interatividade. Segundo Fluckiger (1995), de acordo com o nível de interatividade, os serviços de
vídeo podem ser classificados em:

- Serviços Braadcast (No-VOD), similar aos canais de televisão, em que o usuário é um participante passivo e não possui nenhum controle sobre a sessão.

- Serviço Pay-Per-View (PPV), em que o usuário paga por uma programação especifica, similar ao serviço existente em CATV (Cable TV).

${ }^{24}$ RAID - Redendant Array of Inexpensive Disks 
- Serviço 2uasi video-on-demand (Q-VOD), em que os usuários são agrupados pelo interesse comum que possuem. Os usuários possuem um controle rudimentar, ativado por chaveamento para os diferentes grupos.

- Serviços Near Video-On-Demand (N-VOD), em que funções de avançar e voltar são simuladas por transições em um intervalo de tempo discreto (da ordem de 5 minutos). Isto é feito utilizando vários canais que possuem a mesma programação, porém em tempos diferentes.

- Serviço True Video-On-Demand (T-VOD), em que o usuário possui total controle sobre a apresentação podendo selecionar qualquer parte da programação a hora que desejar. $\mathrm{O}$ usuário tem todas as funções de $\mathrm{VCR}^{25}$, incluindo avançar, voltar, congelar e posicionar diretamente. TVOD aloca para cada usuário um canal exclusivo; com isso, o número de usuários do serviço pode ficar limitado pelo número de canais disponíveis. T-VOD necessita de um sinal bidirecional entre o usuário e o controle central. Serviços T-VOD são essenciais para aplicações como jogos interativos, onde todas as ações de um jogador são vistas pelos outros jogadores.

\section{ORGaNIZAÇÃo dos Dados}

Os dados devem ser organizados de maneira a prover funcionalidade na entrega de mídia contínua. Por outro lado, uma grande parte dos acessos ao sistema realizados pelos usuários visam obter apenas informações sobre os dados armazenados, como: tamanho do arquivo, data de criação, etc. Devido ao volume e a constituição desses dados, essas pesquisas levariam muito tempo, prejudicando a interatividade desejada. A utilização de índices para responder a esses tipos de pesquisa é uma boa alternativa, porém dados de mídia contínua necessitam de novas técnicas de indexação que simplifiquem o mecanismo de busca e aumentem a interatividade.

Dados multimídia consistem de dois componentes: os dados em si e a informação semântica contida nos dados (Griffioen et al., 1996). Diferente de dados alfanuméricos, tipicamente representados por valores ASCII, o conteúdo (valores de pixels, por exemplo) de dados multimídia não contém muita informação interessante. Dever-se-ia indexar a informação que os pixels representam, isto é, o conteúdo semântico dos dados ao invés de indexar os valores em si. Por exemplo, a pesquisa pela cadeia de caracteres alfanumérica 'abc' é direta. Porém, a pesquisa pela imagem de um carro ou pelo som de um leão em um videoclip requer a habilidade de acessar o conteúdo semântico dos dados. Esse conteúdo semântico é denominado metadado (Griffioen et al.).

A vantagem de se utilizar metadados é que essa abordagem permite ao usuário examinar o conteúdo da base de dados sem ter que recuperar objetos volumosos. O conceito de metadados é ideal para aplicações multimídia interativas nas quais vários objetos podem estar envolvidos em uma única apresentação. Por exemplo, um vídeo pode envolver a coordenação de streams de áudio e de vídeo. Um sistema de aprendizado com suporte eletrônico pode envolver a apresentação de áudio, vídeo, gráficos e texto. O servidor de metadados deve manter o relacionamento entre esses diversos objetos e informar sua presença para o cliente quando uma pesquisa é feita.

No contexto de um servidor VOD, o sistema deve armazenar diferentes atributos de vídeo. A identificação desses atributos é uma parte importante no projeto de uma base de metadados pois são esses atributos que irão responder às pesquisas do usuário. Desse modo, a identificação dos atributos é feita através da identificação das pesquisas realizadas pelo usuário, provendo índices para responder a essas perguntas. Índices podem ser: bibliográficos (título, assunto, gênero, diretor,

25 VCR: Video Cassete Recorder 
produtor, elenco, etc.); estruturais (hierarquia: filme-segmento-cena); de conteúdo (para buscas baseadas em conteúdo ou em palavras-chave associadas a um conteúdo) (Berger, 1995).

A utilização desses índices traz a vantagem adicional de prover suporte ao compartilhamento dos dados multimídia armazenados no servidor. Por exemplo, pode-se ter um documento onde um dos componentes é um vídeo e, um outro documento onde se deseja apenas uma imagem do mesmo vídeo. Esse segundo documento pode ser criado apenas pelo acesso aos índices dessa imagem específica, no arquivo original, ao invés de extrair a imagem do arquivo de vídeo e criar um novo arquivo para a imagem desejada.

\section{ARQUITETURA do Sistema}

A figura 1 mostra uma visão geral do sistema descrito até aqui baseado no paradigma cliente/servidor. O sistema é composto por um sistema servidor de dados multimídia (SDM), por um servidor de metadados (SM) e por clientes, sendo esses componentes interligados por uma rede.

O SDM e o SM podem estar na mesma máquina ou não.

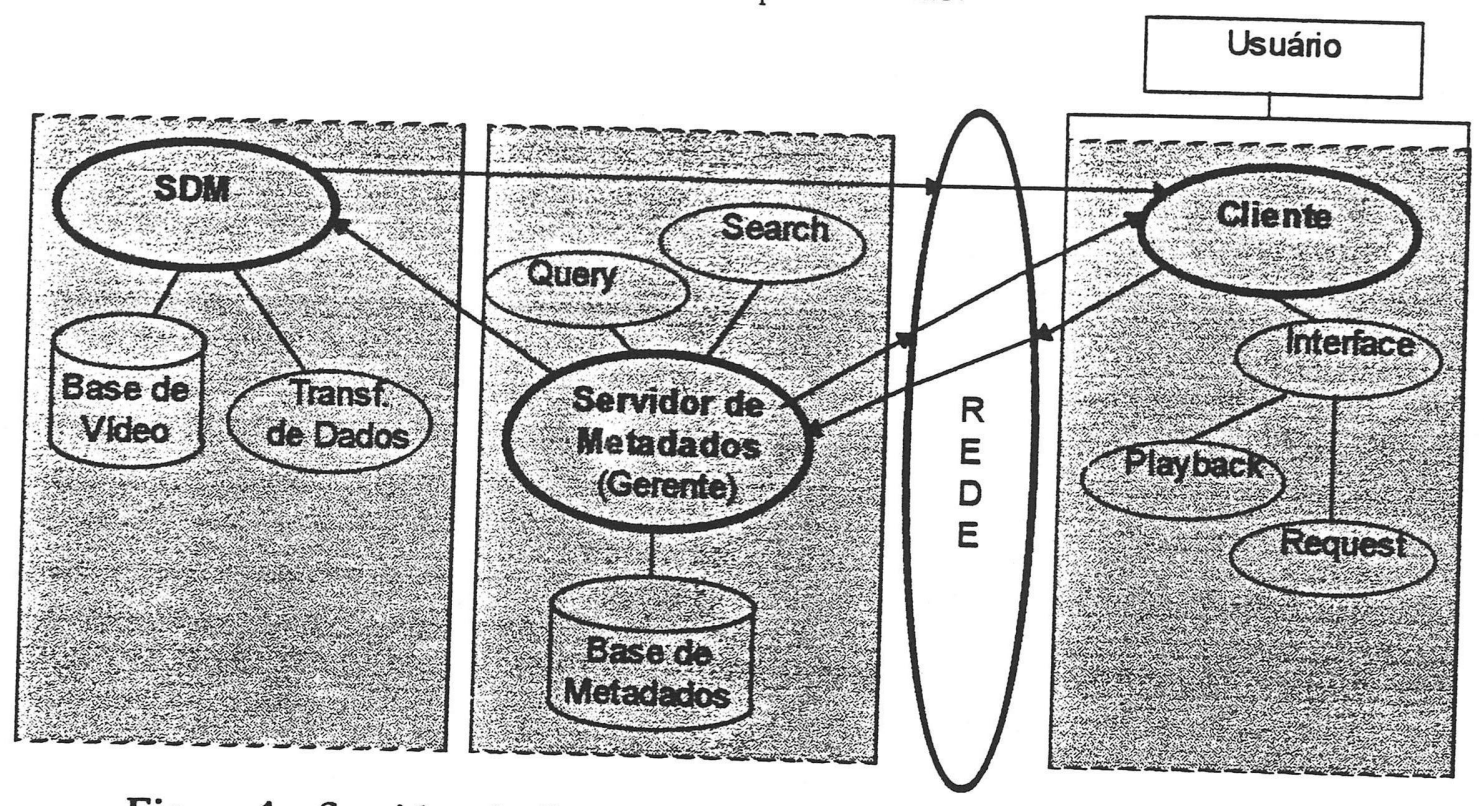

Figura 1 - Servidor de Dados Multimídia integrado ao Servidor de

Cada usuário utiliza uma máquina contendo um módulo cliente e um módulo de interface. O módulo de interface interage diretamente com o usuário e contém funções para enviar pesquisas, buscas e requisições de apresentação ao cliente (Request) e funções para exibir o resultado das pesquisas e buscas e/ou executar uma apresentação (Playback). O módulo cliente é responsável por executar as funções de baixo nível como empacotar os pedidos do usuário e enviá-los ao SM através da rede. Também é esse módulo que recebe a resposta de um pedido, enviada pelo SM ou pelo $\mathrm{SDM}$, e repassa essa resposta ao módulo de interface.

O SM, por sua vez, recebe um pedido do usuário e envia a resposta ao cliente que o solicitou - se for um pedido de pesquisa ou de busca (funções Query e Searcb), ou repassa o pedido para o SDM se for um pedido de execução (de um vídeo, por exemplo).

O SDM recebe um pedido (de um arquivo de áudio, por exemplo), e realiza a transferência dos 


\section{UM AMBIENTE DE APOIO AO APRENDIZADO}

As características do ambiente de apoio ao aprendizado proposto estão baseadas nos requisitos definidos nas seções anteriores. O ambiente é composto por aplicações de autoria e de apresentação hipermídia, implementadas pensando-se nos usuários finais: professores e alunos. Além disso, outras aplicações de apoio ao professor, tais como registro do comportamento dos alunos em bases de dados, devem estar disponiveis.

Às aplicações de autoria, estão associadas as funções de preparação do material do curso online, que será preparado pelo professor. O material dos cursos é descrito por módulos denominados sessões e a cada sessão podem estar associadas bases de dados (contendo informações sobre alunos e restrições de acesso, por exemplo) e recursos do sistema.

Para facilitar o processo de criação das sessões, o Interland fornece uma plataforma configurável; o professor pode, por exemplo, associar suas aplicações preferidas de edição de vídeo, áudio e páginas HTML às respectivas tarefas do ambiente.

Como complemento às capacidades fornecidas por essas ferramentas configuráveis, existe um conjunto de componentes que podem ser inseridos nas páginas HTML durante a edição das mesmas. Tais componentes consistem de scripts, aplicações Java (applets) e programas especiais que suportam tarefas específicas como: programas para acompanhamento dos alunos, servidores de aplicações colaborativas, etc.

\section{FORMAS DE ACESSO AO SISTEMA}

O acesso aos recursos e sessões do sistema Interland é feito através de uma série de clientes especiais. Foram definidos níveis de acesso para controlar quais informações cada usuário tem disponível para si (controle de sessões de vídeo, acesso aos conteúdos e resultados de provas, permissão para criar novas sessões, etc.), a saber: modo supervisor, modo professor e modo aluno. Os usuários são identificados pelo servidor HTTP através do módulo de identificação e classificados em uma dessas categorias (Moreira et al., 1995).

O cliente Supervisor é a interface com o usuário responsável pelas configurações específicas do sistema e por manter a integridade e disponibilidade dos serviços do mesmo. O supervisor tem todos os direitos de gerenciamento do servidor, validação de usuários e acessos, gerenciamento das bases de usuários e cursos.

O cliente Aluno provê um ambiente de estudo personalizado, no qual cada estudante recebe uma instância de sessão correspondente a cada curso elaborado pelo professor. Os alunos podem ser distribuídos em grupos, para executar uma mesma tarefa (que poderá ter relatórios individuais ou conjuntos), atribuindo-se a eles um determinado conjunto de tarefas e privilégios. Esse cliente pode ser utilizado de várias maneiras: (1) em aula, para acompanhamento de exposição feita ao vivo pelo professor, que aciona através de seu computador procedimentos que são mostrados na tela das máquinas de cada aluno; (2) em aula, como o principal instrutor, sendo que nesse caso o professor prepara a aula e a deixa disponível aos alunos, obtendo uma "aula automática", possivelmente com a presença de monitores; (3) para preparar documentos (relatórios, exercícios práticos, etc.); (4) como elemento de comunicação.

Os professores pertencem a um grupo especial, com privilégios excepcionais, que incluem acesso aos aplicativos de gerenciamento. Dessa maneira, o professor poderá preparar um conjunto de objetos para serem utilizados assincronamente por ele durante a aula, ou para formarem o corpo de uma aula (através de scripts) que ficará disponível no servidor para acesso pelos alunos durante uma sessão. Os scripts permitirão ao professor adicionar gráficos, textos, vinhetas, animações, vídeos, aplicações compartilhadas, entre outros recursos. 
O cliente Professor se propõe a auxiliar o professor na tarefa de preparação do material didático dentro do sistema Interland, através de módulos. Suas funções principais são:

1. Oferecer modelos e conjuntos de hiperdocumentos que visem uma estrutura simples e eficiente para a implementação do material didático. Além de oferecer modelos, o cliente Professor também aceita documentos previamente existentes para organizar um conjunto de hiperdocumentos.

2. Prover ferramentas de desenvolvimento e controle para uso de recursos interativos e de multimídia no material. Programas para submissão de formulários, entre outros recursos de interação, serão implementados através da ativação de aplicativos auxiliares pelo cliente Professor. Em especial, um módulo do cliente Professor é um cliente para comunicação com o SDM.

3. Dar acesso a aplicativos para a montagem de sessões; apresentar informações relacionadas a alunos e grupos de alunos, para fins de avaliação e acompanhamento de desempenho. Para isso, o cliente Professor estará realizando consultas aos bancos de dados com informações sobre alunos e sessões.

4. Atuar como interface de controle de apresentações em tempo real, pela ativação do cliente SDM.

Além dessas funções, o cliente Professor conta com um módulo de ajuda que satisfaz tanto as necessidades de usuários que já conhecem o sistema como aqueles que o utilizam pela primeira vez. Os recursos do módulo de ajuda estarão sempre disponíveis, acompanhando as atividades do professor para sugerir modificações e realizar algumas correções automáticas.

Assim, pretende-se evitar que o professor se preocupe com estilo de documentos, gerenciamento de hipertexto e dados multimídia, e detalhes de implementação do próprio sistema Interland.

\section{UM EXEMPlo de Componente: Sessões ConTroladas de Vídeo}

Um exemplo de componente interessante que pode ser utilizado em diversas situações de treinamento é a sessão de vídeo controlada. A função desse componente é permitir a apresentação de um trecho de vídeo (eventualmente, mais de um) para diversos alunos ao mesmo tempo e, além disso, permitir que o professor tenha total controle sobre a execução do mesmo.

Um caso de uso desse componente ocorre na situação em que o professor deseja apresentar um vídeo e parar em posições predeterminadas ou não para explicar um assunto correlacionado e depois continuar a execução. Se, por exemplo, um aluno solicitar um detalhamento sobre um ponto específico do vídeo, o professor pode marcar um trecho do mesmo através de seu console e executar novamente esse trecho em todas as máquinas que estão assistindo a sessão, em um subconjunto dessas máquinas ou apenas na máquina do aluno que solicitou a informação.

Em termos de autoria, o professor deverá apenas escolher esse componente e fomecer parâmetros como o trecho de vídeo a ser utilizado; e a ferramenta de edição será responsável pela inclusão dos tags e scripts necessários na página HTML para execução do componente.

Em termos de apresentação, os alunos deverão carregar a página contendo o componente $e$ este último encarregar-se-á, transparentemente, de tarefas como: registro com o servidor de controle e início da transferência do trecho do vídeo do servidor apropriado para a máquina local. Alternativamente, em sistemas não baseados em páginas como a WWW, o professor pode ativar o programa de apresentação controlada de vídeo nas máquinas dos alunos através de comandos remotos.

Restrições quanto à utilização desse componente em aplicações voltadas para a Internet certamente são aplicáveis, uma vez que a infra-estrutura existente ainda não formece suporte para 
entrega de dados em tempo real e garantia de qualidade de serviço. No entanto, a utilização de vídeo em redes intemas (intranets) é uma realidade (Birkmaier, 1997).

\section{CONCLUSÃo}

Este artigo apresentou uma proposta de ambiente de apoio ao aprendizado utilizando multimídia. Esse ambiente (o Interland) fomece ferramentas para auxiliar na edição e apresentação de documentos contendo objetos multimídia.

A proposta do ambiente Interland inclui implicita ou explicitamente todas as características pertinentes a sistemas hipermídia sugeridas por Harrison (1995), de forma que temos bons indícios para uma implementação bem sucedida do sistema. Alguns componentes estão em fase final de implementação, sendo assim, esperamos poder realizar em breve testes de integração e de desempenho (mesmo que parciais).

\section{REFERÊNCIAS BIBLIOGRÁFICAS}

Allinson, L., \& Hammond, N. (1989). A leaming support environment - The hitchhiker's guide. In R. McAleese (Ed.), Hypertext: Theory into practice. (pp. 62-74). Norwood, NJ: Ablex Publishing Corporation.

Araribóia, G. (1989). Inteligência artificial - Um curso prático. Rio de Janeiro: Livros Técnicos e Científicos Ltda.

Baeker, R. M., \& Buxton, W. A. S. (1987). A historical and intellectual perspective. In R. M. Baeker, \& W. A. S. Buxton (Eds.), Readings in buman computer interaction: $A$ multidisciplinary approach (pp. 41-54). Los Altos, CA: Morgan Kaufmann.

Barker, P., \& Manji, K. (1992). Computer-based training: An institutional approach. Education \& Computing, 8, 229-237.

Berners-Lee, T., Cailliau, R., Luotonen, A., Nielsen, H. F., Secret, A. (1994). The world-wide web. Communications of the ACM, 37 (8), 76-82.

Berger, D. (1995). Video-on-demand metadata query interfaces [Tese de mestrado]. Berkeley: Universidade da Califómia.

Birkmaier, C. (1997). What are the prospects for video on the net? How video might be coming soon to a PC, NC or TV near you [Online]. Available: http://www.netscapeworld.com/nw-01-1997/nw-01-videotech.html. [12 de março de 1997].

Buford, J. F. K. (Ed.) (1994). Uses of multimedia information. In Multimedia systems. New York, NY: Addison-Wesley.

Castro, M. A. S. (1996). Pesquisa científica e os novos ambientes eletrônicos. In Catálogo eletrônico da $48^{a}$ reunião anual da SBPC (PUC-SP, julho, 1996). [CD-ROM]. Available: Infoco Consultoria de Sistemas/Mesa Redonda.

Duncan, E. B. (1989). A faceted approach to hypertext?. In R. McAleese (Ed.), Hypertext: Theory into practice (pp. 157-163). Norwood, NJ: Ablex Publishing 
Corporation.

Federighi, C., \& Rowe, L. A. (fevereiro de 1994). A distributed hierarchical manager for a video-on-demand system. Proc. of Symp. On Elec. Imaging Sic. ev Tech., 185-197.

Ferreira, A. B. H. (1988). Dicionário Aurélio básico da lingua portuguesa. Rio de Janeiro: Editora Nova Fronteira S/A.

Fluckiger, F. (1995). Understanding networked multimedia applications and technology. Hemel Hempstead, UK: Prentice-Hall.

Gibbs, S. J. \& Tsichritzis, D. C. (1995). Multimedia programming - Objects, environments and frameworks. Wokinghan, Inglaterra: Addison-Wesley.

Greenfield, P. M. (1987). Electronic technologies, education, and cognitive development. In D. E. Berger, K. Pezdek, \& W. P. Banks (Eds.), Applications of cognitive psychology: Problem solving, education and computing (pp. 17-32). Hillsdale, NJ: Lawrence Erlbaum Associates.

Griffioen, J., Yavatkar, R., \& Adams, R. (1996). Automatic and dynamic identification of metadata in multimedia, [Online]. Available: http://www.computer.org/conferen/meta96/adams/paper.html [2 de novembro de 1996].

Harrison, M. A. (1995). The essential elements of hypermedia. In Eamshaw, R. A., \& Vince, J. A. (Ed.), Multimedia systems do applications (pp. 79-99). San Diego: Academic Press.

Lee, E. K., Chen, P. M., Hartman, J. H., Drapeau, A. L. C., Miller, E. L., Katz, R. H., Gibson, G. A., \& Patterson, D. A. (abril de 1994). RAID-II: A scalable storage architecture for high-bandwidth network file service. Proc. of $21^{5 t}$ International Symposium on Computer Architcture, 234-244.

Lindstron, R. L. (1995). Guia business week para apresentações em multimídia. São Paulo: Makron Books.

Little, T.D.C., \& Venkatesh, D. (junho de 1994). Client server metadata management for the delevery of movies in a video-on-demand system. Proc. of 1st Inth. Workshop on Services in Distributed and Netwoked Enviroments, 11-18.

Lougher, P., \& Shepherd, D. (1993). The design of a storage server for continuous media. The Computer Journal, 36 (1), 32-42.

McAleese, R. (1989). Navigation and browsing in hypertext. In R. McAleese (Ed.), Hypertext. Theory into practice (pp. 6-44). Norwood, NJ: Ablex Publishing Corporation.

McKnight, C., Richardson, J., \& Dillon, A. (1989). The authoring of hypertext documents. In R. McAleese (Ed.), Hypertext. Theory into practice. (pp. 138-147). Norwood, NJ: Ablex Publishing Corporation.

Moreira, E. S., Nunes, M. G. V., \& Pimentel, M. G. C. (dezembro de 1995). Design 
issues for a distributed hypermedia-based tutoring system (HyDTS). Proc. of International Conference on Computer Application in Industry, 108-113.

Nielsen, J. (1990). Hypertext ér bypermedia. Boston: Academic Press.

Norman, A. D., \& Spohrer, J. C (1996). Learner-centred education. Communications of the ACM, 39 (4), 24-27.

Norman, K. L. (1997). Teaching in the switched on classroom: An introduction to electronic education and bypercourseware, [Online]. Available: http://www.Lap.umd.edu/SOC/sochome.html [9 de março de 1997].

Ringsted, M. (1994). On-site distance leaming. A multimedia full-scale experiment in Denmark. In A. D. N. Edwards, \& S. Holland (Eds.), Multimedia Interface Design in Education (NATO ASI Series, $1^{2}$. reimpressão corrigida) (pp. 45-56). Berlin: SpringerVerlag.

Skillicom, D. B. (1996). Using distributed hypermedia for collaborative learning in universities. The Computer Journal, 39, 471-482.

Streitz, N. A. (1994). Foundations of hypermedia design. In W. Schuler, J. Hannemann, \& N. A. Streitz (Eds.), Designing user interfaces for bypermedia (ESPRIT Research Reports, Project 6532, volume 1) (pp. 1-3). Berlim: Springer-Verlag. 


\section{UTILIZAÇÃo de MUlTimídia EM AMBIENTES EdUCACIONAIS BASEADOS EM WWW}

Edson dos Santos Moreira, Elderclei Regis Reami, Rudinei Goularte, Maria Alice Soares de Castro

Departamento de Ciências de Computação e Estatística - ICMSC - USP - São Carlos

ICMSC-USP, Seção de Pós-Graduação, Av. Dr. Carlos Botelho, 1465. Cx. Postal 668 São Carlos SP

(\{edson, reami, rgoulart, masc\}@icmsc.sc.usp.br)

Palavras-chave: Multimídia, Hipermidia, Informática na Educação, Vídeo na Internet.

\section{RESUMO}

A utilização de recursos multimídia e hipermídia em materiais didáticos melhora o entendimento e a retenção do conteúdo pelos estudantes. No entanto, para que a utilização desses novos recursos seja efetiva é necessário observar uma série de detalhes envolvidos na produção daqueles. Devido à novidade que os recursos multimídia representam, muitos aspectos da inserção de áudio, vídeo e animações nos materiais didáticos não são amplamente conhecidos. Detalhes sutis representam grandes diferenças na qualidade de apresentação desejada. A questão é ainda mais complexa quando se trata da utilização desses recursos na WWW, através da Internet. $\mathrm{O}$ objetivo deste artigo é apresentar os problemas envolvidos na produção dessas mídias fornecendo subsídios para que a utilização das mesmas em material didático obtenha um bom resultado.

\section{ABSTRACT}

The use of multimedia and hypermedia resources in didatic materials certainly enhances understanding and absortion of contents by students. However, in order to make such resources effective on their purpose, one should be aware of the inherent technical issues involved in the production of multimedia content. Problems are even worth when the resulting production must be distributed through computer networks, such as the Internet. This article aims to present the issues surrounding media production and to establish some guidelines for that future projects can offer better results.

\section{INTRODUÇÃo}

Os seres humanos se utilizam de multimídia no seu processo de comunicação, e essa comunicação multimídia auxilia no processo cognitivo ao atuar no processamento de informações (Greenfield, 1987).

Por sua vez, as tecnologias de comunicação exercem a função de disseminadores de conhecimento, liberando estudantes e professores das limitações de tempo e espaço, enriquecendo o ensino com recursos de multimídia, interação, simulações, e permitindo o estudo individualizado. A Internet, como meio de implementação de sistemas didáticos, adiciona a faculdade de se levar tais facilidades de aprendizado a um público maior, podendo diminuir diferenças regionais e quebrando o ciclo de isolamento dos núcleos educacionais e científicos.

Empregar novas tecnologias no ensino não implica em sucesso no aprendizado. Acima de tudo, é necessário haver motivação e abertura das pessoas envolvidas com a nova ferramenta, dando oportunidade ao surgimento de uma nova maneira de ensinar e aprender. As diversas experiências com Tecnologia da Informação no ensino obtêm sucesso quando, além da consulta e apresentação de textos on-line, cada tarefa oferece métodos e tecnologias apropriadas, com grande ênfase na comunicação. Greenfield (1987) comenta que cada meio de comunicação apresenta 
características que o tomam mais adequado do que outros para determinados tipos de informação. Esse fato influi no processo cognitivo ao atuar sobre os sentidos, ativando conjuntos específicos de habilidades responsáveis pelo processamento de informações. Em contraste, a "comunicação monomídia" limita o processo de comunicação, por não considerar os outros canais através dos quais naturalmente enviamos e adquirimos informações (Lindstron,1995). Portanto, as mídias desempenham papéis complementares no processo de aprendizado, o que aponta em direção a um sistema de educação multimídia.

Além disso, é necessário que essas novas tecnologias, como toda ferramenta, sejam empregadas de forma correta e para isso é preciso saber o que pode ser utilizado, onde e como utilizar, além de alguns detalhes técnicos para se obter a qualidade desejada e explorar todo o potencial oferecido.

Este artigo está dividido da seguinte forma: a seção 2 descreve as motivações e os meios de utilização de vídeo digital em computadores, apresentando os tipos de vídeo mais utilizados, as formas de aquisição, apresentação de vídeo na Web e comparações de algumas tecnologias de vídeo, como MPEG, AVI, MOV, VDO e VXtreme; a seção 3 mostra as formas de aquisição e codificação de áudio digital, compressão de áudio, formatos de arquivos, utilização de áudio na Web; a seção 4 discute as formas de apresentação de animações em computadores e na Web; por fim, a seção 5 apresenta uma breve conclusão sobre os assuntos discutidos.

\section{UTILIZAÇÃo de VÍDEO Digital}

O movimento atrai o ser humano, estimulando o interesse, aumentando a compreensão e melhorando a retenção da informação. O movimento (em forma de vídeo) tem sido usado para: atrair a atenção; transportar o espectador a outros locais; transpor barreiras de cultura, linguagem e analfabetismo; treinar pessoas de forma ágil em novas ferramentas; dar credibilidade ao apresentador, à mensagem e à organização; entre outras. Quando usado de forma correta, o vídeo fornece ao público informações que ele não entenderia tão bem de outra forma, possuindo a capacidade de comunicar a maior quantidade de informação no menor tempo possível e com maior impacto.

Lindstrom (1995) cita que, em geral, a utilização de vídeo se destaca nas seguintes áreas de apresentação: descrever movimento; demonstrar procedimentos; transmitir emoção e simular situações. Além disso, o vídeo tem se tomado uma ferramenta imprescindível para a comunicação de informações, a ponto de emissoras de TV colocarem alguns de seus programas na Internet (como a CNN, por exemplo).

O vídeo surgiu na forma analógica e, somente mais tarde, a partir da evolução dos métodos de gravação analógicos e da tecnologia de computador, surgiu o vídeo digital. O vídeo capturado analogicamente, antes de ser armazenado, passa por um processo de digitalização, e através desse processo os valores analógicos da imagem são codificados em valores digitais (bits) (Luther, 1995). Já existem câmeras que capturam imagens de forma digital (as chamadas câmeras digitais). O computador armazena a informação de vídeo digital como código binário, do mesmo modo que armazena fotos, ilustrações, ou qualquer outro tipo de informação. A diferença é que as imagens de vídeo são sincronizadas, sendo os quadros apresentados a uma velocidade constante e rápida (em geral entre 15 e 30 quadros por segundo) para dar a ilusão de movimento.

Entre as vantagens da utilização de vídeo digital no desenvolvimento e realização de apresentações estão (Lindstrom, 1995):

- Economia de custo: software e hardware, mais baratos que os equipamentos analógicos profissionais, podem produzir vídeo com qualidade razoável, além de reduzir o tempo de edição. 
- Interatividade ampliada: devido aos discos rígidos (rápidos) realizarem acessos aleatórios quase instantaneamente, pode-se parar, retroceder ou avançar a apresentação de uma maneira bastante satisfatória.

- Flexibilidade aumentada: pelo fato do vídeo analógico ser baseado no tempo, ele somente pode ser armazenado no tamanho total da tela na qual foi capturado. Se o vídeo for reproduzido em uma pequena janela na tela, ainda assim ele deve conter toda a informação de sinais para uma tela inteira. O vídeo digital pode ser capturado e armazenado de acordo com o tamanho particular da apresentação final.

- Maleabilidade: o vídeo digital permite que se façam alterações de forma mais rápida e fácil, também permite a utilização de modelos.

\section{Produção de Vídeo Para Computadores} Existem duas alternativas para a produção de vídeo para uso em computadores: a produção digital e
a produção analógica.

$\mathrm{Na}$ produção digital um computador está presente durante todo o processo de captura. Como vantagem essa alternativa elimina o passo adicional da digitalização e evita possíveis degradações de qualidade vindas da utilização do tape analógico; porém necessita de muito espaço em disco.

A produção analógica tem como vantagens não necessitar de um computador para a captura de vídeo e o tapte para armazenamento é barato. As desvantagens são que para obter os melhores resultados são necessários equipamentos de gravação profissionais (caros), além de necessitar passar pelo processo de digitalização (Luther, 1995).

A decisão de qual tipo de produção utilizar (digital ou analógica) depende de vários fatores: do nível de qualidade desejada para o vídeo final; de aspectos econômicos; da quantidade de editoração (pósprodução) desejada (Lindstrom, 1995).

O grande problema para a utilização de vídeo digital é o tamanho dos arquivos gerados. Uma produção simples com 1 minuto de duração, quadros com tamanho $640 \times 480$, taxa de captura de 15 quadros por segundo e com 16 milhões de cores (24 bits), necessita de uma taxa de transferência de $14 \mathrm{MB}^{26}$ por segundo, que é maior que as taxas de CD-ROMs ou mesmo discos rígidos. $O$ tamanho desse arquivo (sem compactação) chega a 800MB. Dessa forma, a compressão (também chamada de compactação) torna-se crucial para a utilização de vídeo em computadores, embora ela
degrade a qualidade.

Para ser exibido, o vídeo deve ser descomprimido em tempo real e então apresentado. Existem três maneiras de se apresentar vídeo em um computador, que serão discutidas abaixo.

A primeira é utilizando um hardware especialista para realizar a descompressão e a apresentação, obtendo uma melhor qualidade. O padrão MPEG (Moving Pictures Experts Group) é uma das principais técnicas para esse tipo de apresentação.

MPEG é o nome do comitê ISO que trabalha com compressão de áudio digital e vídeo (colorido) digital. A especificação MPEG é desenvolvida especialmente para permitir a transmissão de imagens padrão broadcast com alta qualidade. Existem 3 versões de MPEG: MPEG-1, para transmissão de vídeo qualidade VHS (em tomo de $1.5 \mathrm{Mbps}$ ); MPEG-2, para transmissão de vídeo com velocidades entre 3 e $10 \mathrm{Mbps}$; MPEG-4 (o MPEG-3 foi abandonado), que se destina a ser um padrão extremamente poderoso para videofone e videoconferência (Luther, 1995).

Uma placa para descompressão MPEG custa entre 250 e 1500 dólares, oferecendo alta qualidade de apresentação. Também existem softwares para descompressão MPEG, porém a qualidade da apresentação é bastante degradada. Já as placas para captura (compressão) são bem mais caras, podendo chegar a 20000 dólares. Então, devido aos altos custos para aquisição de vídeo

${ }_{26} \mathrm{MB}$ : significa Megabytes, enquanto Mb significa Megabits. 
MPEG, normalmente captura-se o vídeo em algum outro formato (discutiremos alguns mais adiante) convertendo-o para MPEG (por meio de softwares de conversão disponíveis na Web) e, realiza-se a apresentação por hardware. O processo de conversão, na maioria das vezes, degrada um pouco a qualidade.

A segunda forma de apresentação de vídeo é utilizando softwares (conhecidos como players ou CODECs) para realizar a descompressão e a apresentação. Esta forma consome muita memória e requer muito trabalho do processador, então geralmente os vídeos apresentados por este método são exibidos em pequenas janelas na tela (algo como 160x120, isto equiivale ao tamanho do quadro).

Um player utiliza um formato de arquivo de vídeo padrão, como MOV e AVI (MOV e AVI também são as extensões dos nomes dos arquivos) que serão discutidos adiante. Os players mais populares são o video for Windows (VFW) e o QuickTime.

$\mathrm{O}$ formato AVI (Audio-Video Interleaved) é utilizado pelo video for Windows (VWW) da Microsoft, que é um pacote constituído de drivers com algoritmos instaláveis e um conjunto de ferramentas para captura, edição e apresentação de áudio e vídeo em ambiente Windows.

O formato MOV foi originalmente projetado para ser utilizado com o player QuickTime em máquinas Macintosh. Mais tarde a Apple Computers lançou uma versão para Windows do seu Player, o QuickTime for Windows, que também utiliza extensão MOV para nomes de arquivos. O QuickTime for Windows possui algumas facilidades para a editoração de vídeo, embora sejam bastante rudimentares.

MOV e AVI são muito parecidos no que diz respeito à forma de apresentação e plataformas. Ambos podem ser apresentados via player ou na Web via um plug-in instalado em um Browser, ambos possuem taxas de compressão menores que as do MPEG, foram projetados para realizar apresentação sem auxílio de hardware e consomem muito processador e memória. Quando é necessária uma editoração mais apurada, utilizam-se softwares especiais, como o Adobe Premiére, que também realiza conversão AVI-MOV.

A terceira forma é utilizar software para a apresentação do vídeo e hardware para ajudar na descompressão, aumentado a qualidade. Este hardware é um acelerador gráfico, que têm como vantagens: prover descompressão via hardware, o que aumenta a taxa de transferência de dados; capturar e enviar dados mais rapidamente para a tela, o que possibilita tamanhos de quadros maiores. Apesar dos aceleradores melhorarem o desempenho e a qualidade da apresentação, a apresentação via hardware ainda é superior. formatos.

A tabela 3.1 compara o mesmo vídeo (Luther, 1995a) de 15.4 segundos gravado em vários 
Tabela 3.1: Comparação utilizando configurações diferentes

\begin{tabular}{|c|c|c|c|c|c|c|c|c|c|}
\hline \multirow{2}{*}{$\begin{array}{c}\text { Arquiv } \\
0\end{array}$} & \multicolumn{4}{|c|}{ Áudio } & \multicolumn{4}{|c|}{$\overline{\text { Video }}$} & \multirow{2}{*}{$\begin{array}{c}\text { Tama } \\
\text { nho }\end{array}$} \\
\hline & $\begin{array}{l}\text { Amos } \\
- \\
\text { trage } \\
\mathrm{m} \\
\end{array}$ & $\begin{array}{l}\text { Cana } \\
1\end{array}$ & $\begin{array}{l}\text { Bit p/ } \\
\text { Amos } \\
\text { t. }\end{array}$ & $\begin{array}{l}\text { Comp } \\
\text { r. }\end{array}$ & $\begin{array}{l}\text { Tam. } \\
\text { Fram } \\
\text { e }\end{array}$ & $\underset{27}{\text { FPS }}$ & Cor & Compr. & \\
\hline MPEG & $\begin{array}{l}44.1 \\
\mathrm{kHz}\end{array}$ & mono & 16 & $\underset{1}{\mathrm{MPEG}}$ & $\begin{array}{c}352 X \\
240\end{array}$ & 30 & $\begin{array}{c}\mathrm{YCb} \\
\mathrm{Cr} \\
4: 2: 0 \\
\end{array}$ & $\begin{array}{c}\mathrm{MPEG} \\
1\end{array}$ & $\begin{array}{c}3.1 \mathrm{M} \\
\mathrm{B}\end{array}$ \\
\hline $\mathrm{MOV}$ & $\begin{array}{l}44.1 \\
\mathrm{kHz}\end{array}$ & mono & 8 & $\begin{array}{c}\text { não } \\
\text { compr. }\end{array}$ & $\begin{array}{c}320 \mathrm{X} \\
240\end{array}$ & 25 & $\begin{array}{c}24 \\
\text { bits }\end{array}$ & $\begin{array}{c}\text { Apple } \\
\text { Compa } \\
\text { ct } \\
\text { Video } \\
\end{array}$ & $\begin{array}{c}3.6 \mathrm{M} \\
\mathrm{B}\end{array}$ \\
\hline AVI & $\begin{array}{l}22.05 \\
\mathrm{kHz}\end{array}$ & mono & 8 & $\begin{array}{c}\text { não } \\
\text { compr. }\end{array}$ & $\begin{array}{c}320 X \\
240 \\
\end{array}$ & 25 & $\begin{array}{c}24 \\
\text { bits }\end{array}$ & Cinepak & $\begin{array}{c}3.4 \mathrm{M} \\
\mathrm{B} \\
\end{array}$ \\
\hline AVI & $\begin{array}{l}22.05 \\
\mathrm{kHz} \\
\end{array}$ & mono & 8 & $\begin{array}{c}\text { não } \\
\text { compr. }\end{array}$ & $\begin{array}{c}320 \mathrm{X} \\
240 \\
\end{array}$ & 25 & $\begin{array}{c}24 \\
\text { bits } \\
\end{array}$ & Indeo & $\begin{array}{c}3.3 \mathrm{M} \\
\mathrm{B} \\
\end{array}$ \\
\hline
\end{tabular}

Os vídeos da tabela 3.1 possuem configurações diferentes, porém nota-se que mesmo possuindo taxas de amostragem e tamanho de quadro maiores, o arquivo MPEG é menor, resultado do algoritmo de compressão (MPEG-1) utilizado. O impacto do algoritmo de compressão também pode ser constatado nos dois arquivos AVI, eles possuem os mesmos atributos, a menos do algoritmo de compressão. Cada um desses diferentes atributos influi diretamente na qualidade de imagem e de apresentação (desempenho) do vídeo, quanto maiores, melhor será o resultado, porém maior será o arquivo gerado. Dentre esses quatro, o vídeo MPEG apresentou melhor qualidade de imagem e de apresentação. O vídeo AVI com compactação Indeo obteve qualidade de imagem melhor que o vídeo MOV e que o vídeo AVI com compactação Cinepak, estes dois apresentando qualidade de imagem muito próximas. A apresentação do vídeo MOV foi melhor que a dos AVIs. Utilizando o vídeo da tabela 3.1, mas agora aplicando o mesmo compressor (Indeo) e as mesmas configurações, o vídeo MOV apresentou melhores desempenho e qualidade de imagem que o vídeo AVI, tanto na forma comprimida quanto na forma não comprimida (tabela 3.2).

${ }^{27}$ FPS: Frames Por Segundo (fps), é o número de quadros de vídeo apresentados em um segundo. 
Tabela 3.2: Comparação utilizando o mesmo compressor

\begin{tabular}{|c|c|c|c|c|c|c|c|c|c|}
\hline \multirow[t]{2}{*}{ Arquivo } & \multicolumn{4}{|c|}{ Áudio } & \multicolumn{4}{|c|}{ Vídeo } & \multirow{2}{*}{$\begin{array}{c}\text { Tama- } \\
\text { nho }\end{array}$} \\
\hline & $\begin{array}{l}\text { Amos- } \\
\text { tragem }\end{array}$ & Canal & $\begin{array}{l}\text { Bit p/ } \\
\text { Amost } \\
\end{array}$ & Compr. & $\begin{array}{l}\text { Tam. } \\
\text { Fram } \\
\mathrm{e} \\
\end{array}$ & $\begin{array}{l}\text { FP } \\
S\end{array}$ & Cor & Compr. & \\
\hline$\overline{\mathrm{MOV}}$ & $\begin{array}{l}22.05 \\
\mathrm{kHz}\end{array}$ & mono & 8 & $\begin{array}{c}\text { não } \\
\text { compr. }\end{array}$ & $\begin{array}{c}320 \mathrm{X} \\
240 \\
\end{array}$ & 25 & $\begin{array}{c}24 \\
\text { bits } \\
\end{array}$ & Indeo & $\begin{array}{l}3.81 \\
\mathrm{MB} \\
\end{array}$ \\
\hline $\mathrm{AVI}$ & $\begin{array}{l}22.05 \\
\mathrm{kHz}\end{array}$ & mono & 8 & $\begin{array}{c}\text { não } \\
\text { compr. }\end{array}$ & $\begin{array}{c}320 \mathrm{X} \\
240 \\
\end{array}$ & 25 & $\begin{array}{c}24 \\
\text { bits }\end{array}$ & Indeo & $\begin{array}{l}3.81 \\
\mathrm{MB} \\
\end{array}$ \\
\hline $\mathrm{MOV}$ & $\begin{array}{l}22.05 \\
\mathrm{kHz}\end{array}$ & mono & 8 & $\begin{array}{c}\text { não } \\
\text { compr. }\end{array}$ & $\begin{array}{c}320 \mathrm{X} \\
240 \\
\end{array}$ & 25 & $\begin{array}{c}24 \\
\text { bits }\end{array}$ & $\begin{array}{l}\text { uncom- } \\
\text { pressed }\end{array}$ & $120 \mathrm{MB}$ \\
\hline AVI & $\begin{array}{l}22.05 \\
\mathrm{kHz}\end{array}$ & mono & 8 & $\begin{array}{c}\text { não } \\
\text { compr. }\end{array}$ & $\begin{array}{c}320 \mathrm{X} \\
240 \\
\end{array}$ & 25 & $\begin{array}{c}24 \\
\text { bits }\end{array}$ & $\begin{array}{l}\text { uncom- } \\
\text { pressed }\end{array}$ & $\begin{array}{c}119.5 \\
\mathrm{MB}\end{array}$ \\
\hline
\end{tabular}

\section{APRESENTAÇÃo de VídeO EM REdES de COMPUTAdoreS} Existem duas formas principais para a apresentação de vídeo em redes de computadores: o
downloading e o streaming video.

O processo de downloading, bastante comum na Web, consiste em conectar um computador remoto e transferir um arquivo deste para ser apresentado em seu computador. A transferência ocorre através de protocolos de transmissão de dados pela rede (como FTP e HTTP), podendo-se utilizando um browser. Nesse processo, o arquivo é primeiramente todo transferido para depois ser utilizado. Esse meio de transferência é geralmente lento, por isso os vídeos disponíveis na Web via downloading raramente possuem alta resolução (para reduzir o tamanho do arquivo). Uma vez que o arquivo tenha sido transferido, o vídeo pode ser apresentado em um Browser através de plug-in ou em
um player.

No processo de streaming video, assim que os primeiros dados chegam ao seu destino eles são apresentados, enquanto a fonte continua a transmitir. Não existe uma fase intermediária de armazenamento entre a transmissão e a apresentação.

Existem diversos fatores a serem considerados na transmissão streaming video. $O$ vídeo, como todo dado de mídia contínua (mídias que variam com o tempo), é gerado a uma certa taxa e deve ser apresentado nessa mesma taxa, de forma que o vídeo apresenta características de tráfego contínuo, exigindo uma taxa contínua de transmissão. Cada quadro tem um tempo limite para a sua apresentação (deadline), se esse tempo for ultrapassado, ocorrerão tremores na imagem (jitter) (Buford, 1994). Explicando de forma mais detalhada, imagine um vídeo com 10 minutos de duração sendo transmitido de uma máquina à outra através da rede. $O$ quadro número 15 (hipotético) deve ser apresentado no tempo 1'00", o quadro $16 \mathrm{em} \mathrm{1'03',} \mathrm{e} \mathrm{assim} \mathrm{por} \mathrm{diante.} \mathrm{Se} \mathrm{o} \mathrm{quadro} 16$ sofre um atraso na sua transmissão, ele poderá chegar no tempo 1'06", que é o deadline para a apresentação do quadro 17. Então, ou o quadro 16 será descartado ou será apresentado, causando tremores ou congelando a imagem por alguns instantes.

Se o propósito é a transmissão do vídeo em uma pequena rede local, os problemas podem desaparecer, dependendo da tecnologia de rede utilizada:

- Ethernet: apesar de ser uma tecnologia barata e bastante disseminada, não é adequada à transmissão de vídeo (mesmo em redes locais) devido às suas baixas velocidades de transmissão 
(10 Mbps), a não ser determinística e a ocorrência muitas colisões provocando atrasos, principalmente em situações de altas cargas (como no caso da transmissão de vídeo) (Comer,
1995).

- FDDI: é uma tecnologia mais cara que a Ethernet, porém transmite a $100 \mathrm{Mbps}$, o que a torna uma boa candidata para pequenas e médias produções multimídia. (Comer, 1995).

- ATM: a tecnologia ATM apresenta diversas facilidades ao suporte de dados multimidia, transmitindo a velocidades entre 155 e $600 \mathrm{Mbps}$. É atualmente a tecnologia mais apropriada para a transmissão de dados multimídia em geral, contudo ainda é uma tecnologia cara (Comer, 1995; Tanenbaum, 1996).

Streming video é o modo de transmissão adotado para a apresentação de programas ao vivo pela Web e para a realização de videoconferências. Apesar de todos os problemas discutidos, existem tecnologias já bem desenvolvidas para suportar vídeo em tempo real através da Internet. VDO e VXtreme são duas dessas tecnologias. Ambas utilizam arquivos AVI sem compressão, convertem e comprimem o mesmo para seus próprios formatos. O VDO utiliza o formato vdo e o VXtreme utiliza o formato vxi. As taxas de compressão chegam a 500:1 com o VXtreme, muito superiores às taxas de MOVs e AVIs. A qualidade de apresentação é impressionante, em se tratando de transmissão de vídeo pela Internet. Dependendo das condições de tráfego da rede, o desempenho é igual ao de uma apresentação local. O VXtreme possui ferramentas para a captura, codificação e editoração de vídeo, podendo inclusive construir páginas HTML que interagem com o vídeo. O VDO não possui ferramenta para interação com HTML e nem ferramenta própria para editoração de vídeos, mas é compativel com várias delas, como o Adobe premiére, por exemplo. Para visualizar um vídeo VDO ou VXtreme em um computador, basta instalar o respectivo plug-in no Browser. Para transmissão ao vivo, os requisitos para máquinas clientes estão na tabela 3.3.

Tabela 3.3: Requisitos para clientes VDO e VXtreme em computadores.

\begin{tabular}{|c|c|c|c|c|c|}
\hline & Processador & Memória & $\begin{array}{l}\text { Espaço em } \\
\text { Disco }\end{array}$ & Plataforma & Browser \\
\hline VXtreme & Pentium & $16 \mathrm{MB}$ & $6 \mathrm{MB}$ free & $\begin{array}{l}\text { Win95 ou } \\
\text { WinNT } 4.0\end{array}$ & $\begin{array}{l}\text { Navigator } \\
2.0 \\
\text { IExplorer } \\
3.0 \\
\end{array}$ \\
\hline VDO & Pentium 166 & $32 \mathrm{MB}$ & - & Win95 & $\begin{array}{l}\text { Navigator } \\
2.0 \\
\text { IExplorer } \\
3.0 \\
\end{array}$ \\
\hline
\end{tabular}

Os vídeos apresentados pelos clientes estão armazenados em máquinas remotas que executam um programa servidor. O servidor recebe pedidos de transmissão de vídeo dos clientes e, envia o vídeo através da rede. Os requisitos de máquina para a instalação de servidores estão na tabela 3.4. 
Tabela 3.4: Requisitos para servidores VDO e VXtreme em computadores.

\begin{tabular}{|l|l|l|l|l|}
\hline & Processador & Memória & $\begin{array}{l}\text { Espaço em } \\
\text { Disco }\end{array}$ & Plataforma \\
\hline VXtreme & Pentium & 64MB & 20MB free & WinNT 4.0 \\
\hline VDO & Pentium 166 & $32 \mathrm{MB}$ & ----- & WinNT3.51/4.0 \\
\hline
\end{tabular}

A interface do VXtreme, tanto de apresentação quanto de gerenciamento, é mais atraente e amigável que a do VDO, porém a instalação é mais complicada.

\section{3. ÁUDIO}

O som é produzido por vibrações mecânicas que provocam alterações na pressão do ar. $O$ ouvido recebe essas vibrações, convertendo o som em um sinal elétrico a ser interpretado pelo cérebro. De maneira semelhante, equipamentos transdutores - tais como o microfone - convertem a variação da pressão do ar em uma voltagem elétrica que varia no tempo. Esse formato eletrônico é chamado de sinal de áudio.

O sinal de áudio é representado como uma onda contínua. Assim como todas as ondas, apresenta duas propriedades físicas: uma delas é a amplitude (altura da onda, ou altura do som), outra é a freqüência (taxa de variação periódica da voltagem positiva para a negativa e vice-versa, expressa em ciclos por segundo, ou Hertz - Hz). O espectro de freqüências que um sistema de áudio pode reproduzir é chamado largura de banda ou bandwridth (Lindstron, 1995; Luther, 1995).

\section{Áudio Digital}

Para que um computador possa trabalhar com som, é preciso transformar o sinal de áudio analógico em digital. Essa transformação é realizada através de um processo de amostragem, que produz um fluxo de amostras em valores analógicos; esses valores, por sua vez, são aproximados por valores digitais pelo processo de quantização. Essa aproximação geralmente apresenta diferenças entre a amplitude real e a digital, perceptivel como uma perda na qualidade do áudio digital. O sinal pode ser reproduzido sem erros a partir de um conjunto de amostras quando a taxa de amostragem é, no mínimo, duas vezes a freqüência mais alta presente no sinal original (Luther, 1995; Tanenbaum, 1996)

\section{AQUISIÇÃo E CODIFICAÇÃo}

Vários fatores influenciam na qualidade final do áudio digital: a taxa de amostragem, o número de canais e o tamanho da amostra.

A taxa de amostragem é a freqüência na qual são realizadas amostras da onda de som. Quanto mais alta for a taxa de amostragem, mais próximo será o resultado do som original, porém mais memória será necessária. Taxas de amostragem comuns são $11 \mathrm{KHz}, 22 \mathrm{KHz}$ e $44 \mathrm{KHz}$. $\mathrm{O}$ número de canais indica a utilização de um ou dois canais, respectivamente para som mono e estéreo. Tamanho da amostra é a quantidade de informações armazenadas em cada amostra, isto é, o número de bits utilizados para a quantização: 8 ou 16 bits por amostra. A Tabela 1 apresenta os níveis de qualidade comuns para áudio (Lindstron, 1995; Tanenbaum, 1996). 


\begin{tabular}{lccc}
\hline Qualidade & Taxa de amostragem & Bits por amostra & n. ${ }^{\circ}$ de Canais \\
\hline Telefonia & $3 \mathrm{KHz}$ & 8 & 1 (mono) \\
Rádio AM & $11 \mathrm{KHz}$ & 8 & 1 (mono) \\
Rádio FM & $22 \mathrm{KHz}$ & 16 & 2 (estéreo) \\
$\mathrm{CD}$ & $44 \mathrm{KHz}$ & 16 & 2 (estéreo) \\
\hline \multicolumn{4}{c}{}
\end{tabular}

Tabela 1: Parâmetros de qualidade de áudio

Quanto mais alta a taxa de amostragem e o número de bits por amostra, melhor a qualidade do som. Por exemplo, o CD de áudio tem $44 \mathrm{KHz}$ e amostras de tamanho 16 bits, o que é uma alta qualidade de som. Portanto, os arquivos de áudio tendem a ser grandes. Dez segundos de áudio gravado em forma digital (amostrado a $22,05 \mathrm{KHz}, 8$ bits e qualidade de rádio, mono) ocupam cerca de 250.000 bytes. Gravando os mesmos dez segundos a taxas de amostragem mais altas $(44,1 \mathrm{KHz}$, 16 bits e qualidade de CD, estéreo), o arquivo chegará a cerca de $2 \mathrm{MB}$.

Altas taxas de amostragem contribuem pouco para a qualidade do registro de voz, pois o espectro da freqüência da fala normal é muito menor do que o de uma música.

\section{Formatos DE ARQUIVo}

Os formatos AIFF (Audio Interchange File Format), WAV (Wave) e U-LAW ( $\mu$-LAW ou AU) são os arquivos de áudio digital mais freqüentemente encontrados em aplicações. O formato AIFF suporta de 8 a 32 bits por amostra, áudio mono ou estéreo e taxas de amostragem até $44 \mathrm{KHz}$, disponível especialmente em plataforma Apple e Silicon Graphics. Wave $\dot{f}_{a z}$ parte da codificação RIFF ${ }^{28}$ em sistemas Windows; armazena som digital em estéreo ou mono, com amostras de 8 ou 16 bits e várias taxas de amostragem (as mais comuns: $11,025 \mathrm{KHz}$, $22,05 \mathrm{KHz}$ e $44,1 \mathrm{KHz})$. $\mathrm{O}$ formato $\mu$-LAW tem um mecanismo diferente de codificação $(8 \mathrm{KHz}$, quantização logaritmica de 8 bits), usado principalmente por estações de trabalho com plataforma UNIX (Lindstron, 1995; Luther, 1995)

\begin{tabular}{|c|c|c|c|c|c|}
\hline Formato & Amostra & Taxa de amostragem & Canais & & Plataformas \\
\hline AIFF & $\begin{array}{l}8,16 \text { ou } 32 \\
\text { bits }\end{array}$ & até $44 \mathrm{KHz}$ & $\begin{array}{l}\text { mono } \\
\text { estéreo }\end{array}$ & ou & $\begin{array}{l}\text { Macintosh, } \\
\text { Amiga, Silicon } \\
\text { Graphics }\end{array}$ \\
\hline Wave & 8 ou 16 bits & até $44.1 \mathrm{KHz}$ & $\begin{array}{l}\text { mono } \\
\text { estéreo }\end{array}$ & ou & $\mathrm{IBM}$ \\
\hline$\mu$-LAW & 8 bits & $8 \mathrm{KHz}$ & mono & & UNIX \\
\hline
\end{tabular}

Tabela 2: Formatos de arquivo mais comuns para áudio digital

\section{SOM SINTETIZADO}

MIDI (Musical Instrument Digital Interface) é uma linguagem de definição de música e um protocolo de comunicação que habilita a comunicação de informações musicais entre instrumentos eletrônicos de todos os fabricantes. As notas tocadas em um sintetizador enviam um comando

${ }^{28}$ RIFF: Resource Interchange File Format. Um arquivo RIFF pode conter vários tipos de dados. 
MIDI para o chip sintetizador, que então produz o som especificado. Como os sons sintetizados são armazenados como instruções, os arquivos MIDI (extensão .mid) requerem espaço muito menor que os arquivos de áudio digital. L'm arquivo MIDI de um minuto requer aproximadamente $10 \mathrm{~KB}$; um arquivo Wave de mesma duração pode atingir de 5 a $10 \mathrm{MB}$, dependendo da qualidade do áudio armazenado (Gibbs \& Tsichritzis, 1995; Lindstron, 1995).

\section{Compressão de Áudio}

As técnicas de compressão de áudio interpretam matematicamente os dados e reduzem o valor de código necessário para representar a informação. Essas técnicas podem ser aplicadas diretamente no sinal no momento da gravação, sendo executadas por hardware ou software. Para áudio, os índices de compressão indicados estão abaixo de 4:1. Algoritmos específicos para compressão de voz, por exemplo, chegam a comprimir com eficiência a taxas maiores que 20:1.

O padrão de compressão mais utilizado é o ADPCM (Adaptive Differential Pulse Code Modulation). Esse método mede a alteração de amplitude entre amostras sucessivas, prevendo os próximos valores de áudio; a freqüência segundo a qual essa medição é feita oferece poucas distorções no áudio apresentado. (Lindstron, 1995)

\section{Áudio em Documentos Web}

Arquivos de áudio e vídeo podem ser embutidos em documentos Web através de URLs; a sintaxe é a mesma que a usada para imagens, porém apresenta opções diferentes para os browsers Netscape Navigator (Tabela 3) e Internet Explorer (Tabela 4), a partir de suas versões 2.0.

Ao receber um arquivo, os browsers analisam a extensão do arquivo e, se houver um programa ou módulo externo (plug-in) estabelecido para interpretar o tipo de recurso, o arquivo é transferido e carregado nesse módulo externo para tocá-lo. Alguns plug-ins de áudio já vêm embutidos nos browsers, o LiveAudio, por exemplo, é um componente do browser Netscape, que suporta formatos AIFF, AU, MIDI, e Wave. (Microsoft Corporation, 1997; Netscape
Communications Corporation, 1997)

$<$ BGSOUND SRC $=$ "url" LOOP $=\mathrm{n}>$

Insere sons de fundo ("trilha sonora") em uma página HTML.

$\mathrm{SRC}=$ url: especifica endereço de um arquivo de áudio digital (.wav, .au) ou som sintetizado (.mid) a ser apresentado

$\mathrm{LOOP}=\mathrm{n}$ : indica quantas vezes o som será repetido. Se $\mathrm{n}=-1$ ou "infinite", o áudio continuará a ser apresentado enquanto a página estiver ativa.

Tabela 3: Formatação padrão para inserção de áudio (Microsoft, 1997)

\section{Áudio ConVencional e STREAMing}

Um minuto de áudio em qualidade CD ocupa $10 \mathrm{Mbytes}$. Isto significa mais de duas horas de cópia com um modem de $14.4 \mathrm{Kbps}$ modem, assumindo uma taxa de tranferência de $1 \mathrm{~KB} / \mathrm{s}$.

Arquivos de som e vídeo convencionais precisam ser completamente copiados da rede para serem apresentados. Algumas tecnologias permitem que se apresente o som ou vídeo à medida em que os dados chegam. Assim, o áudio em tempo real (ou streaming audio) pode ser tocado enquanto (download) do arquivo e sua apresentação.

Algumas técnicas de streaming prometem bom desempenho mesmo para conexões de baixa velocidade e modems de 14,4 Kbps; embora aconteçam pequenas interrupções na apresentação em situações de grande carga, o áudio em tempo real já oferece boa qualidade nas transmissões pela Internet (Richmond A. \& Richmond L., 1997; Progressive Networks, 1997). 


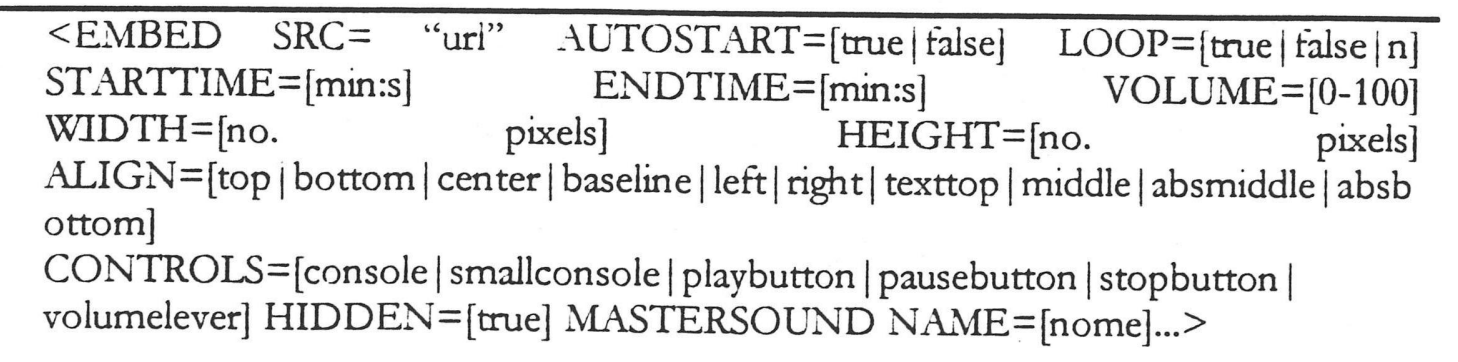

Insere sons de fundo ou controle para apresentação de som em uma página HTML.

$\mathrm{SRC}=u r l$ especifica endereço de um arquivo de áudio digital (.wav, .aiff, .au) ou som sintetizado (.mid) a ser apresentado

AUTOSTART: indica quando o som deve ser apresentado automaticamente após ser copiado

LOOP: determina número de vezes que o áudio será apresentado, ou se a apresentação será contínua

STARTTIME e ENDTIME: início e fim de apresentação do áudio (este controle só é possivel em plataformas Windows 95, NT e Macintosh)

VOLUME: volume do som

WIDTH e HEIGHT: dimensão (em pixels) do controle de áudio

ALIGN: alinhamento do controle

CONTROLS: especifica controles a serem mostrados

HIDDEN: o valor true indica quando o controle não é mostrado na página MASTERSOUND NAME

Tabela 4: Formatação estendida para inserção de áudio (Netscape, 1997)

\section{ÁUdIo DidÁTICo}

Em apresentações e atividades didáticas, os efeitos sonoros oferecem a possibilidade de chamar a atenção para fatos e idéias importantes; alguns benefícios estão relacionados à capacidade de gerar maior interesse, concentração e envolvimento com o assunto apresentado (Lindstron). A fala é outro meio de comunicação com palavras. A fala digitalizada pode oferecer todas as inflexões e nuances das palavras faladas, o que dá um aumento significativo ao impacto do texto, comparado aos caracteres escritos na tela. Também oferece a vantagem de que o usuário não precisa olhar para a tela para ouvir, e a tela pode ser usada para mostrar alguma coisa inteiramente diferente, tal como uma imagem que ilustre o que está sendo dito (Luther, 1995).

\section{ANIMAÇÃO POR COMPUTAdOR}

Assim como as técnicas utilizadas na produção de vídeo, as técnicas de animação baseiam-se na apresentação contínua de diferentes imagens estáticas. No entanto, a produção de uma animação possui suas nuanças próprias, uma vez que cada imagem deve, muitas vezes, ser desenhada individualmente. Para facilitar o processo de produção, técnicas de computação podem ser utilizadas para fazer a geração automática de quadros intermediários por exemplo.

\section{O PROCESSO CONVENCIONAL DE PRODUÇÃO DE ANIMAÇÕES}

A produção convencional de animações possui diversas semelhanças com a produção de filmes e, assim, deve iniciar-se com a preparação de um roteiro constituído das seqüências, cenas e da trilha sonora. Tori (Tori et al. 87) apresenta um processo de produção básico, que pode ser utilizado com algumas modificações na prática. Esse processo é composto pelas seguintes fases: 
criação do storyboard, gravação da trilha sonora, layy-out detalhado, sincronismo com a trilha sonora, criação dos cenários, criação dos quadros-chave, geração dos quadros intermediários, teste de animação, passagem dos desenhos para acetatos, arte final e pintura dos acetatos e filmagem final.

\section{O COMPUTADOR NO PROCESSO DE PRODUÇÃO}

Atualmente, no que se refere a animação, computadores são utilizados especialmente nas fases de criação dos cenários e geração dos quadros intermediários. Entretanto, produções sofisticadas de longa metragem, que utilizam computadores durante todo o processo de criação têm sido feitas; e outras tantas de curta metragem vêm sendo apresentadas ao público diariamente. Outra área na qual os computadores têm se destacado é na criação de personagens, objetos e animações que levariam anos para serem feitas através do processo manual.

Quando o computador é utilizado durante a produção, normalmente, o processo de produção convencional é seguido e uma ferramenta, como o Autodesk Animator/3DStudio é usada para apoiar a produção das seqüências.

\section{O COMPUTADOR NA APRESENTAÇÃO DE ANIMAÇÕES}

Quando o computador é utilizado para apresentar uma animação ao usuário, duas formas de uso devem ser consideradas: o computador apresentando uma animação pré-produzida (pre-rendered) e o computador gerando a animação, ou parte dela, em tempo real.

A animação gerada em tempo real deve ser considerada de forma especial, pois uma vez que os resultados não estão prontos, alguns parâmetros da animação podem ser modificados antes ou durante a apresentação. O resultado disso é uma maneira interessante de prover interação com o usuário e dinamismo.

Um bom exemplo do uso dessa técnica, seria ensinar os princípios de lançamento de projeteis a alunos de física. Nesse caso, o aluno poderia controlar o ângulo do lançamento e a força inicial que seria aplicada ao projetil. Interativamente, o aluno poderia disparar o canhão e a trajetória teórica do mesmo seria apresentada na tela do aluno através de uma animação. Em outro cenário mais complicado de uso, um professor poderia ter o controle dos parâmetros da animação e iniciar a apresentação remotamente (Castro et al. 97).

\section{IMPLEMENTAÇÃO DE ANIMAÇÕES EM TEMPO REAL}

Para implementar animações em tempo real, diversas técnicas podem ser utilizadas, desde o uso de linguagens de programação a ferramentas de autoria especializadas. Atualmente, as ferramentas de autoria, em geral, fornecem módulos separados para apresentação interativa das animações.

No caso específico dos browsers é possível apresentar, por exemplo, animações criadas no Macromedia Director, animações em 3D criadas usando-se a linguagem VRML, animações utilizando-se técnicas simples de scripting através do uso de JavaScript ou de Java, ou animações mais complicadas que envolvem a fusão dessas diversas técnicas compondo um cenário amplo e rico de aplicações, entre outras técnicas disponíveis.

\section{CONSIDERAÇÕES SOBRE A QUALIDADE DAS ANIMAÇÕES APRESENTADAS}

Uma vez que animações são normalmente utilizadas para apresentar simulações de forma realística, as considerações que devem ser feitas com relação a qualidade das imagens possui menor impacto
do que na produção de vídeo.

Entretanto, como no caso dos vídeos, também é necessário haver uma certa preocupação com o tamanho dos arquivos gerados para as animações pré-produzidas, que normalmente atingem tamanhos da ordem de megabytes. 
Devido a esse fato, quando o objetivo é utilizar as animações via Intemet, é preferivel rojetar animações que sejam geradas em tempo real, pois estas, geralmente, necessitam de muito menor capacidade de transmissão que as animações pré-produzidas. Além disso, ganha-se a possitsulidade de maior interação do usuário com os conceitos que a animação quer apresentar.

\section{CONCLUSÃo}

Podemos concluir que a apresentação de material multimídia possui tecnologia suficiente sua produções elaboradas, porém por ser uma ferramenta muito nova, existe uma gama muito de conhecimento a ser adquirida por desenvolvedores. Contudo, aplicações simples de produzir podem surtir um efeito satisfatório.

\section{BibLiOgRAFIA}

Buford, J. F. K. (Ed.) (1994). Uses of multimedia information. In Multimedia systems. New York, NY: Addison-Wesley.

Castro, M. A. S.; Goularte, R.; Reami, E. R.; Moreira, E. S. (1997). Infra-estrutura de Suporte à Editoração de Mareial Didático Utilizando Multimídia. Revista Brasileira de Informática na Educação (a ser publicado).

Comer, D. E. (1995). Internetworking with TCP/IP (3a. Edição), vol. 1. New Jersey, Prentice-Hall.

Gibbs, S. J. \& Tsichritzis, D. C. (1995). Multimedia programming - Objects, environments and frameworks. Wokinghan, Inglaterra: Addison-Wesley.

Greenfield, P. M. (1987). Electronic technologies, education, and cognitive development. In D. E. Berger, K. Pezdek, \& W. P. Banks (Eds.), Applications of cognitive psychology: Problem solving, education and computing (pp. 17-32). Hillsdale, NJ: Lawrence Erlbaum Associates.

Lindstron, R. L. (1995). Guia business week para apresentações em multimidia. São Paulo: Makron Books.

Luther, A. C. (1995). Using Digital Video. Cambridge, MA: AP Professional

Luther, A. C. (1995a). Using Digital Video,[CD-ROM].

Microsoft Corporation. HTML Reference [Online] 1997. Available: http://www.microsoft.com/workshop/author/newhtml/htmlr020.htm\#htmlref2_00 01000114000a00

Netscape Communications Corporation. LiveAudio Syntax [Online] 1997. Available: http://home.netscape.com/comprod/products/navigator/version_3.0/multimedia/a udio/how.html [15 de agosto de 1997]

Progressive Networks. RealMedia Architecture [Online] 1997. Available: http://www.real.com/prognet/rm/index.html [05 de agosto de 1997] 
Richmond, A.\& Richmond L. (1997). Te Web Developer's ['irtual Library [Onune! Available: http://WWWW.Stars.com/WDVL/ [15 de agosto de 1997]

Tanenbaum, Andrew S. (1996). Computer Networks (3ª Edição). Prentice-Hall.

Tori, R.; Arakaki, R.; Massola, A. M. A.; Filgueiras, L. V. L. (1987). Fulhdamentos de Computação Gráfica. Rio de Janeiro, Livros Técnicos e Científicos LTDA. 